\title{
WestVirginiaUniversity
}

THE RESEARCH REPOSITORY @ WVU

Graduate Theses, Dissertations, and Problem Reports

2007

\section{Numerical modeling of soil-geosynthetic interaction}

Joshua Dennis Pike

West Virginia University

Follow this and additional works at: https://researchrepository.wvu.edu/etd

\section{Recommended Citation}

Pike, Joshua Dennis, "Numerical modeling of soil-geosynthetic interaction" (2007). Graduate Theses,

Dissertations, and Problem Reports. 4327.

https://researchrepository.wvu.edu/etd/4327

This Thesis is protected by copyright and/or related rights. It has been brought to you by the The Research Repository @ WVU with permission from the rights-holder(s). You are free to use this Thesis in any way that is permitted by the copyright and related rights legislation that applies to your use. For other uses you must obtain permission from the rights-holder(s) directly, unless additional rights are indicated by a Creative Commons license in the record and/ or on the work itself. This Thesis has been accepted for inclusion in WVU Graduate Theses, Dissertations, and Problem Reports collection by an authorized administrator of The Research Repository @ WVU. For more information, please contact researchrepository@mail.wvu.edu. 


\title{
Numerical Modeling of Soil - Geosynthetic Interaction
}

\author{
By \\ Joshua Dennis Pike \\ Thesis submitted to the \\ College of Engineering and Mineral Resources \\ at West Virginia University \\ in partial fulfillment of the requirements \\ for the degree of \\ Master of Science \\ in \\ Civil Engineering \\ Hema Siriwardane, Ph.D., Chair \\ Udaya B. Halabe, Ph.D. \\ Roger C. Viadero, Ph.D. \\ Department of Civil and Environmental Engineering \\ Morgantown, West Virginia \\ 2007
}

Keywords: Finite Element Analysis, Geosynthetics, Interface Properties 


\section{ABSTRACT \\ Numerical Modeling of Soil - Geosynthetic Interaction}

\section{Joshua Dennis Pike}

Geosynthetics are being used for a wide range of civil engineering applications such as reinforced earth fills, soft foundations etc. The use of geosynthetics can greatly increase the efficiency while reducing the cost of the project. The objective of this research is to study the pullout resistance of the geosynthetic and the effect of friction on the soil-geosynthetic interface. Finite element analysis was performed on different sizes of pullout box to match load-displacement results with that found during laboratory experiments. Friction coefficient was selected by trial and error method to match the load-displacement curves calculated from the laboratory experiments to that found from the finite element analysis. Models were made using three different soils; sand, silt, and clay at $0 \%, 10 \%$, and $15 \%$ moisture content under normal pressures of 5 psi, 10 psi, and 15 psi. 


\section{ACKNOWLEDGEMENT}

There are several people that I would really like to thank for the successful completion of this thesis. First and foremost I would like to thank the advisor and committee chairman, Dr. Siriwardane. His guidance and support made the completion of this research possible. I would like to thank Dr. Udaya Halabe and Dr. Roger Viadero for reviewing my thesis and participating on my examination committee.

I would also like to give a special thanks to Raj Kumar Gondle for his help and guidance throughout the preparation of this thesis.

Finally, I would like to thank my friends and family for their support and patience. 


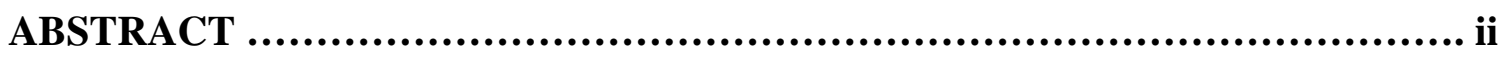

ACKNOWLEDGEMENT ….................................................... iii

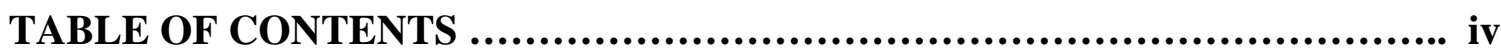

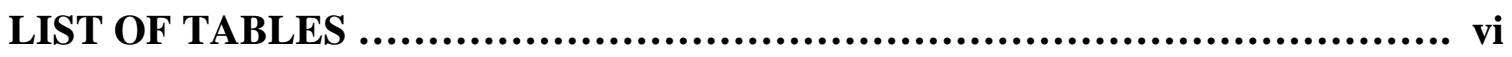

LIST OF FIGURES .............................................................. vii

CHAPTER 1: INTRODUCTION ............................................. 1

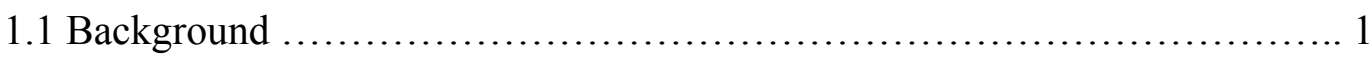

1.2 Function of Geosynthetics ........................................ 1

1.3 Types of Geosynthetics ............................................... 2

1.4 Geosynthetic Applications ........................................... 3

1.4.1 Soil Reinforcement ......................................... 3

1.4.2 Filter and Drainage Layer ................................... 4

1.4.3 Separation and Reinforcement in Roadways ...................... 4

1.5 Problem Statement ..................................................... 5

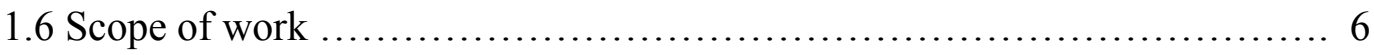

1.7 Research Objectives ............................................ 6

CHAPTER 2: EXPERIMENTAL PROCEDURES ............................... 8

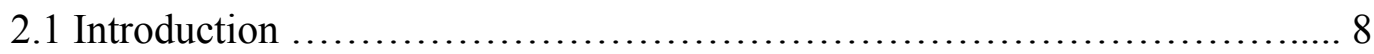

2.2 Material Properties ................................................... 8

2.2.1 Geosynthetic material ...................................... 9

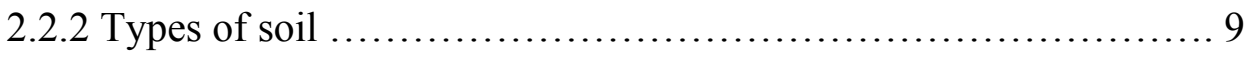

2.3 Pullout Box ..................................................... 13

2.3.1 Pullout Box "A" ............................................... 13

2.3.2 Pullout Box "B"................................................. 14

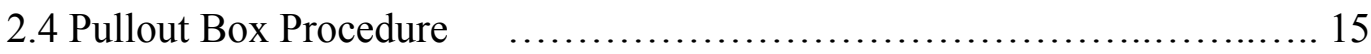




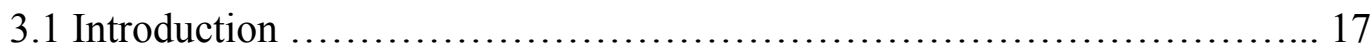

3.2 Finite Element Method ............................................ 17

3.3 Recent Studies .................................................... 18

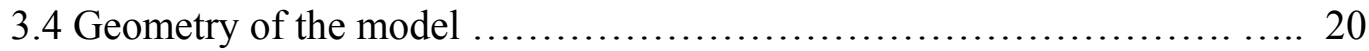

3.5 Material Properties ........................................................ 24

3.6 Loading, Boundary Conditions, and Step Sequence ...................... 24

3.7 Interaction between soil and geosynthetic ….......................... 25

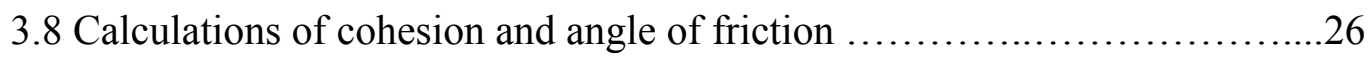

CHAPTER 4: RESULTS AND DISCUSSIONS …........................... 28

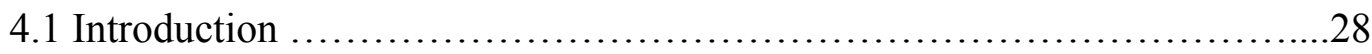

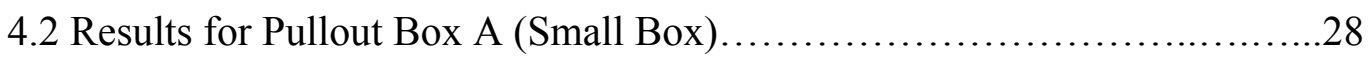

4.3 Results for Pullout Box B (Large Box) ........................................41

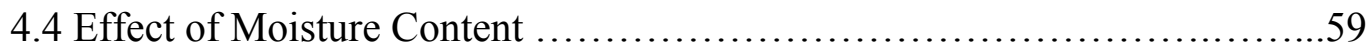

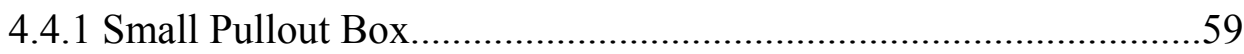

4.4.2 Large Pullout Box..............................................................................67

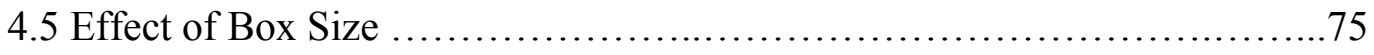

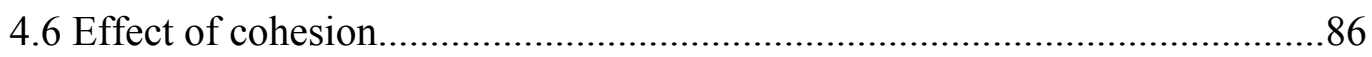

CHAPTER 5: SUMMARY AND CONCLUSIONS .............................. 90

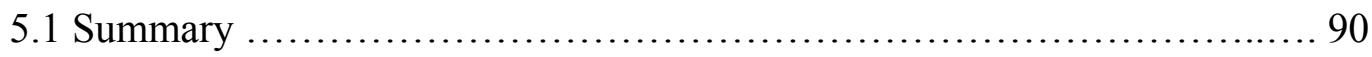

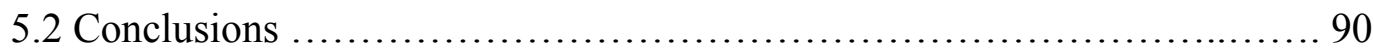

5.2.1 Sand - Geosynthetic Interaction.................................................... 90

5.2.2 Silt - Geosynthetic Interaction..................................................... 91

5.2.3 Clay - Geosynthetic Interaction..................................................... 91

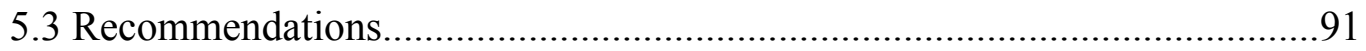

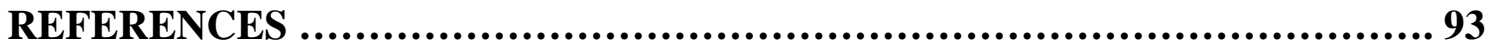




\section{LIST OF TABLES}

Table 3.1: Specifications of the geosynthetic placement for the small and large pullout

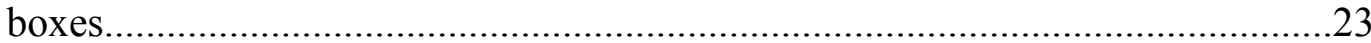

Table 3.2: Assumed material properties .......................................... 24

Table 4.1: Percent difference in friction coefficient for a change in normal pressure and

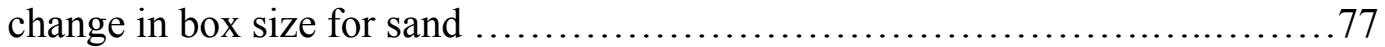

Table 4.2: Percent difference in friction coefficient for a change in normal pressure and change in box size for silt ......................................... 78

Table 4.3: Percent difference in friction coefficient for change in moisture content for

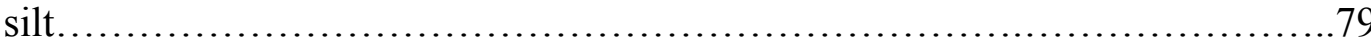

Table 4.4: Percent difference in friction coefficient for a change in normal pressure and change in box size for clay .80

Table 4.5: Percent difference in friction coefficient for change in moisture content for

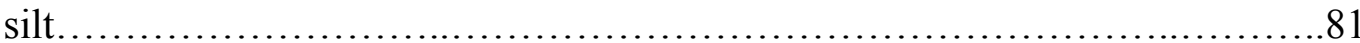

Table 4.6: Friction coefficient and calculated friction angle for sand...........................82

Table 4.7: Friction coefficient and calculated friction angle for silt.............................83

Table 4.8: Friction coefficient and calculated friction angle for clay..............................84

Table 4.9: Comparison of measured friction angle and calculated friction angle............85

Table 4.10: Angle of friction and cohesion developed in the laboratory and corresponding angle of friction and cohesion used in ABAQUS..............................................86 


\section{LIST OF FIGURES}

Figure 2.1: WG 120 "Atlas" Geogrid (Material A) .................................. 10

Figure 2.2: KG 30 "Thor" Geogrid (Material B).......................................11

Figure 2.3: Amoco 4510 Geotextile (Material C)................................... 12

Figure 2.4: Pullout Box A (Small pullout box)......................................... 14

Fgure 2.5: Pullout Box B (Large pullout box)........................................ 15

Figure 3.1: Geometry of the pullout box............................................

Figure 3.2: Placement of the geosynthetic .......................................... 22

Figure 3.3: Boundary conditions for pullout box …............................ 25

Figure 4.1: Load - displacement relationship for sand - material A interaction at $0 \%$ moisture under normal pressures of 5 psi, 10 psi, and 15 psi with their respective friction coefficients........................................29

Figure 4.2: Load - displacement relationship for sand - material C interaction at $0 \%$ moisture under normal pressures of 5 psi, 10 psi, and 15 psi with their respective friction coefficients.............................................. 30

Figure 4.3: Load - displacement relationship for silt - material A interaction at $0 \%$ moisture under normal pressures of $5 \mathrm{psi}, 10 \mathrm{psi}$, and $15 \mathrm{psi}$ with their respective friction coefficients......................................... 31

Figure 4.4: Load - displacement relationship for silt - material A interaction at $10 \%$ moisture under normal pressures of 5 psi, 10 psi, and 15 psi with their respective friction coefficients....................................... 32

Figure 4.5: Load - displacement relationship for silt - material A interaction at 15\% moisture under normal pressures of $5 \mathrm{psi}, 10 \mathrm{psi}$, and $15 \mathrm{psi}$ with their respective friction coefficients......................................... 33

Figure 4.6: Load - displacement relationship for silt - material $\mathrm{C}$ interaction at $0 \%$ moisture under normal pressures of 5 psi, 10 psi, and 15 psi with their respective friction coefficients....................................... 34

Figure 4.7: Load - displacement relationship for silt - material C interaction at $10 \%$ moisture under normal pressures of 5 psi, 10 psi, and 15 psi with their respective friction coefficients....................................... 35 
Figure 4.8: Load - displacement relationship for silt - material C interaction at 15\% moisture under normal pressures of 5 psi, 10 psi, and 15 psi with their respective friction coefficients................................... 36

Figure 4.9: Load - displacement relationship for clay - material $\mathrm{C}$ interaction at $0 \%$ moisture under normal pressures of 5 psi, 10 psi, and 15 psi with their respective friction coefficients.

Figure 4.10: Load - displacement relationship for clay - material A interaction at 10\% moisture under normal pressures of 5 psi, 10 psi, and 15 psi with their respective friction coefficients. .38

Figure 4.11: Load - displacement relationship for clay - material C interaction at $0 \%$ moisture under normal pressures of 5 psi, 10 psi, and 15 psi with their respective friction coefficients.

Figure 4.12: Load - displacement relationship for clay - material C interaction at $10 \%$ moisture under normal pressures of 5 psi, 10 psi, and 15 psi with their respective friction coefficients.

Figure 4.13: Load - displacement relationship for sand - material A interaction at $0 \%$ moisture under normal pressures of 5 psi, 10 psi, and 15 psi with their respective friction coefficients.

Figure 4.14: Load - displacement relationship for sand - material B interaction at $0 \%$ moisture under normal pressures of 5 psi, 10 psi, and 15 psi with their respective friction coefficients.

Figure 4.15: Load - displacement relationship for sand - material $\mathrm{C}$ interaction at $0 \%$ moisture under normal pressures of 5 psi, 10 psi, and 15 psi with their respective friction coefficients.

Figure 4.16: Load - displacement relationship for silt - material A interaction at $0 \%$ moisture under normal pressures of 5 psi, 10 psi, and 15 psi with their respective friction coefficients. .44

Figure 4.17: Load - displacement relationship for silt - material A interaction at 10\% moisture under normal pressures of 5 psi, 10 psi, and 15 psi with their respective friction coefficients .45 
Figure 4.18: Load - displacement relationship for silt - material A interaction at 15\% moisture under normal pressures of 5 psi, 10 psi, and 15 psi with their respective friction coefficients...................................46

Figure 4.19: Load - displacement relationship for silt - material B interaction at $0 \%$ moisture under normal pressures of 5 psi, 10 psi, and 15 psi with their respective friction coefficients.

Figure 4.20: Load - displacement relationship for silt - material B interaction at $10 \%$ moisture under normal pressures of 5 psi, 10 psi, and 15 psi with their respective friction coefficients.

Figure 4.21: Load - displacement relationship for silt - material B interaction at 15\% moisture under normal pressures of 5 psi, 10 psi, and 15 psi with their respective friction coefficients.

Figure 4.22: Load - displacement relationship for silt - material $\mathrm{C}$ interaction at $0 \%$ moisture under normal pressures of 5 psi, 10 psi, and 15 psi with their respective friction coefficients.

Figure 4.23: Load - displacement relationship for silt - material C interaction at 10\% moisture under normal pressures of 5 psi, 10 psi, and 15 psi with their respective friction coefficients.

Figure 4.24: Load - displacement relationship for silt - material C interaction at 15\% moisture under normal pressures of 5 psi, 10 psi, and 15 psi with their respective friction coefficients....................................5

Figure 4.25: Load - displacement relationship for clay - material A interaction at $0 \%$ moisture under normal pressures of 5 psi, 10 psi, and 15 psi with their respective friction coefficients.................................53

Figure 4.26: Load - displacement relationship for clay - material A interaction at 10\% moisture under normal pressures of 5 psi, 10 psi, and 15 psi with their respective friction coefficients. .54

Figure 4.27: Load - displacement relationship for clay - material B interaction at 0\% moisture under normal pressures of 5 psi, 10 psi, and 15 psi with their respective friction coefficients. .55 
Figure 4.28: Load - displacement relationship for clay - material B interaction at 10\% moisture under normal pressures of 5 psi, 10 psi, and 15 psi with their respective friction coefficients..................................56

Figure 4.29: Load - displacement relationship for clay - material A interaction at $0 \%$ moisture under normal pressures of 5 psi, 10 psi, and 15 psi with their respective friction coefficients..................................57

Figure 4.30: Load - displacement relationship for clay - material A interaction at $0 \%$ moisture under normal pressures of 5 psi, 10 psi, and 15 psi with their respective friction coefficients.

Figure 4.31: Effect of moisture content for silt and geogrid A for normal pressure of 5 psi .60

Figure 4.32: Effect of moisture content for silt and geogrid A for normal pressure of 10 psi

Figure 4.33: Effect of moisture content for silt and geogrid A for normal pressure of 15 psi

Figure 4.34: Effect of moisture content for silt and geotextile (geosynthetic material C) for normal pressure of 5 psi

Figure 4.35: Effect of moisture content for silt and geotextile (geosynthetic material C) for normal pressure of $10 \mathrm{psi}$

Figure 4.36: Effect of moisture content for silt and geotextile (geosynthetic material C) for normal pressure of $15 \mathrm{psi}$ .63

Figure 4.37: Effect of moisture content for clay and geogrid A for normal pressure of 5 psi

Figure 4.38: Effect of moisture content for clay and geogrid A for normal pressure of 10 psi

Figure 4.39: Effect of moisture content for clay and geogrid A for normal pressure of 15 psi

Figure 4.40: Effect of moisture content for clay and geotextile (geosynthetic material C) for normal pressure of 5 psi .66

Figure 4.41: Effect of moisture content for clay and geotextile (geosynthetic material C) 
for normal pressure of $10 \mathrm{psi}$ .66

Figure 4.42: Effect of moisture content for clay and geotextile (geosynthetic material C) for normal pressure of $15 \mathrm{psi}$ .67

Figure 4.43: Effect of moisture content for silt and geogrid A for normal pressure of 5 psi .68

Figure 4.44: Effect of moisture content for silt and geogrid A for normal pressure of 10 psi

Figure 4.45: Effect of moisture content for silt and geogrid A for normal pressure of 15 psi

Figure 4.46: Effect of moisture content for silt and geotextile (geosynthetic material C) for normal pressure of 5 psi .70

Figure 4.47: Effect of moisture content for silt and geotextile (geosynthetic material C) for normal pressure of $10 \mathrm{psi}$ 70

Figure 4.48: Effect of moisture content for silt and geotextile (geosynthetic material C) for normal pressure of $15 \mathrm{psi}$

Figure 4.49: Effect of moisture content for clay and geogrid A for normal pressure of 5 psi

Figure 4.50: Effect of moisture content for clay and geogrid A for normal pressure of 10

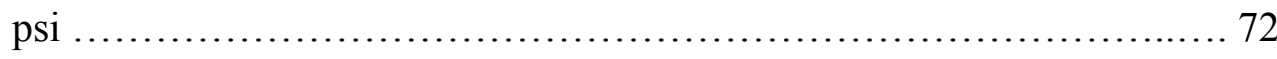

Figure 4.51: Effect of moisture content for clay and geogrid A for normal pressure of 15 psi 73

Figure 4.52: Effect of moisture content for clay and geotextile (geosynthetic material C) for normal pressure of 5 psi 74

Figure 4.53: Effect of moisture content for clay and geotextile (geosynthetic material C) for normal pressure of $10 \mathrm{psi}$ 74

Figure 4.54: Effect of moisture content for clay and geotextile (geosynthetic material C) for normal pressure of $15 \mathrm{psi}$ 75

Figure 4.55: Cohesion comparison of clay and material A interaction at 10\% moisture at 5,10 , and 15 psi with their corresponding friction coefficients.

Figure 4.56: Cohesion comparison of clay and material $\mathrm{C}$ interaction at $10 \%$ moisture at 5,10 , and 15 psi with their corresponding friction coefficient. .88 
Figure 4.57: Cohesion comparison of clay and material A interaction at 10\% moisture at 5,10 , and 15 psi with their corresponding friction coefficient.............88

Figure 4.58: Cohesion comparison of clay and material A interaction at $10 \%$ moisture at 5,10 , and 15 psi with their corresponding friction coefficient..............89 


\section{CHAPTER 1}

\section{INTRODUCTION}

\subsection{Background}

Advancements in structural engineering through the use of technology have really altered the way construction is performed. The development of steel from wrought iron and the improvement of reinforced concrete and prestressed reinforced concrete have really changed the world of construction. Taller buildings and longer spanned bridges are now possible. A recent discovery in geotechnical engineering may revolutionize the way construction is done in this field. The use of geosynthetics for reinforcing soil is becoming a rapidly growing technology. Geosynthetics can be used in many different applications in geotechnical engineering such as embankments, soft foundations, soil slope reinforcement, and retaining walls. The use of geosynthetics can improve soil performance, increase the safety factor, and reduce the construction cost for a project. This is why geosynthetic research has become a more common topic in the field of geotechnical engineering (Sobhi and $\mathrm{Wu}, 1996)$.

An extensive literature review was conducted to provide a basic background of geosynthetics and the pullout test. There are a wide variety of types and functions for geosynthetics used in the world of construction. The selection of the geosynthetic material for a particular job depends on the type of application and the material properties.

\subsection{Function of Geosynthetics}

The selection of geosynthetic for a particular job is done in one of three ways. Design-by-experience, which is the selection of geosynthetic designer's familiarity with 
the geosynthetic, design-by-specification, which is selecting a geosynthetic for common application areas, and design-by function, which is the selection of a geosynthetic based on what kind of job is needed and can be used with the combination of the previous two (Koerner, 1990; Zornberg et al., 1999).

Brief descriptions of the different functions for geosynthetics are (Zornberg et al., 1999):

1. Separation - the separation of two different mediums by the use of geosynthetics so that the function of both materials will be intact or improved.

2. Reinforcement - the use of geosynthetics to develop tensile forces that help with the stability of the soil.

3. Filtration - involves the movement of liquid through the geosynthetic while retaining the soil.

4. Drainage - transmits liquid within the plane of the structure.

5. Infiltration Barrier - used with geosynthetics that have a hydraulic conductivity low enough to contain the liquid or vapor.

6. Protection - used to protect other geosynthetics (mainly geomembranes) from damage

\subsection{Types of Geosynthetics}

Different types of geosynthetics available in the industry are given below (Zornberg et al., 1999; Koerner, 1990):

1. Geotextiles - have the widest range of properties of all the geosynthetics

2. Geomembranes - flexible, polymeric sheets that have a very low hydraulic conductivity (typically used as fluid barriers)

3. Geogrids - used as a reinforcement function

4. Geosynthetic clay liners - infiltration barriers consisting of a layer of unhydrated, loose granular or powdered bentonite placed between two or on top of one geosynthetic layer 
5. Geocomposite sheet drains - consists of a number of different types of geosynthetics

6. Geocomposite strip drains - used as a way to replace the use of sand drains in applications involving the increase in consolidation rate of soft, saturated finegrained soils

7. Geocells - three-dimensional expandable panels made from HDPE (high-density polyethylene) or polyester strips

\subsection{Geosynthetic Applications}

Geosynthetics are used in a wide range of civil engineering applications. They can be used in geotechnical, transportation, and environmental areas to perform the various functions as listed above. Each geosynthetic serves a different purpose and performs a different type of function for a particular engineering situation. Some of the more common types of applications are discussed in the following (Ling, 2003).

\subsubsection{Soil Reinforcement}

There are three primary applications for soil reinforcement. The applications are reinforcement of the base of an embankment that is constructed over a soft foundation; increase the stability of a slope; and reducing the pressure behind a retaining wall or an abutment (Ling, 2003).

The design and construction of embankments can be a very challenging geotechnical problem. If there is a problem with settlements being too large or instable, then soil improvement modifications must be considered. Some traditional soil improvements are preloading/surcharging with drains; lightweight fill; excavation and replacement; deep soil mixing; and many other methods. With the advancement in the geosynthetic technology, soil reinforcing with geosynthetics can be considered. Using 
geosynthetics as a reinforcement material can provide economical design. Geosynthetics can also be used with a combination of traditional methods (Holtz, 2001; Ling, 2003).

Another application of geosynthetics in civil engineering practice is for the reinforcement of unstable slopes. Sometimes design requires a steeper slope than can be constructed and be stable. When this happens, reinforcement is necessary during the construction. Multiple layers of geosynthetics can be placed in a fill slope to increase the stability of the slope. Some projects necessitate the use of geosynthetics for construction of new embankments, alternatives to retaining walls, the widening of an existing embankment, and the repair of an already failed slope (Holtz, 2001; Ling, 2003).

Retaining walls are necessary when a structure needs protection from an unstable slope. Adding reinforcement to the backfill provides a very economical addition to the retaining wall. This combination of geosynthetic and retaining wall provides more flexibility than the traditional concrete cantilever and gravity walls (Holtz, 2001; Ling, 2003).

\subsubsection{Filter and Drainage Layer}

The geosynthetic (typically geotextiles) acts like a filter by retaining the soil while allowing adequate permeability so that cross-plane flow will occur. The equivalent opening in the geotextile is determined during the design process. This filter function of the geotextile is expected to remain working throughout the lifetime of the system without clogging. For the use in drainage applications (landfills), geonets and geocomposites are typically used. These geosynthetics are designed to allow a largecapacity flow (Ling, 2003).

\subsubsection{Separation and Reinforcement in Roadways}

In unpaved roadways and railways, geotextiles are used to separate the soil subgrade from the stonebase. The geotextile prevents the intrusion of the stone aggregate 
into the soil subgrade in roadway applications. In railways, the separation of the soil particles from the stone aggregates is possible with the use of geotextiles. The use of separation is not a practice that is commonly emphasized in the designing compared to reinforcement and drainage applications (Ling, 2003).

In the use of reinforcement of unpaved roadways, geotextile reinforcement is a very cost effective solution in the design by reducing the thickness of the stone aggregate layer. In paved roadways, geotextiles can prevent reflective cracking from occurring in the overlaying asphalt. Geotextile is placed overtop of the old cracking pavement and new asphalt is placed on top of the geotextile. Preventing these cracks causes the life of the asphalt overlay to extend much longer than that if the geotextile was not used (Ling, 2003).

\subsection{Problem Statement}

Finding the interaction mechanism between soil and geosynthetic is very important in the design and analysis of reinforced soil structures. There are two primary tests that can be performed to understand the soil-geosynthetic interaction; the direct shear test and the pullout test (Bobet and Lee, 2005). For this study, finite element modeling of a pullout test is the procedure used to analyze this interaction mechanism. Although a relatively new procedure, the pullout test is being increasingly used to understand the pullout behavior of geosynthetic reinforced soils (Perkins and Cuelho, 1999).

Pullout tests are performed to determine the interface properties between the soil and geosynthetic material. These tests are performed by laterally pulling a geosynthetic placed between two like soil mediums. This creates two failure planes when subjected to a normal load. The pullout test calculates the shear stress and strain during the pulling of the geosynthetic membrane. With the technology today it is possible to compare the work done in the laboratory with a finite element computer program. Using the finite element approach helps to obtain a better understanding of the effects of the pullout test. 
The finite element analysis also allows for a better grasp of the results obtained from the laboratory pullout tests. The present study analyzes the effect of friction for a particular soil and geosynthetic interaction. Three different soils were tested under various moisture contents. A geotextile and two different geogrids with different aperture sizes were selected for the purpose of this study. Also, two different box sizes were considered to understand the effect of box size (Niemiec, 2005; Ingram, 2006; Lopes, 1997; Moore, 2002).

\subsection{Scope of Work}

Extensive literature has been conducted to study the pullout mechanism. Material properties of the geosynthetic and the soils used were investigated. Finite element analysis was performed to investigate and analyze the interaction properties for different geosynthetics and different combinations of soils. Three different geosynthetic material A, B and C were used. Material A is a uniaxially woven high strength geogrid, material B is a uniaxially knitted high strength geogrid and material $\mathrm{C}$ is a non-woven needlepunched polypropylene geotextile. Three different soils - sand, silt and clay were selected at different moisture contents to investigate the effect of moisture content on the soil-geosynthetic interface. The tests were performed by laterally pulling the geosynthetic while maintaining the external loading. In order to investigate the effect of normal pressure on the soil-geosynthetic interface, three different normal loading pressures were selected. Load-displacement results obtained from finite element analysis were compared

to that of results obtained from the laboratory experiments that were preformed by Ingram (2006) and Niemiec (2005) at West Virginia University (Ingram, 2006; Niemiec, 2005; Moore, 2002; Lopes (1997).

\subsection{Research Objectives}

The primary objectives of this study are:

- Review existing literature of pullout test procedures 
- Perform FEM analysis for recent laboratory pullout test (Niemiec, 2005; Ingram, 2006) influenced by the soil type (natural sand, silty sand, and clayey sand), geosynthetic type, moisture content $(0,5,15 \%)$, and different loading conditions of 5, 10, and 15 psi.

- Study the influence of friction for different combination of case types.

- Compare the calculated friction angle from finite element analysis to the measured friction angle found in the laboratory. 


\section{CHAPTER 2}

\section{EXPERIMENTAL PROCEDURES}

\subsection{Introduction}

In studies conducted earlier at West Virginia University, two pullout tests were performed using two pullout boxes of different sizes (Niemiec, 2005; Ingram, 2006). For this study, the small pullout box was referred to as "Pullout Box A" (Niemiec, 2005) and the large pullout box (Ingram, 2006) was referred to as "Pullout Box B". The tests used three different types of geosynthetics and three types of soils; natural sand, silt, and clay. The geosynthetics used consisted of two types of geogrids referred to as materials A and $\mathrm{B}$ and a geotextile which was referred to as material C.

Each combination of soil and geosynthetic was performed under different conditions of normal stress and moisture content. The three normal stresses used in this study were 5 psi, 10 psi, and 15 psi. To generate the effect of normal stress, air bags made of $1 / 16$ " neoprene sheets were made. The bags were filled with the correct amount of air to create the desired stress exerted onto the soil and geosynthetic. Because the air bags tend to lose some of their ductility around their edges, bags were routinely replaced to ensure exact measurements. Each type of soil was tested with different moisture contents. Silt was tested with $0 \%, 10 \%$, and $15 \%$ moisture, Clay was tested with $0 \%$ and $10 \%$ moisture, and sand was tested only with $0 \%$ moisture. Natural sand is a soil with zero cohesion so it is only tested in its dry state (Niemic, 2005; Ingram, 2006; Bobet and Lee 2005).

\subsection{Material Properties}


The pullout test consisted of different materials. The material properties of the materials used are discussed in the following sections.-

\subsubsection{Geosynthetic material}

Both pullout tests were performed using the same three types of geosynthetics. The geosynthetics used were WG 120 “Atlas” (Material A), KG 30 "Thor” (Material B) and Amoco 4510 (Material C) (Niemiec, 2005; Ingram, 2006). Material A is a uniaxially woven high strength geogrid with a Young's Modulus of $188 \mathrm{ksi}$ and density of 39.98 pcf. Material thickness is 0.025 in $(0.064 \mathrm{~cm})$. Material B is a uniaxially knitted high strength geogrid with a Young's Modulus of $41.44 \mathrm{ksi}$ and density of $15.77 \mathrm{pcf}$. The thickness of this material is 0.041 in. Both materials A and B fibers are constructed of multifilament polyester yarns. Material $\mathrm{C}$ is a non-woven, needle-punched polypropylene geotextile. The Young's modulus for material C is $30 \mathrm{ksi}$ with a density of $15.08 \mathrm{pcf}$. The thickness is $0.12 \mathrm{in}$. The densities were calculated during laboratory tests conducted at West Virginia University in 2006 (Niemiec, 2005; Ingram, 2006).

The geosynthetics used during the laboratory experiment can be seen in Figures $2.1,2.2$, and 2.3 respectively. 


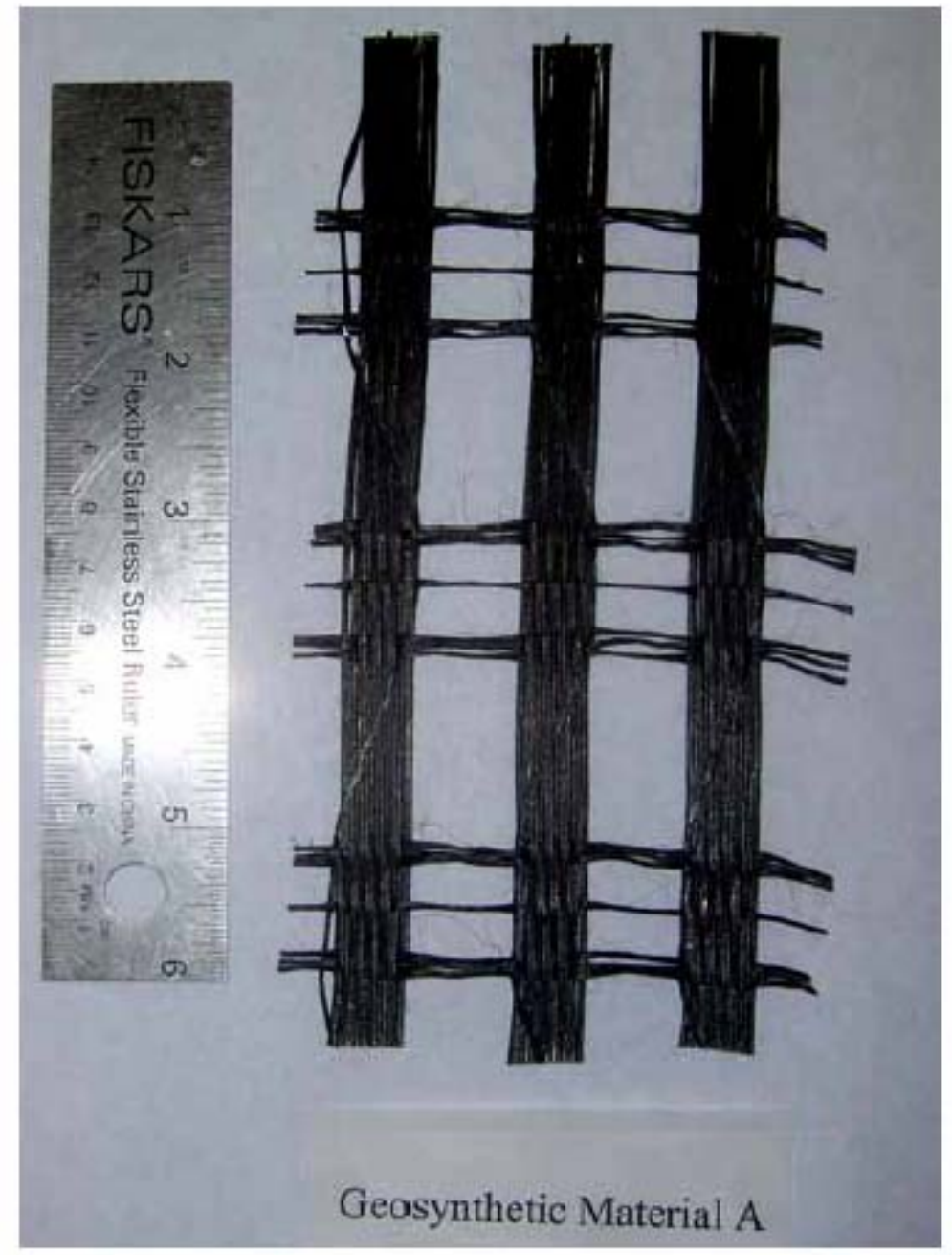

Figure 2.1: WG 120 “Atlas” Geogrid - Material A (Niemiec, 2005) 


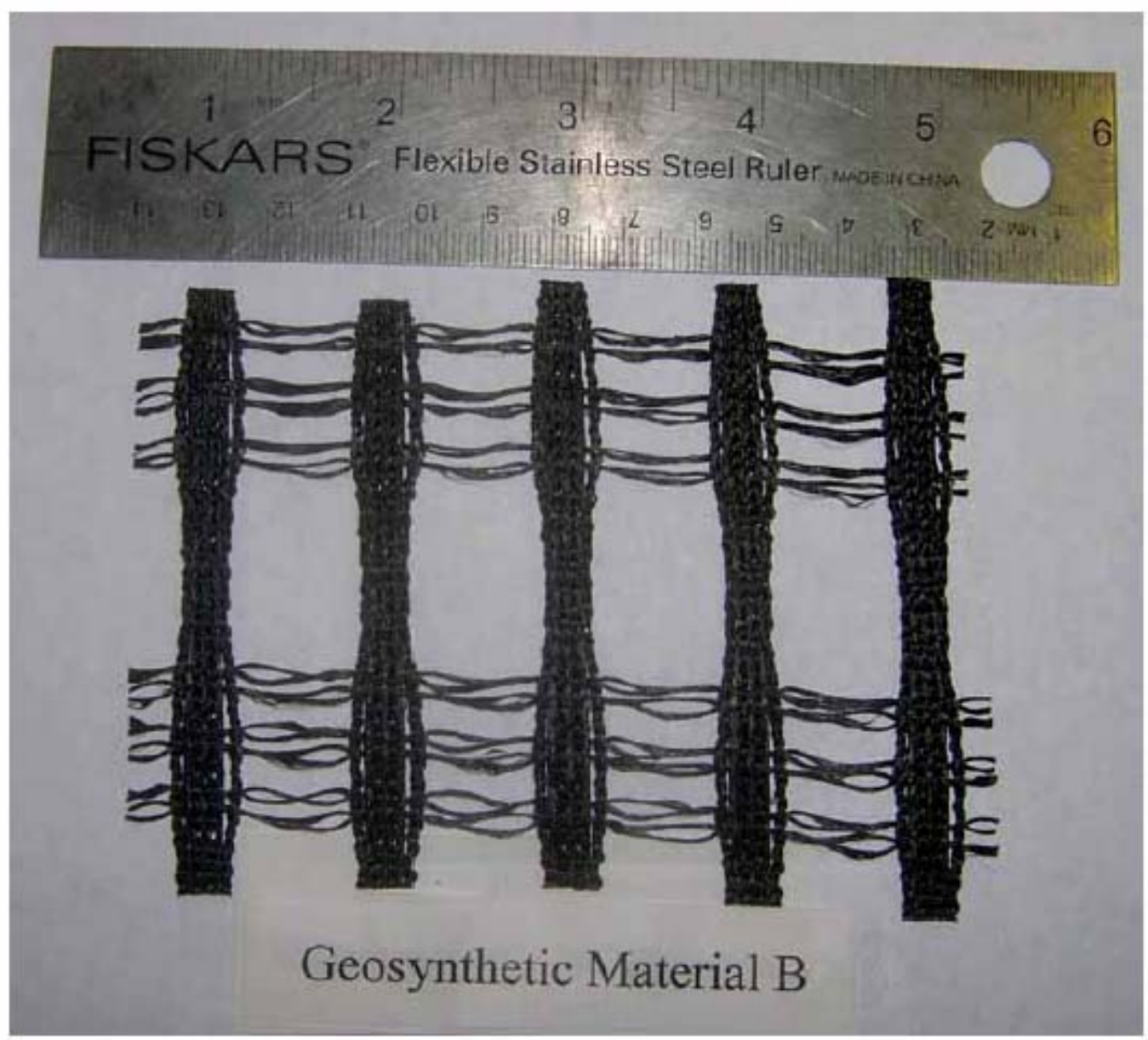

Figure 2.2: KG 30 “Thor” Geogrid - Material B (Niemiec, 2005) 


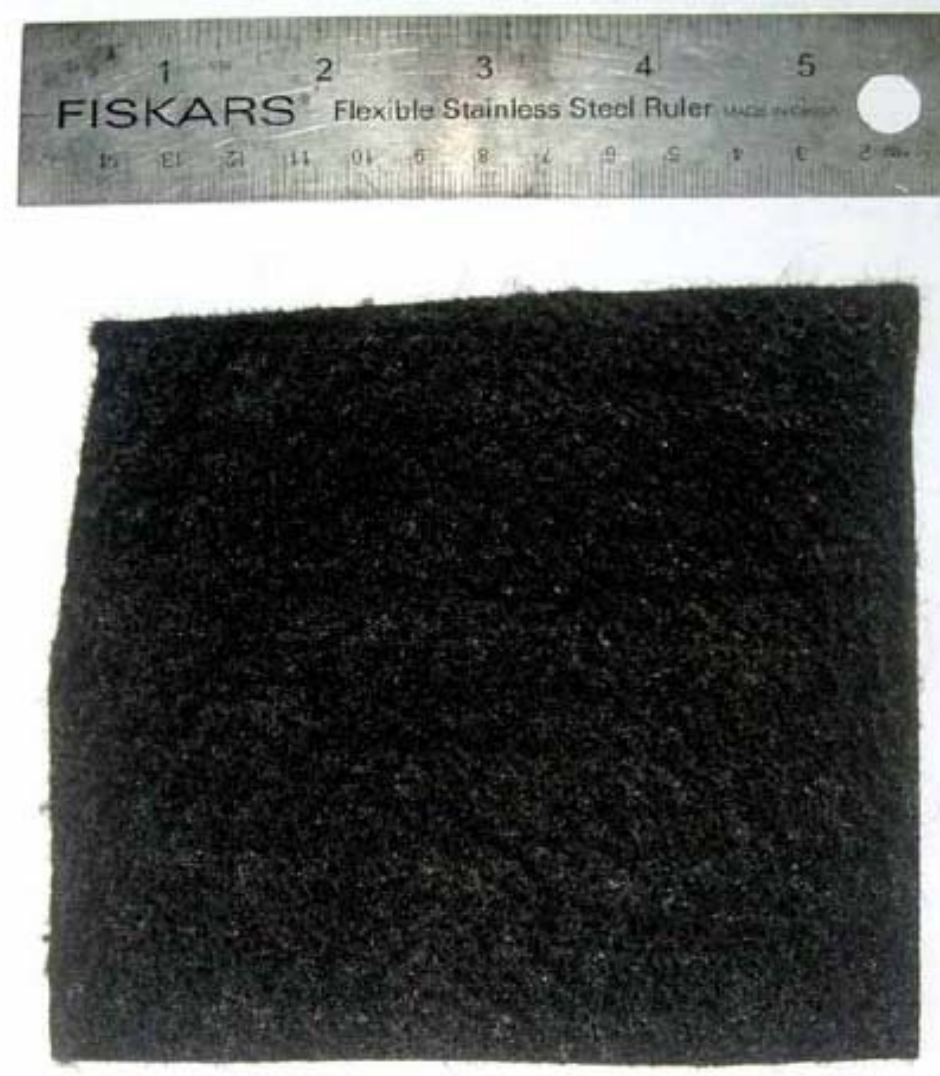

Geosynthetic Material C

Figure 2.3: Amoco 4510 Geotextile - Material C (Niemiec, 2005) 


\subsubsection{Types of soil}

The three types of soils used in these experiments are natural sand, silt and clay. The natural sand was obtained from the Ohio River. Its non-compacted density was derived to be $1.53 \mathrm{~g} / \mathrm{ml}$. The second soil used in these studies was a silty-sand. The silt was composed of $15 \%$ clay (Kaolinite) and $85 \%$ sand. The third soil was clayey sand comprised of $35 \%$ clay and $65 \%$ sand. The percentages for the different types of soils were determined during previous pullout tests performed at West Virginia University (Niemiec, 2005; Ingram, 2006).

\subsection{Pullout Box}

Two different sizes of pullout box were used for the purpose of this experimental study (Niemiec, 2005; Ingram, 2006). Brief details of each pullout box are discussed in the following sections.

\subsubsection{Pullout Box “A”}

Pullout Box A was the smaller of the two pullout boxes. Its dimensions were 6" $\mathrm{x}$ 12 " x 18 " and was made out of steel. The pull out box consisted of a bottom layer of soil with the desired moisture content, a geosynthetic, and a top layer of soil with the same moisture content as the bottom layer. This bottom layer is placed in the box in approximately 1.5 inch thick layers. Each layer is then leveled and compacted manually. A desired geosynthetic is then placed on top of the bottom layer of soil so that the maximum contact surface of the soil is reached without the geosynthetic touching any side of the pullout box. The top layer of soil is then placed on top of the geosynthetic in the same manner as the bottom layer of soil. Normal stress was applied to both the top and bottom sections of the sample by placing the air bags both under and on top of the soil sample. This simulates a realistic scenario for each test. The geosynthetic in use was 
then pulled out of the box and the shear stress - strain relationship was recorded. The geosynthetic was pulled from the pull out box manually using a clamp and a hand wheel. The hand wheel was attached to a worm screw that causes movement to the clamp when turned. The rate of pulling of the geosynthetic was approximately $5 \mathrm{~mm} / \mathrm{min}$. The displacements were recorded using a LVDT and the shear force was recorded with a load cell every 0.1 inches. Pullout Box A (small pullout box) can be seen in Figure 2.4.

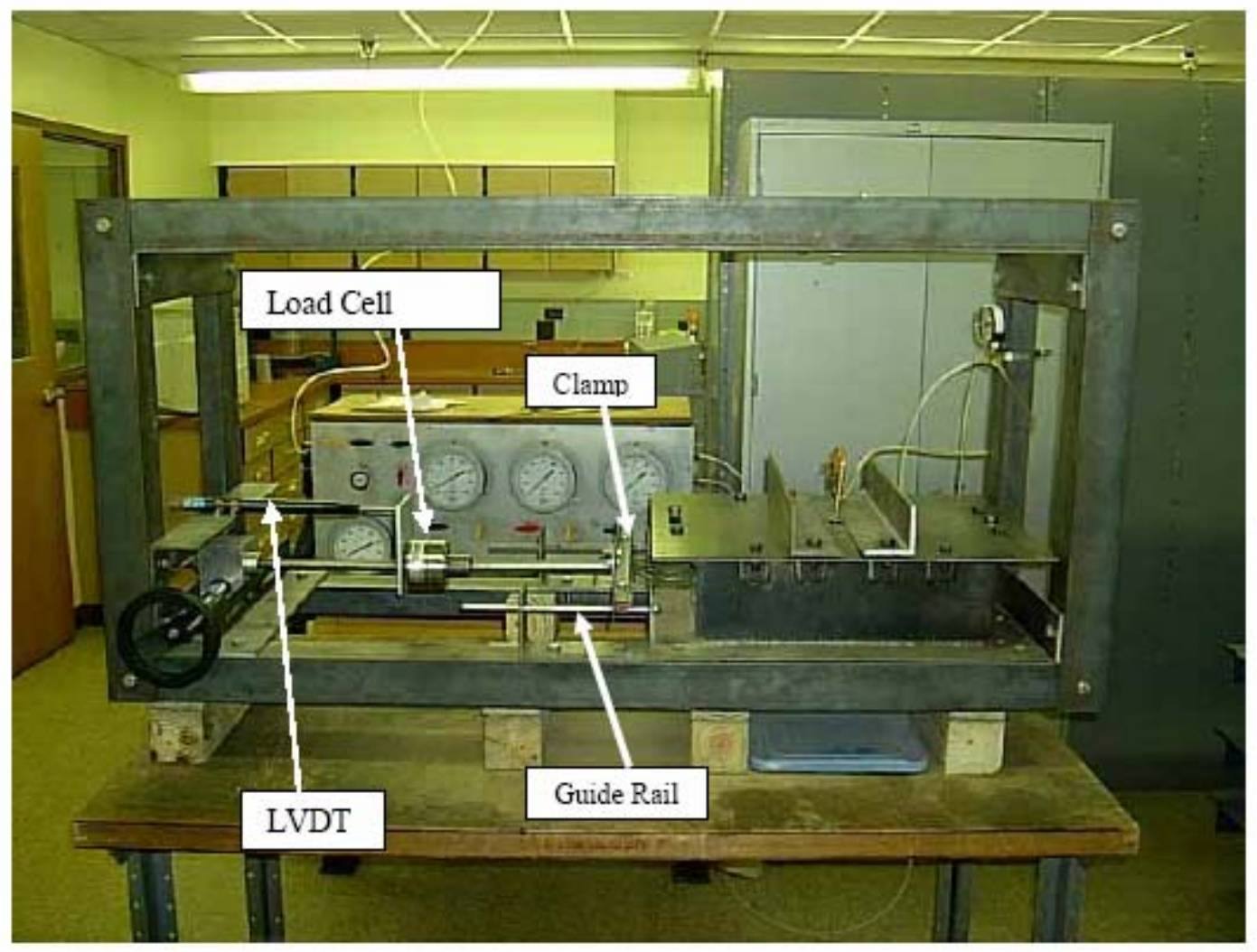

Figure 2.4: Pullout Box A (Small pullout box) (Niemiec, 2005)

\subsubsection{Pullout Box “B”}

Pullout Box B was the larger of the two boxes. The dimensions for pullout box B are 6" x 18" x 48" and was made of steel. Like pullout box A, the box consisted of a bottom layer of soil, the geosynthetic, and a top layer of soil. The placement of the soil was done in the same way as pullout box A by placing the layers of soil in 1.5 inch layers 
and compacting and leveling. The LVDT and hand wheel were not used in the tests done in this box. They were replaced by a variable speed electric gear motor to pull the geosynthetic. An "S" type load cell was used to measure the load of the pull out. The geosynthetic was pulled at a rate of $5 \mathrm{~mm} / \mathrm{min}$. Readings were taken every 30 seconds at 0.1 inch intervals. Pullout Box B (large pullout box) can be seen in Figure 2.5.

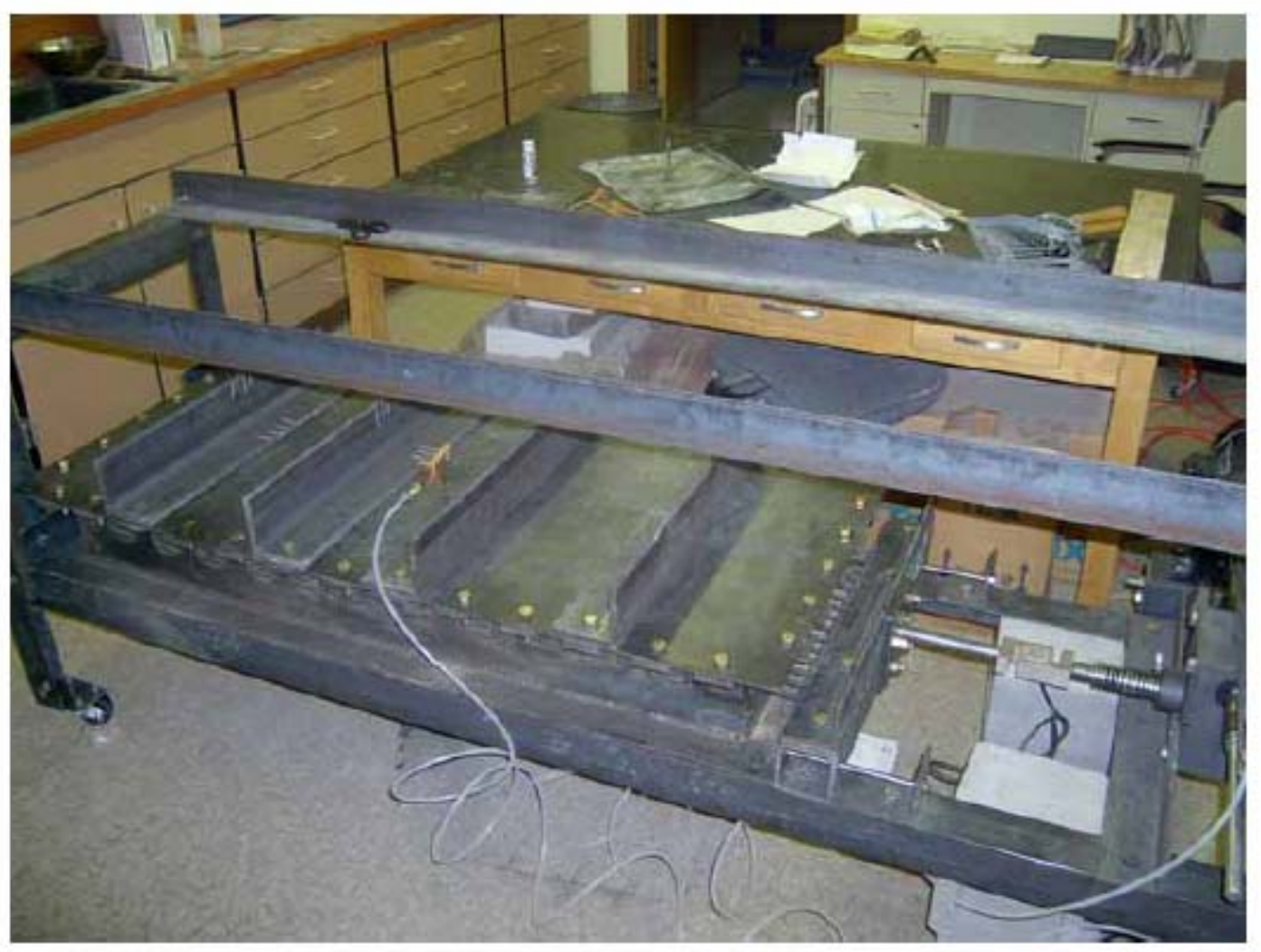

Figure 2.5: Pullout Box B (Large pullout box)

\subsection{Pullout Box Procedure}

As discussed earlier the data collection is done manually during the pullout test. It was noted that if the displacement rate is less than $6 \mathrm{~mm} / \mathrm{min}$ the displacement rates are minimized (Niemiec 2005). The procedure for both pullout boxes is listed below (Niemiec, 2005; Ingram, 2006). 
1. Obtain and weigh more than enough soil to be used for test.

2. Insert air bag into bottom of box and connect to air hose.

3. Distribute soil in several layers evenly into box, level, and compact each layer. Do this until soil reaches the midpoint of the box.

4. Assemble clamp with geosynthetic attached.

5. Place geosynthetic into the soil box and connect clamp to pullout shaft.

6. Measure and record distance of geosynthetic to back wall of the soil box at each node.

7. Distribute soil in several layers evenly into top half of box, level, and compact each layer. Do this until soil reaches the marked line on inside of box, which is $1 / 2 "$ from the top of the box.

8. Insert top air bag, place lid onto box, and connect airbags to the air pressure regulator.

9. Fasten lid and top stiffeners with bolts.

10. Weigh leftover soil.

11. Record an initial reading and proceed with test.

12. When test is done remove lid, top airbag and carefully remove top half of soil until geosynthetic is showing.

13. Measure and record distance of geosynthetic to back wall of the soil box. 


\section{CHAPTER 3}

\section{NUMERICAL METHODOLOGY}

\subsection{Introduction}

In recent years, finite element method (FEM) has become a powerful tool to solve many engineering problems faced today. Recent advancements in computer technology allow finite element program to even solve complex engineering problems. In the present research study, a finite element program called 'ABAQUS' was used to numerically study the pullout resistance of the geosynthetic and the effect of friction on the soilgeosynthetic interface. The pullout analyses were carried out using ABAQUS/Explicit solver. ABAQUS/Explicit solver can be used efficiently to solve transient dynamic and highly complex non-linear problems (ABAQUS, 2005). The finite elements results obtained were compared with previous laboratory experiments discussed in the literature (Niemiec, 2005; Ingram, 2006). Analyses were performed to study the effect of box size, soil type and the geosynthetic material under various conditions. Also, a number of simulations were performed to investigate the influence of moisture content on the pullout capacity.

\subsection{Finite Element Method}

A basic understanding of the basic fundamentals of the Finite Element Method (FEM) is important when doing analysis on a high powered computer program. It allows the user to have a better perceptive of what is actually happening during and after the tests. This section describes some fundamentals in the Finite Element Method. In the finite element analysis, the model is divided into a number of small elements called finite elements. This process is known as discretization. The type of element selected depends 
on the nature of the problem. These elements are connected together at certain points known as nodal points. The grouping of these elements together is defined as the finite element mesh. This gathering of elements produces sets of elemental equations. The elemental equations are assembled together to obtain global equation that are essential to finding the solution for the particular model. This equation can be expressed as (Cook et al., 2003; Bathe, 2002):

$$
[K]\{r\}=\{R\}
$$

where

$$
\begin{aligned}
& {[K]=\text { global stiffness matrix }} \\
& \{\mathrm{r}\}=\text { global displacement vector } \\
& \{\mathrm{R}\}=\text { global load vector }
\end{aligned}
$$

\subsection{Recent Studies}

In one particular study (Perkins and Edens, 2003); a finite element analysis of a laboratory pullout test was performed. Load-displacement curves were calculated from the laboratory results. Finite element modeling was performed to match the loaddisplacement curves found in the laboratory. The pullout test was done using two types of geosynthetics; a type of geogrid and a type of geotextile. The soil material that the geosynthetic was placed between in this particular experiment was aggregate. The aggregate was modeled to best represent its realistic properties. The interaction between the geosynthetic and the aggregate was investigated using Coulomb friction model. This model contains two parameters to be changed; a friction coefficient $(\mu)$ and a parameter $\mathrm{E}_{\text {slip. }}$. These parameters were adjusted to match the load-displacement curves produced by the laboratory pullout test. This study tested different variations of creep components and plasticity components for the two geosynthetics. A model was made using both the creep and plasticity components present for the geosynthetic. A second model was made with 
the creep component removed and a third model was made with both the creep and the plasticity components removed. This was done to test the importance of these components and their effect on pullout behavior. The results gathered from this study show that the geosynthetic creep properties have a noticeable but small effect on loaddisplacement predictions. The results did however show that the geosynthetic plasticity properties had a more significant effect on the load-displacement predictions when the geosynthetic approaches the point where it breaks (Perkins and Edens, 2003; Perkins and Cuelho, 1999).

In another study, pullout tests and finite element analysis were performed on two types of geogrids; SS-1 and SR-55. The geogrids were tested using silica sand under normal pressures of 5,49 , and $93 \mathrm{kN} / \mathrm{m}^{2}$. The purpose of this study was to determine the behavior of two geogrids of different stiffness under different conditions and to determine the accuracy of the finite element analysis simulation. The geogrid behavior was categorized in three ways; Type A, Type B, and Type C. Type A is when the geogrid shows no elongation or slippage along its entire length and the bond stress is at a maximum at the front face. Type B is when the geogrid shows elongation and the bond stress depends on strain. Type $\mathrm{C}$ is when the geogrid shows slippage and the bond stress depends on overburden stress. The geogrids were modeled in FEM according to these behavior types. The sand - geogrid interface was simulated using a bond - slip model for Type B and Coulomb friction model for Type C geogrids. The study showed that as stiffness is increased and overburden pressure is decreased the geogrid failure moves from Type B to Type C. Also, the study showed that a bond - slip model can give relatively accuracte results when the geogrid shows elongation and the Coulomb friction model can simulate the geogrid behavior when the geogrid slips along its surface. The study concluded that finite element analysis (FEM) can simulate the pullout force of the geogrid and the distributions of geogrid displacements, strains, tensile forces, and bond stresses throughout the geogrid during the pullout process (Sugimoto and Alagiyawanna, 2003). 
Another study was done using Tensar SR 80 georid at lengths of 1.8 meters (Test A) and 1.1 meters (Test B). Pullout tests were performed in the laboratory and finite element analysis was done to model the simulation. The elastic modulus was different for different sections of the geogrid. The section modulus was found from the ratio of measured loads and strains of the particular section. Load - strain curves were to compare the two analyses. The results show a good relation between the experimental and the finite element simulation. The shear modulus found in Test A was larger than that of Test B. This is because of the longer length of the geogrid in Test A causing higher friction. Also, a simulation was done for Test B using a constant elastic modulus for the entire geogrid. The results show that the load distribution agrees with the measured data but the strain distribution was always higher than that of the measured data (Yogarajah and Yeo, 1993).

\subsection{Geometry of the model}

The numerical models were developed based on the previous laboratory experiments discussed in the literature (Niemiec, 2005; Ingram, 2006). The finite element models replicate the experimental models of small and large pullout box (Niemiec, 2005; Ingram, 2006). A three-dimensional model of the small and large pullout box was created using the pre-processor ABAQUS CAE as shown in the Figure 3.1. The model was divided into three parts - the top soil, the bottom soil and the geosynthetic. Threedimensional solid deformable elements were used to model the soil and threedimensional membrane elements were used to model the geosynthetic material. Table 3.1(a) and 3.1(b) show the details of small and large pullout box, respectively. The geosynthetic was placed between the top and bottom soil with part of the geosynthetic extending out for the pullout mechanism.

The placement for the geosynthetic for the small pullout box and large pullout boxes can be seen in Figure 3.2(a) and Figure 3.2(b). The placement of the geosynthetic was done according to the specifications of the previous laboratory experiments (Niemiec, 2005; Ingram, 2006). 


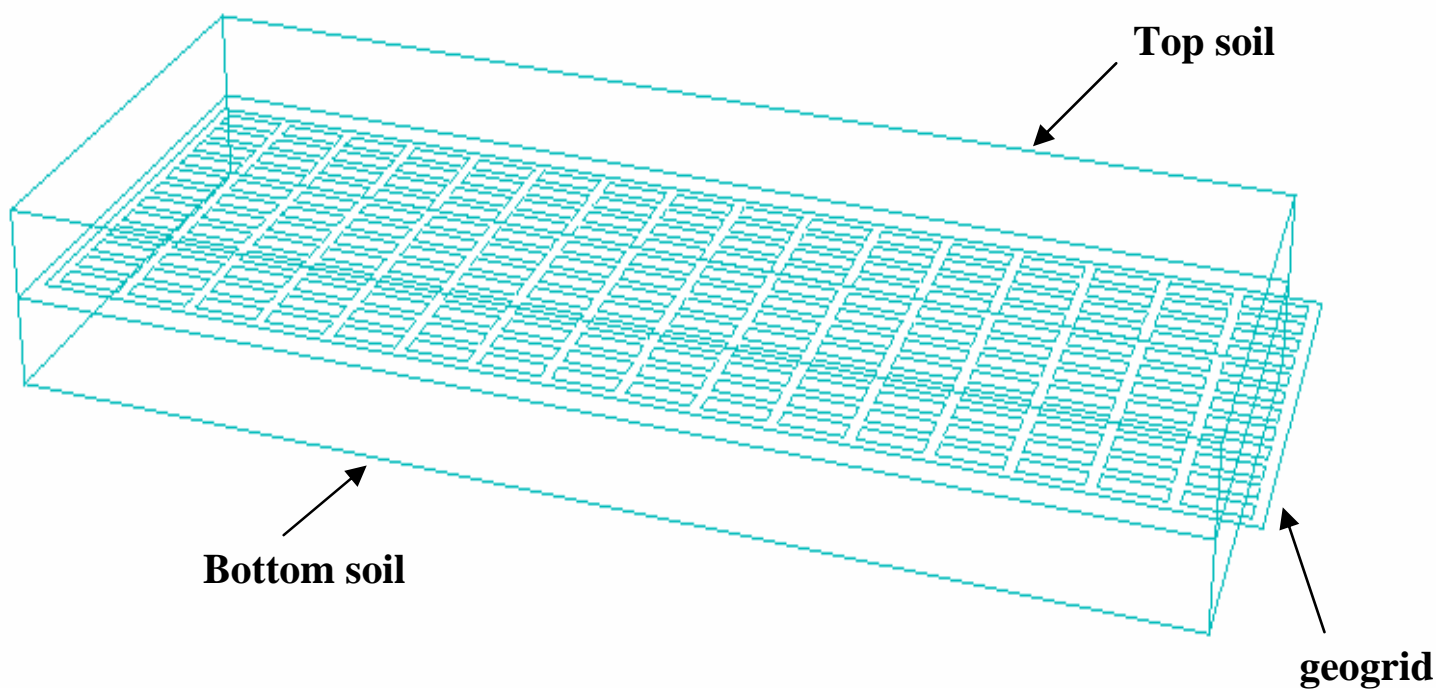

Figure 3.1: Geometry of the large pullout box (Pullout Box - B).

The top and bottom soil were modeled using 8-noded linear brick elements as two different parts. The geosynthetic was modeled as a separate part using 4-noded quadrilateral membrane elements. In an attempt to simulate the exact conditions used during the laboratory experiment the parts were modeled according to specifications used during the laboratory. The dimensions used for each pullout box and geosynthetic can be seen in Figure 3.2. The dimensions for the geosynthetics differ slightly in some cases for the large and small pullout boxes in length and width. When creating the geosynthetic membrane, continuity became difficult when the grid apertures were taken into account. Because of different sized apertures, the lengths or widths weren't able to match between 
the geosynthetic A and geosynthetic B. The analysis used in this study was a contact pullout analysis. A quasi-static solution was found by using ABAQUS/Explicit.

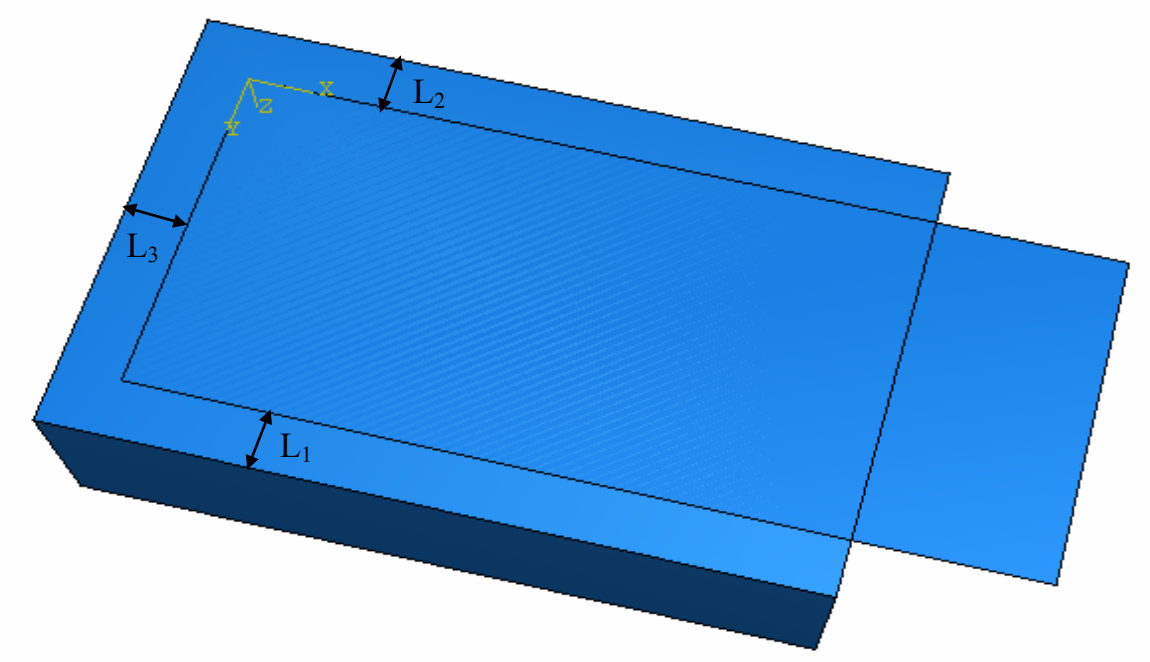

(a) Pullout Box A (small box)

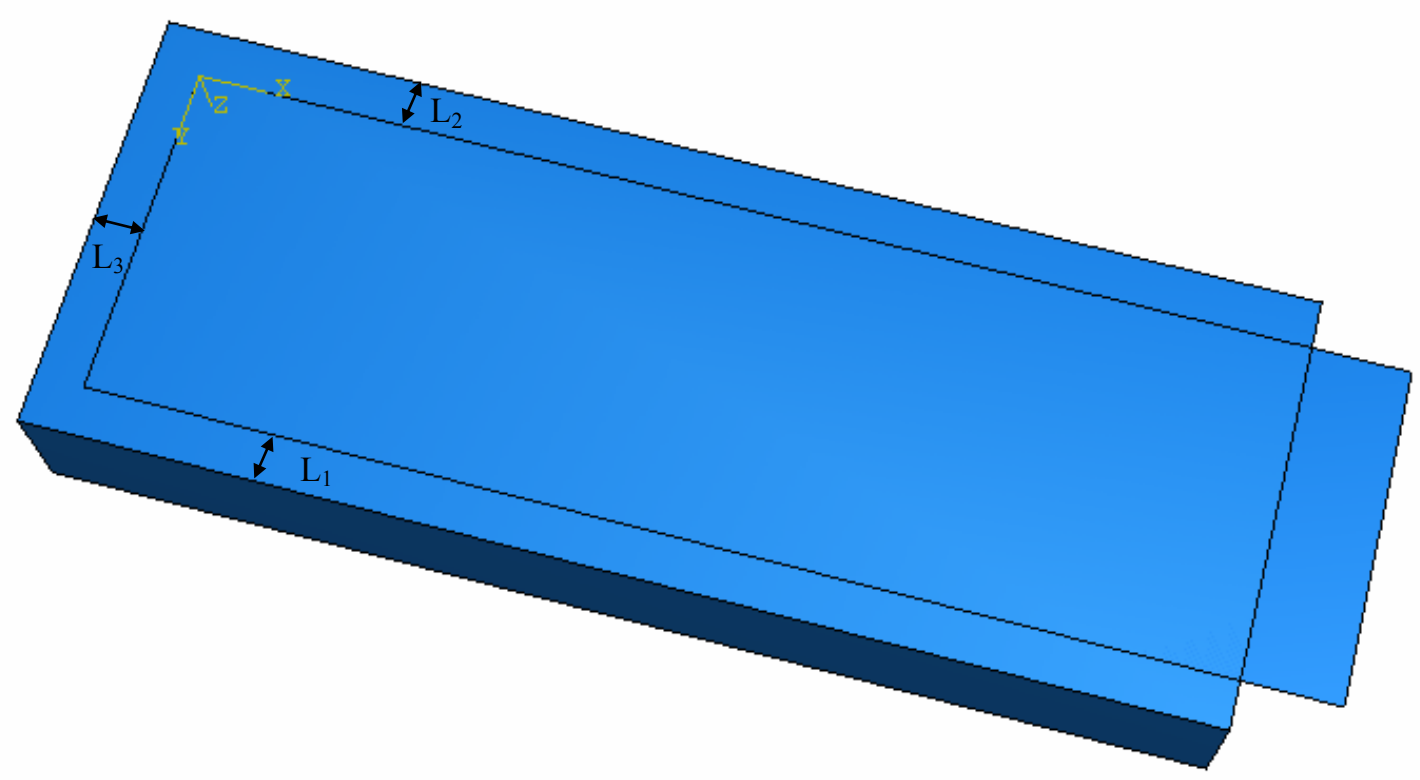


(b) Pullout Box B (large box)

Figure 3.2: Placement of the geosynthetic

Table 3.1: Specifications of the geosynthetic placement for the small and large pullout boxes

(a) Small Pullout Box

\begin{tabular}{|c|c|c|c|c|c|c|c|}
\hline \multicolumn{2}{|c|}{ Small Pullout Box } & \multirow[b]{2}{*}{$\begin{array}{c}\text { Grid } \\
\text { Aperture } \\
\text { Size, MD } \\
(\mathbf{m m})\end{array}$} & \multirow[b]{2}{*}{$\begin{array}{c}\text { Grid } \\
\text { Aperture } \\
\text { Size, } \\
\text { XMD } \\
(\mathrm{mm})\end{array}$} & \multirow[b]{2}{*}{$\begin{array}{c}\text { Mass } \\
\text { per } \\
\text { Unit } \\
\text { Area } \\
\left(\mathrm{g} / \mathrm{m}^{2}\right) \\
\end{array}$} & \multirow[b]{2}{*}{$\begin{array}{l}\text { Thickness } \\
\text { (in) }\end{array}$} & \multirow[b]{2}{*}{$\begin{array}{l}\text { Length } \\
\text { (in) }\end{array}$} & \multirow[b]{2}{*}{ Width (in) } \\
\hline Geosynthetic & $\begin{array}{c}\text { Tensile } \\
\text { Strength } \\
(\mathrm{kN} / \mathrm{m})\end{array}$ & & & & & & \\
\hline A & 120 & 65 & 20 & 415 & 0.0255 & 21.75 & 9.29 \\
\hline C & 0.36 & $\mathrm{~N} / \mathrm{A}$ & N/A & $310^{*}$ & 0.12 & 21.75 & 10.62 \\
\hline
\end{tabular}

*MD = machine direction

*XMD = across machine direction

(b) Large Pullout Box

\begin{tabular}{|c|c|c|c|c|c|c|c|}
\hline \multicolumn{2}{|l|}{ Large Pullout Box } & \multicolumn{2}{|l|}{} \\
\hline Geosynthetic & $\begin{array}{c}\text { Tensile } \\
\text { Strength } \\
\text { (kN/m) }\end{array}$ & $\begin{array}{c}\text { Grid } \\
\text { Aperture } \\
\text { Size, MD } \\
\text { (mm) }\end{array}$ & $\begin{array}{c}\text { Grid } \\
\text { Aperture } \\
\text { Size, } \\
\text { XMD } \\
\text { (mm) }\end{array}$ & $\begin{array}{c}\text { Mass } \\
\text { per } \\
\text { Unit } \\
\text { Area } \\
(\mathbf{g} / \mathbf{m} 2)\end{array}$ & $\begin{array}{c}\text { Thickness } \\
\text { (in) }\end{array}$ & $\begin{array}{c}\text { Length } \\
\text { (in) }\end{array}$ & Width (in) \\
\hline A & 120 & 65 & 20 & 415 & 0.0255 & 49 & 15.58 \\
\hline B & 35 & 40 & 25 & 170 & 0.0405 & 48.074 & 15.58 \\
\hline C & 0.36 & N/A & N/A & $310^{*}$ & 0.12 & 49 & 15.58 \\
\hline
\end{tabular}

*MD = machine direction

*XMD = across machine direction 


\subsection{Material Properties}

Table 3.2 shows the material properties used for this analysis.

\section{Table 3.2 Assumed material properties}

\begin{tabular}{|c|c|c|c|c|}
\hline & Material & $\begin{array}{l}\text { Young's } \\
\text { Modulus (E) } \\
\text { (psi) }\end{array}$ & $\begin{array}{c}\text { Poisson's } \\
\text { Ratio (v) }\end{array}$ & $\begin{array}{c}\text { Density } \\
\text { (pci) }\end{array}$ \\
\hline \multirow{3}{*}{ 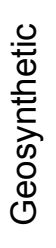 } & WG 120 "ATLAS" (A) & 188000 & 0.3 & 0.023137 \\
\hline & KG "THOR" (B) & 41440 & 0.3 & 0.009128 \\
\hline & BP/Amoco No. 4553 (C) & 30000 & 0.3 & 0.00873 \\
\hline \multirow{3}{*}{$\overline{\bar{\phi}}$} & Sand & 7500 & 0.3 & 0.058887 \\
\hline & Silt & 6544 & 0.3 & 0.052746 \\
\hline & Clay & 5269 & 0.3 & 0.046062 \\
\hline
\end{tabular}

\subsection{Step Sequence, Boundary Conditions, and Loading}

After each model is successfully made, it is now possible to configure the analysis of the pullout box. For this experiment it is important to understand the dynamic response during this analysis. This simulation consists of two steps occurring during the pullout analysis. The initial step in the analysis is the applied pressure acting on the top of the pullout box. The second step in the analysis is the pulling of the geosynthetic 
membrane. A pullout rate of $5 \mathrm{~mm} / \mathrm{min}$ was used for the large pullout box and a pullout rate of $2 \mathrm{~mm} / \mathrm{min}$ was used for the small pullout box.

Boundary conditions and loads can now be identified in the model. Boundary conditions are given to an area in the model where rotations or displacements are known. The displacement is zero at the bottom of the pullout box so it becomes fixed while the sides are made to slide along the axis for each model. The normal pressure is applied to the top of the pullout box. The loads of 5 psi, 10 psi, and 15 psi used in the finite element modeling are the same used in the laboratory experiments. Figure 3.3 shows the boundary conditions and loads specified for the small pullout box. Similar boundary conditions and loads are specified for the large pullout box.

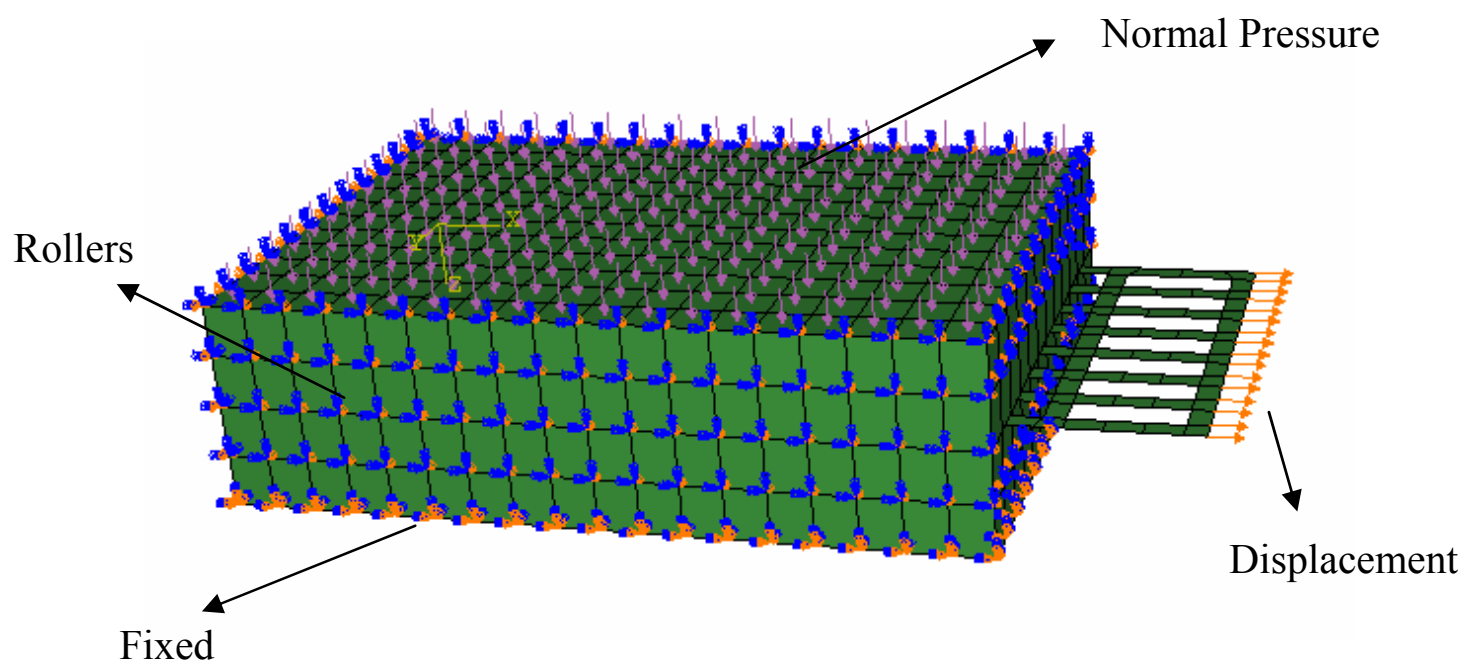

Figure 3.3: Boundary conditions for small pullout box

\subsection{Interaction between soil and geosynthetic}

The interaction between two bodies that slide against each other can be defined as a contact pair. In this case the two bodies refer to as the surfaces of the geosynthetic and the soil. The two surfaces must be defined as either a master surface or a slave surface. 
The slave surface must be a deformable body and the master surface must be a rigid body. The stiffer of the two bodies is chosen as the master surface. For the present study the interaction between the soil and the geosynthetic grid is modeled as a contact pair. The geosynthetic was chosen as the master surface because of its much higher Young's modulus. For the analysis the nodes of the slave surface (soil) were not allowed to penetrate the master surface, however the nodes of the master surface (geosynthetic) were allowed to penetrate the slave surface.

The analysis for the soil and geosynthetic interaction is based upon the MohrCoulomb failure criterion. This theory is based on the principle that a material will fail because of a combination of normal stress and shearing stress. Most soil mechanics problems assume that the shear stress on the failure plane is a linear function of the normal stress. This can be expressed as (Das, 2002):

$$
\tau_{f}=c+\sigma \tan \phi
$$

where:

$$
\begin{aligned}
& \mathrm{c}=\text { cohesion } \\
& \phi=\text { angle of internal friction } \\
& \sigma=\text { normal stress } \\
& \tau_{\mathrm{f}}=\text { shear stress }
\end{aligned}
$$

\subsection{Calculations of cohesion and angle of friction}

Pullout experiments involving clay were investigated with the addition of cohesion and angle of friction. The cohesion and angle of friction were added to the ABAQUS simulation for clay by the use of the Drucker-Prager plasticity model. The cohesion and angle of friction that were measured in the laboratory at West Virginia University are not the same cohesion and angle of friction used for the Drucker-Prager model. They are, however, function of two variables; Drucker-Prager angle of friction 
and stress in uniaxial compression, used for the Drucker-Prager model. The DruckerPrager angle of friction is a function of the measured angle of friction and the stress in uniaxial compression is a function of the measured cohesion of the soil. These equations are expressed as (ABAQUS, 2005, Murad et al., 2004):

$$
\tan \beta=\frac{3 \sqrt{3} \tan \phi}{\sqrt{9+12 \tan ^{2} \phi}}
$$

where:

$$
\begin{aligned}
& \beta=\text { Drucker-Prager angle of friction } \\
& \Phi=\text { angle of friction }
\end{aligned}
$$

$$
\sigma_{c}^{o}=\frac{d}{\left(1-\frac{1}{3} \tan \beta\right)}
$$

where:

$$
\begin{aligned}
& \mathrm{d}=\text { cohesion } \\
& \sigma_{\mathrm{c}}{ }^{\circ}=\text { stress in uniaxial compression }
\end{aligned}
$$




\section{CHAPTER 4 \\ RESULTS AND DISCUSSIONS}

\subsection{Introduction}

The present study uses three-dimensional finite element analysis to evaluate the pullout interaction between the soil and the geosynthetic. The analysis was done using three different soils; sand, silt, and clay and three different geosynthetics. Two geogrids and one geotextile was used. In order to investigate the effect of moisture content, soils with different moisture contents were considered. Moisture content was varied as $0 \%$, $10 \%$, and $15 \%$. In order to investigate the effect of normal loading, normal pressures of 5 psi, $10 \mathrm{psi}$, and $15 \mathrm{psi}$ were used for this study. Analyses were performed for most combinations of soil, geosythetic, moisture content, and normal pressure. Sand with moisture content greater than $0 \%$ was not performed due to the fact that natural sand has no cohesion so it was only tested in its dry state. Experiments with clay at $15 \%$ moisture were not performed during the laboratory experiments. At 15\% moisture, the clay becomes oversaturated and loses some of its properties. Finite element analysis was not performed for material B in the small pullout box.

Load-displacement curves were made during the laboratory analysis at West Virginia University. During the finite element analysis, the friction coefficient was changed so that the load-displacement curve created by the finite element analysis would match the load-displacement curves for the laboratory experiments.

\subsection{Results for Pullout Box A (Small Box)}

The results for Pullout Box A are shown in load - displacement figures for each soil, geosynthetic, and moisture content. The figures compare the experimental data 
gathered from the laboratory tests and the data computed from the finite element analysis. A trial and error procedure was followed to find the desired friction coefficient for the soil - geosynthetic interaction that best matched the experimental data. The friction coefficient was modified to obtain a load - displacement curve that matched the results curves created from laboratory experiments.

Figure 4.1 shows the load - displacement curves calculated from the experimental tests and those generated from the finite element analysis for interaction of sand and material $\mathrm{A}$ at $0 \%$ moisture. The corresponding friction coefficients used during the finite element analysis can be seen in the tool bar in the figure. The figure shows that an increase in normal pressure results in an increase of friction coefficient.

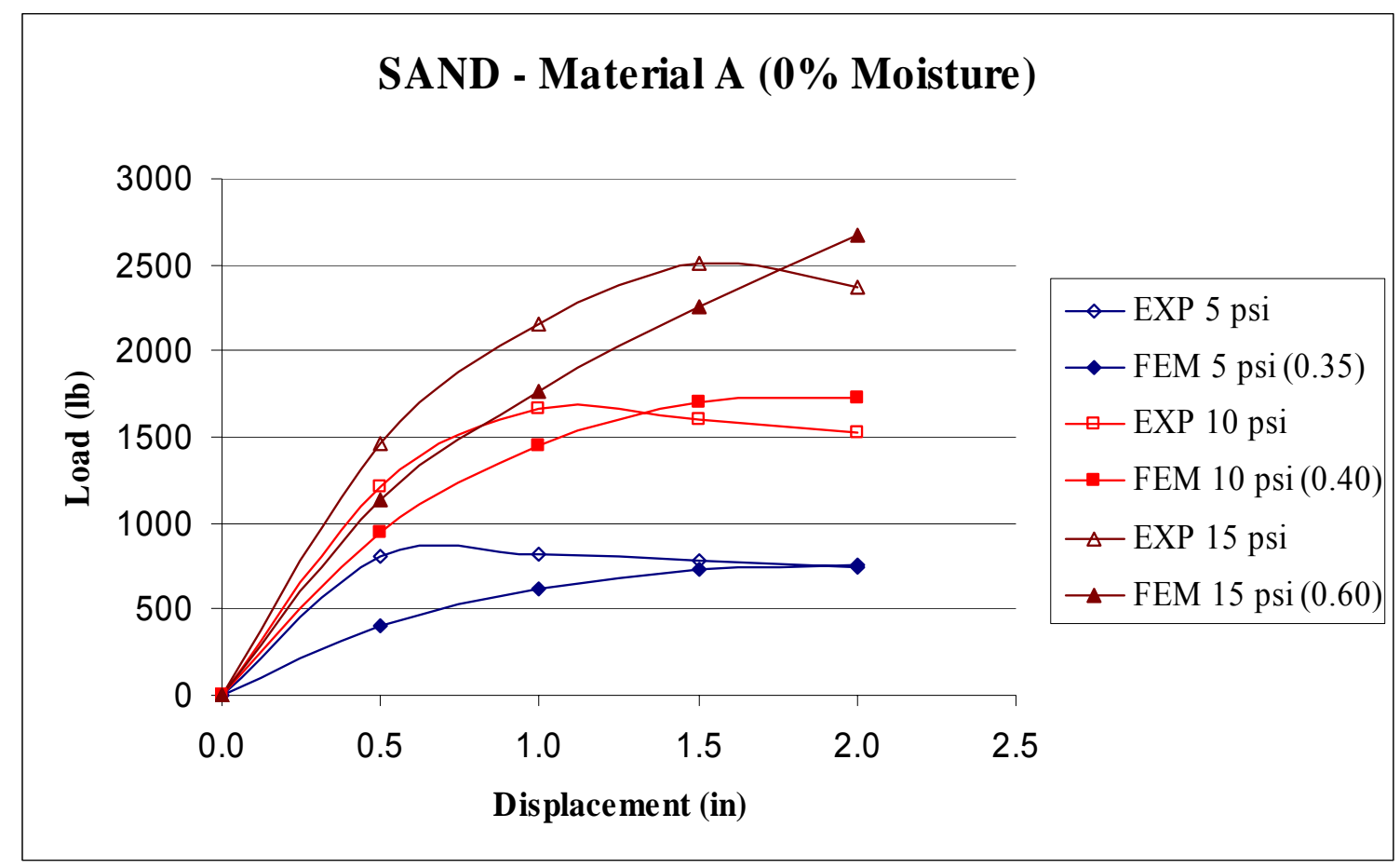

Figure 4.1: Load - displacement relationship for sand - material $A$ interaction at $0 \%$ moisture under normal pressures of $5 \mathrm{psi}, 10 \mathrm{psi}$, and 15 psi with their respective friction coefficients. 
Figure 4.2 shows the load - displacement curves calculated from the experimental tests and those generated from the finite element analysis for interaction of sand and material $\mathrm{C}$ at $0 \%$ moisture. The corresponding friction coefficients used during the finite element analysis can be seen in the tool bar in the figure. The figure shows a constant friction coefficient with the increase of normal pressure from 5 psi to $10 \mathrm{psi}$. There is an increase of friction coefficient from 10 psi to 15 psi.

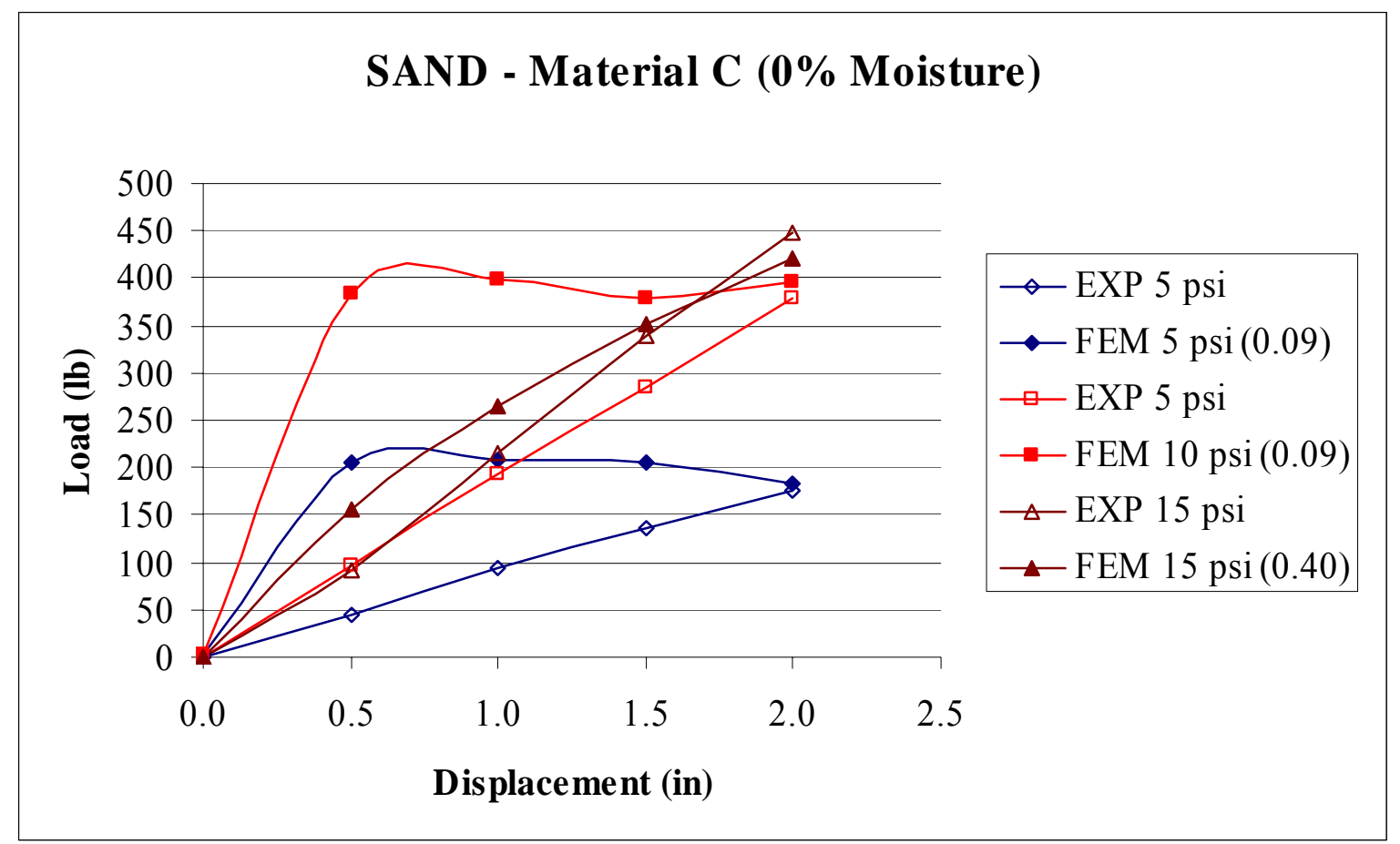

Figure 4.2: Load - displacement relationship for sand - material $C$ interaction at $0 \%$ moisture under normal pressures of 5 psi, 10 psi, and 15 psi with their respective friction coefficients. 
Figure 4.3 shows the comparison of experimental and finite element results. The load - displacement curves obtained from the finite element analysis match perfectly with the laboratory experiments. The figure shows a decrease in friction coefficient as normal pressure increases for silt and material $\mathrm{A}$ interaction at $0 \%$ moisture content.

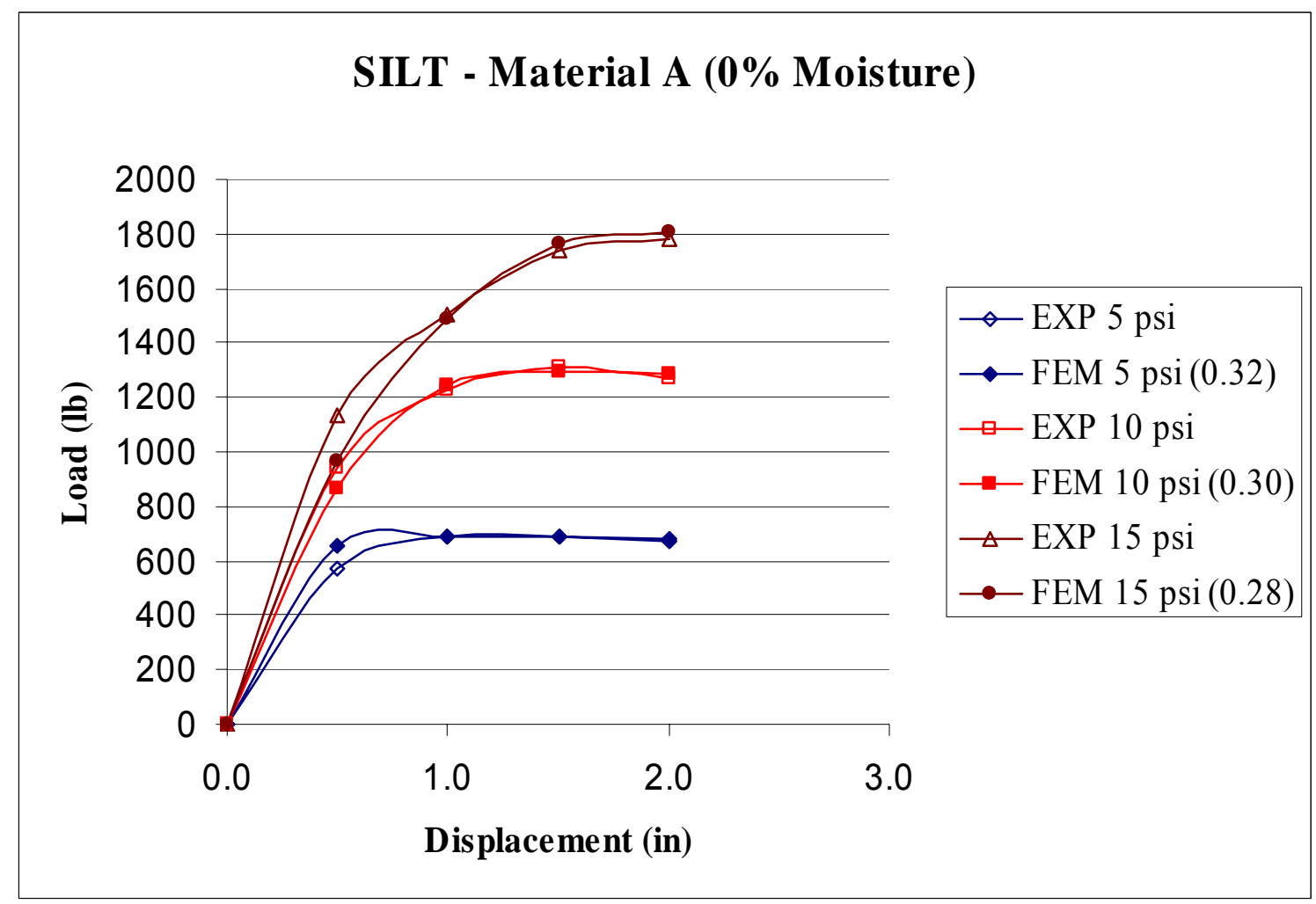

Figure 4.3: Load - displacement relationship for silt - material A interaction at $0 \%$ moisture under normal pressures of $5 \mathrm{psi}, 10 \mathrm{psi}$, and $15 \mathrm{psi}$ with their respective friction coefficients. 
Figure 4.4 shows the load - displacement curves generated from the laboratory and finite element analysis results. The figure shows a close match between the load displacement curves. The friction coefficient decreases as normal pressure increases for silt and material A interaction at $10 \%$ moisture.

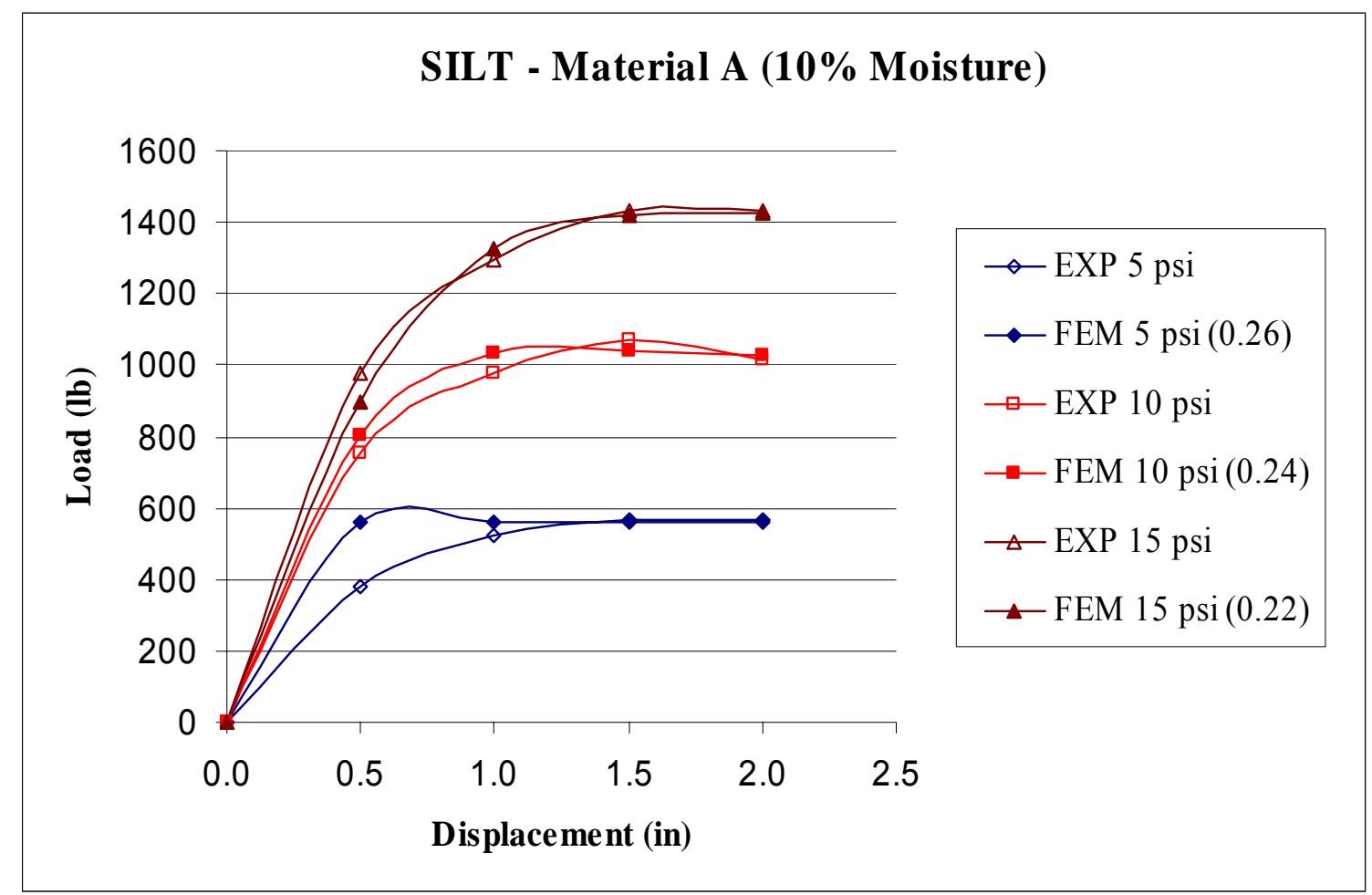

Figure 4.4: Load - displacement relationship for silt - material A interaction at $10 \%$ moisture under normal pressures of $5 \mathrm{psi}, 10 \mathrm{psi}$, and $15 \mathrm{psi}$ with their respective friction coefficients. 
Figure 4.5 shows the load - displacement curves calculated from the experimental tests and those generated from the finite element analysis for interaction of silt and material $\mathrm{A}$ at $15 \%$ moisture. The figure shows that as normal pressure increases, the friction coefficient deceases minimally for silt and material $\mathrm{A}$ at $15 \%$ moisture. The results show a close match between the experimental and finite element analysis.

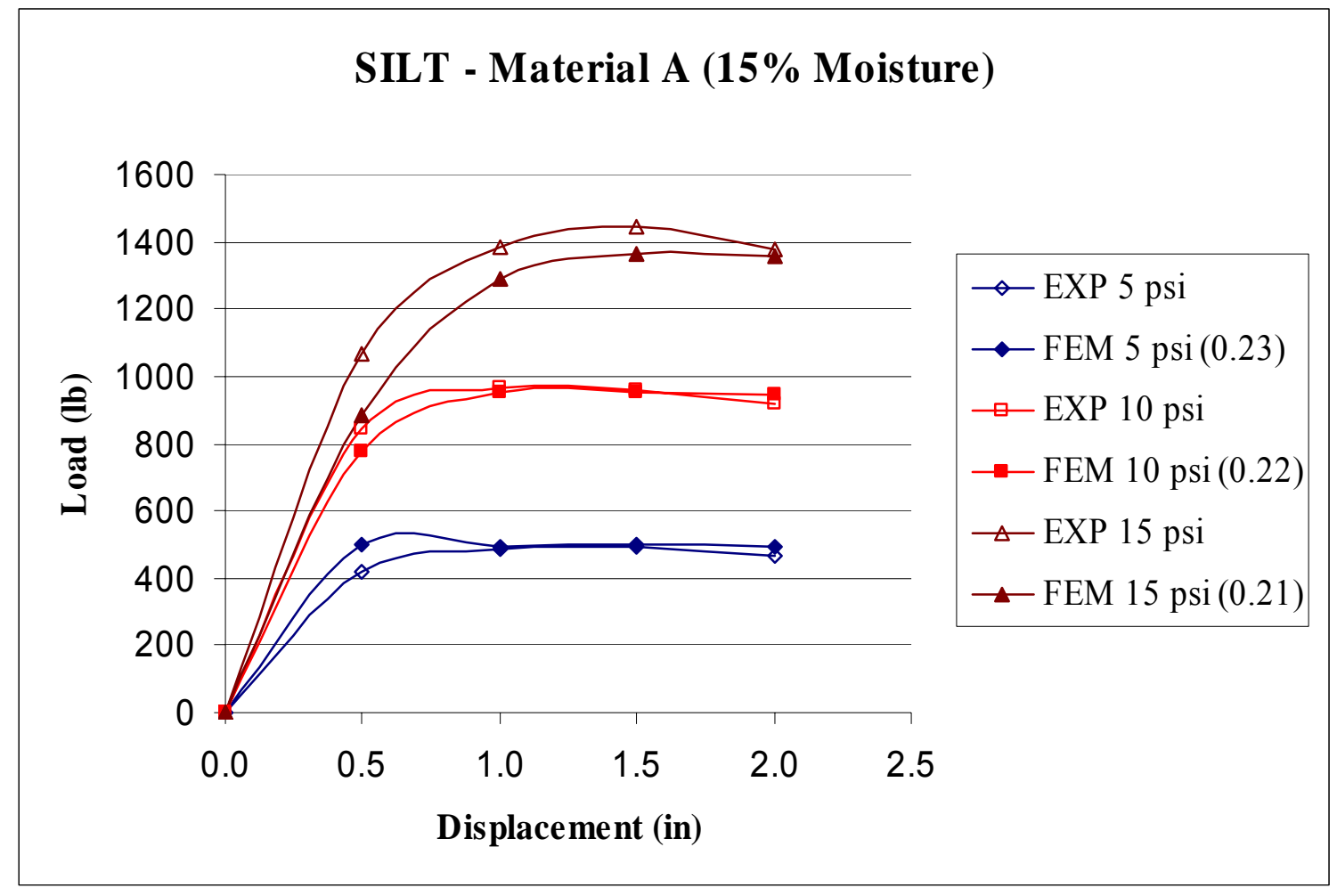

Figure 4.5: Load - displacement relationship for silt - material A interaction at 15\% moisture under normal pressures of 5 psi, 10 psi, and 15 psi with their respective friction coefficients. 
Figure 4.6 shows a decrease in friction coefficient as normal pressure increases for silt and material $\mathrm{C}$ interaction at $0 \%$ moisture content. The figure shows an inconsistent slope between the laboratory and finite element analysis load - displacement curves.

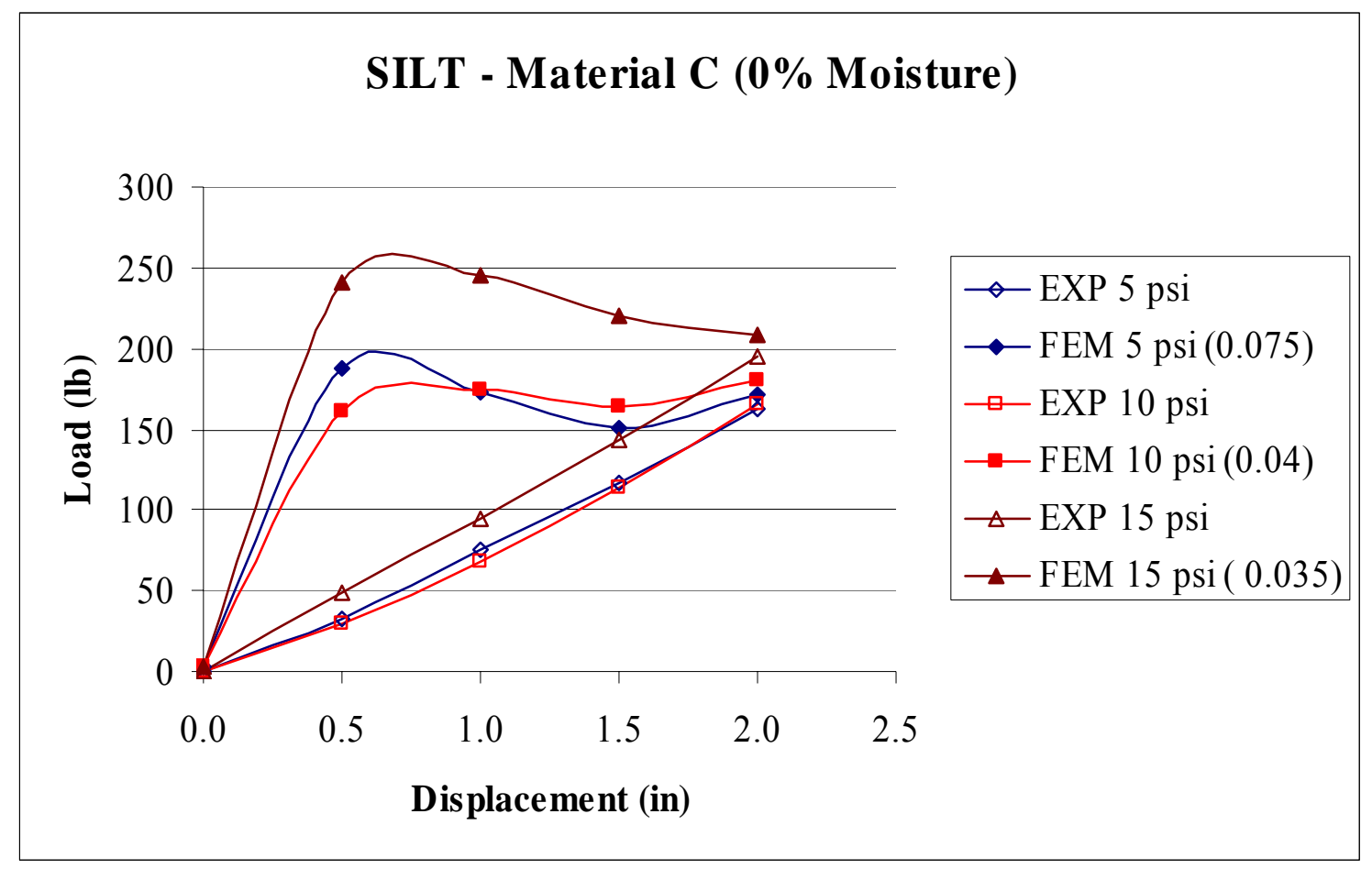

Figure 4.6: Load - displacement relationship for silt - material C interaction at $0 \%$ moisture under normal pressures of $5 \mathrm{psi}, 10 \mathrm{psi}$, and $15 \mathrm{psi}$ with their respective friction coefficients. 
Figure 4.7 shows the load - displacement curves calculated from the experimental tests and those generated from the finite element analysis for interaction of silt and material $\mathrm{C}$ at $10 \%$ moisture. The figure shows that as normal pressure increases from 5 psi to $10 \mathrm{psi}$, the friction coefficient deceases. The friction coefficient remains constant from 10 psi to 15 psi.

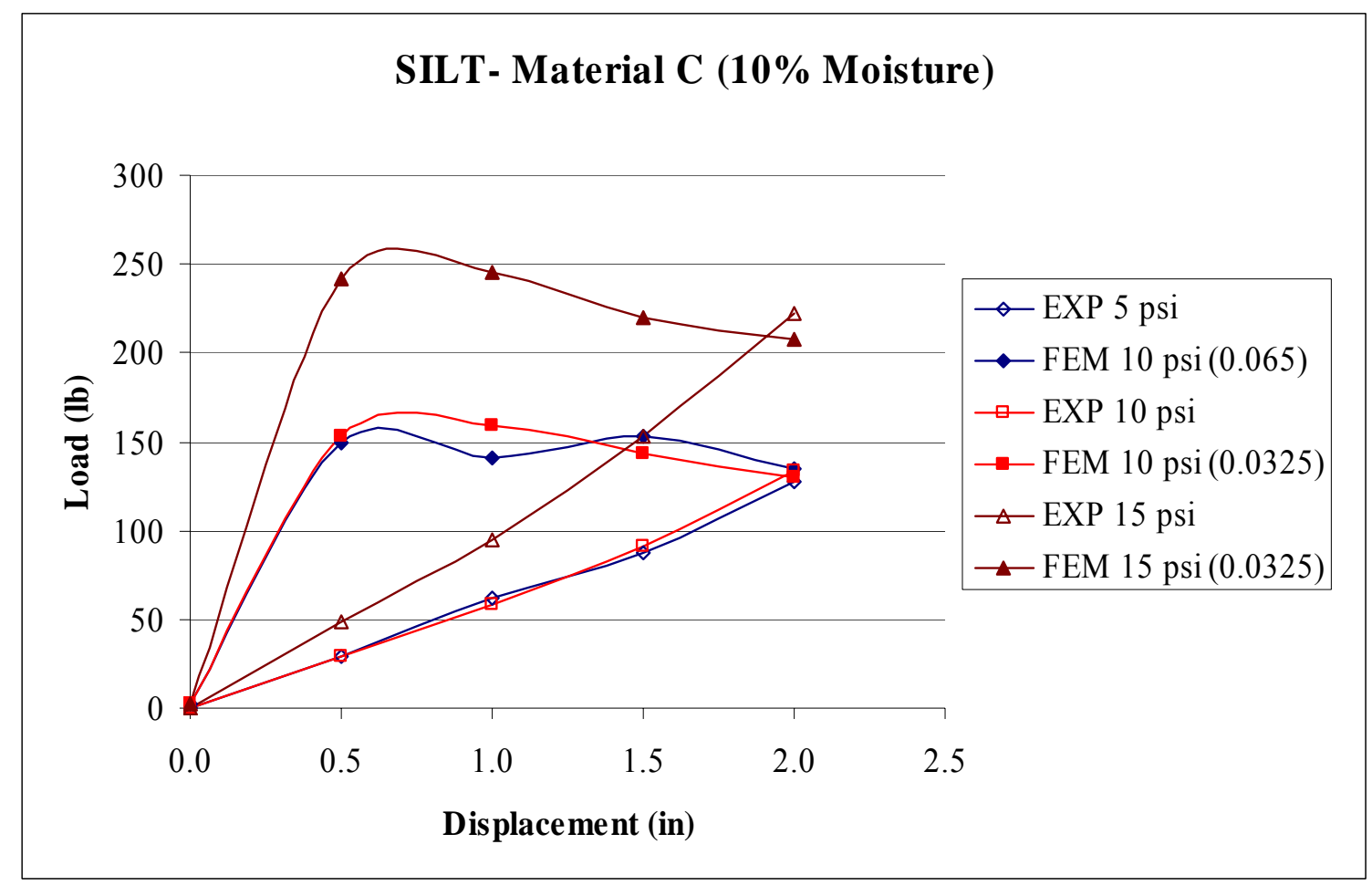

Figure 4.7: Load - displacement relationship for silt - material C interaction at $10 \%$ moisture under normal pressures of $5 \mathrm{psi}, 10 \mathrm{psi}$, and $15 \mathrm{psi}$ with their respective friction coefficients. 
Figure 4.8 shows the load - displacement curves calculated from the experimental tests and those generated from the finite element analysis for interaction of silt and material $\mathrm{C}$ at $15 \%$ moisture. The figure shows a decrease of friction coefficient from 5 psi to 10 psi and remains constant from 10 psi to 15 psi.

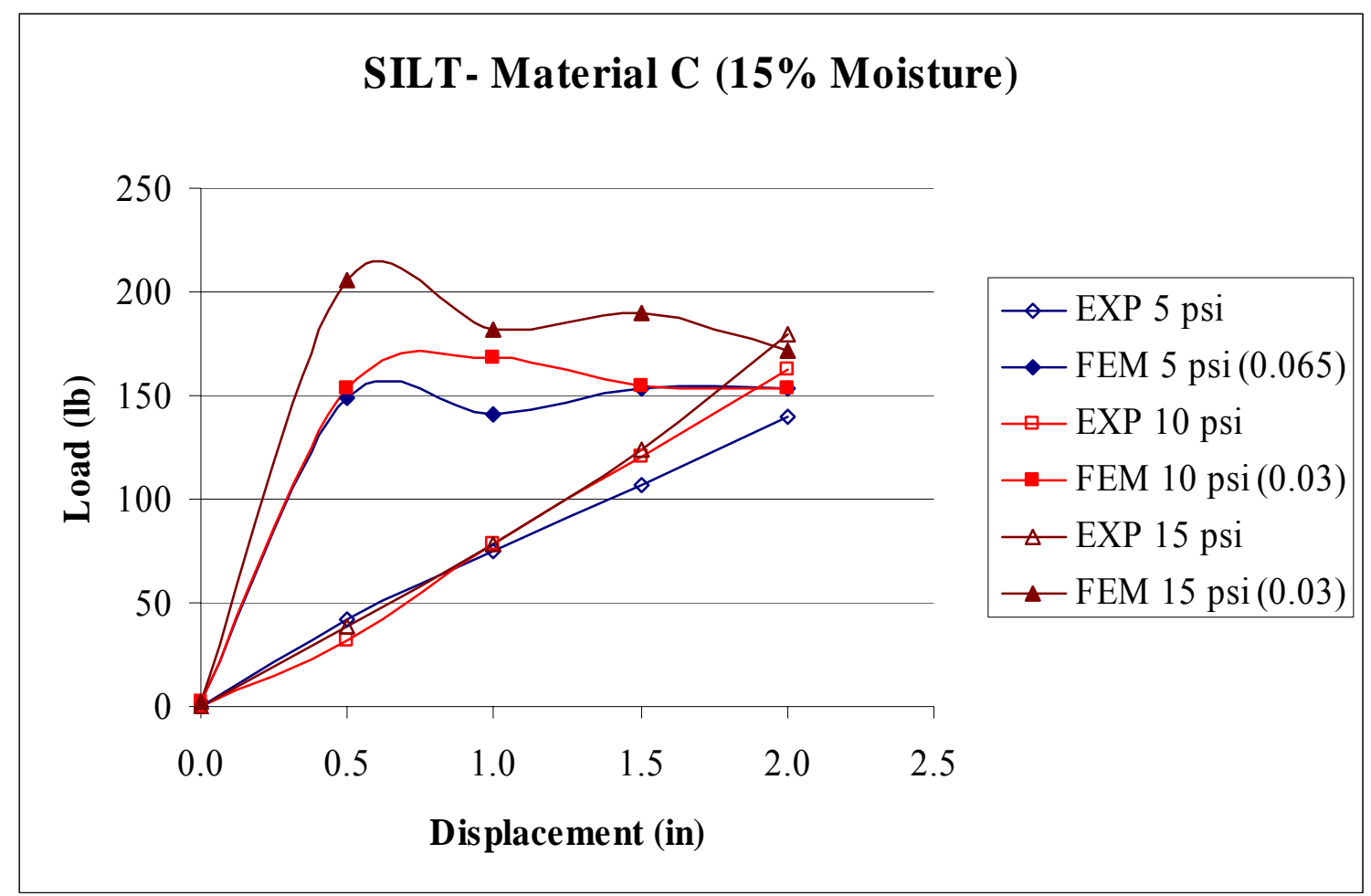

Figure 4.8: Load - displacement relationship for silt - material C interaction at $15 \%$ moisture under normal pressures of $5 \mathrm{psi}, 10 \mathrm{psi}$, and $15 \mathrm{psi}$ with their respective friction coefficients. 
Figure 4.9 shows the load - displacement curves calculated from the experimental tests and those generated from the finite element analysis for interaction of clay and material $\mathrm{A}$ at $0 \%$ moisture. The figure shows that the friction coefficient decreases from 5 psi to 10 psi then remains constant from 10 psi to 15 psi for clay and material A at $0 \%$ Moisture. The experimental and finite element curves do not show much of a match. This may be the result of inaccurate experimental data. Notice the inconsistent slope for the experimental data at $10 \mathrm{psi}$.

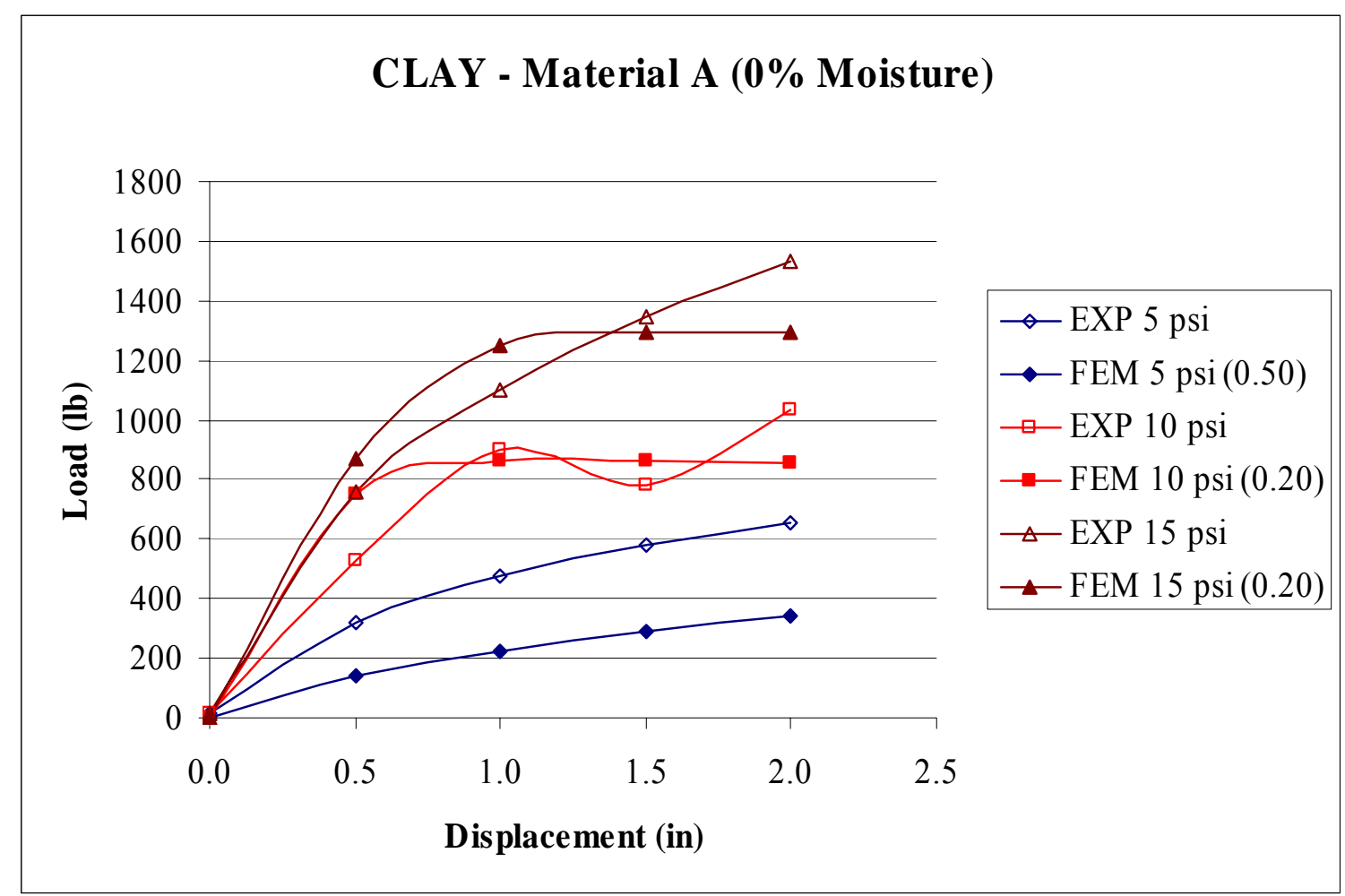

Figure 4.9: Load - displacement relationship for clay - material $\mathrm{C}$ interaction at $0 \%$ moisture under normal pressures of 5 psi, 10 psi, and 15 psi with their respective friction coefficients. 
Figure 4.10 shows a decrease in friction coefficient as normal pressure increases for clay and material A interaction at 10\% moisture. The figure shows a relatively good match between the experimental and finite element analysis results.

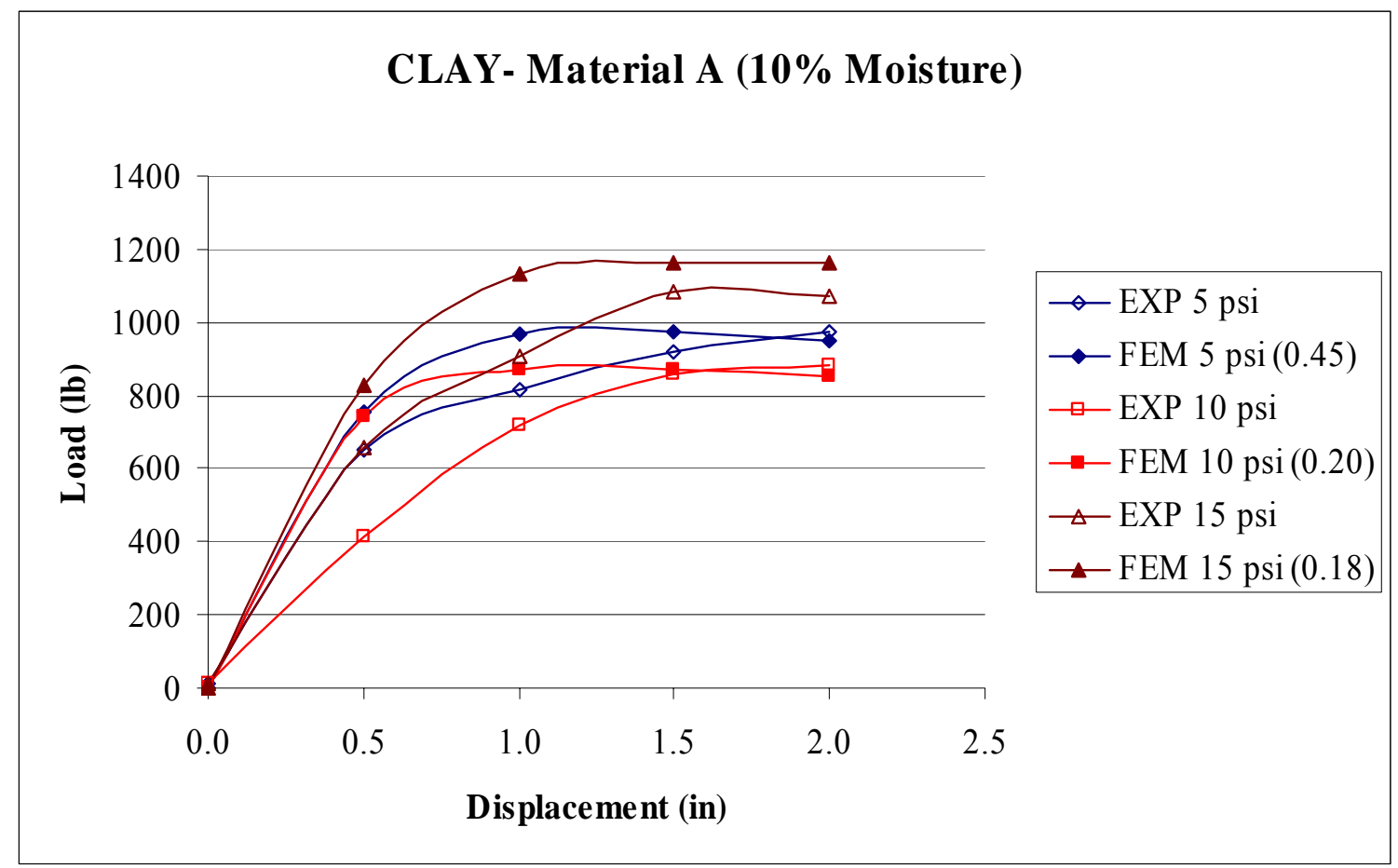

Figure 4.10: Load - displacement relationship for clay - material A interaction at $10 \%$ moisture under normal pressures of $5 \mathrm{psi}, 10 \mathrm{psi}$, and $15 \mathrm{psi}$ with their respective friction coefficients. 
Figure 4.11 shows the load - displacement curves calculated from the experimental tests and those generated from the finite element analysis for interaction of clay and material $\mathrm{C}$ at $0 \%$ moisture. The figure shows that as normal pressure increases, the friction coefficient remains constant for clay and material $\mathrm{C}$ at $0 \%$ moisture.

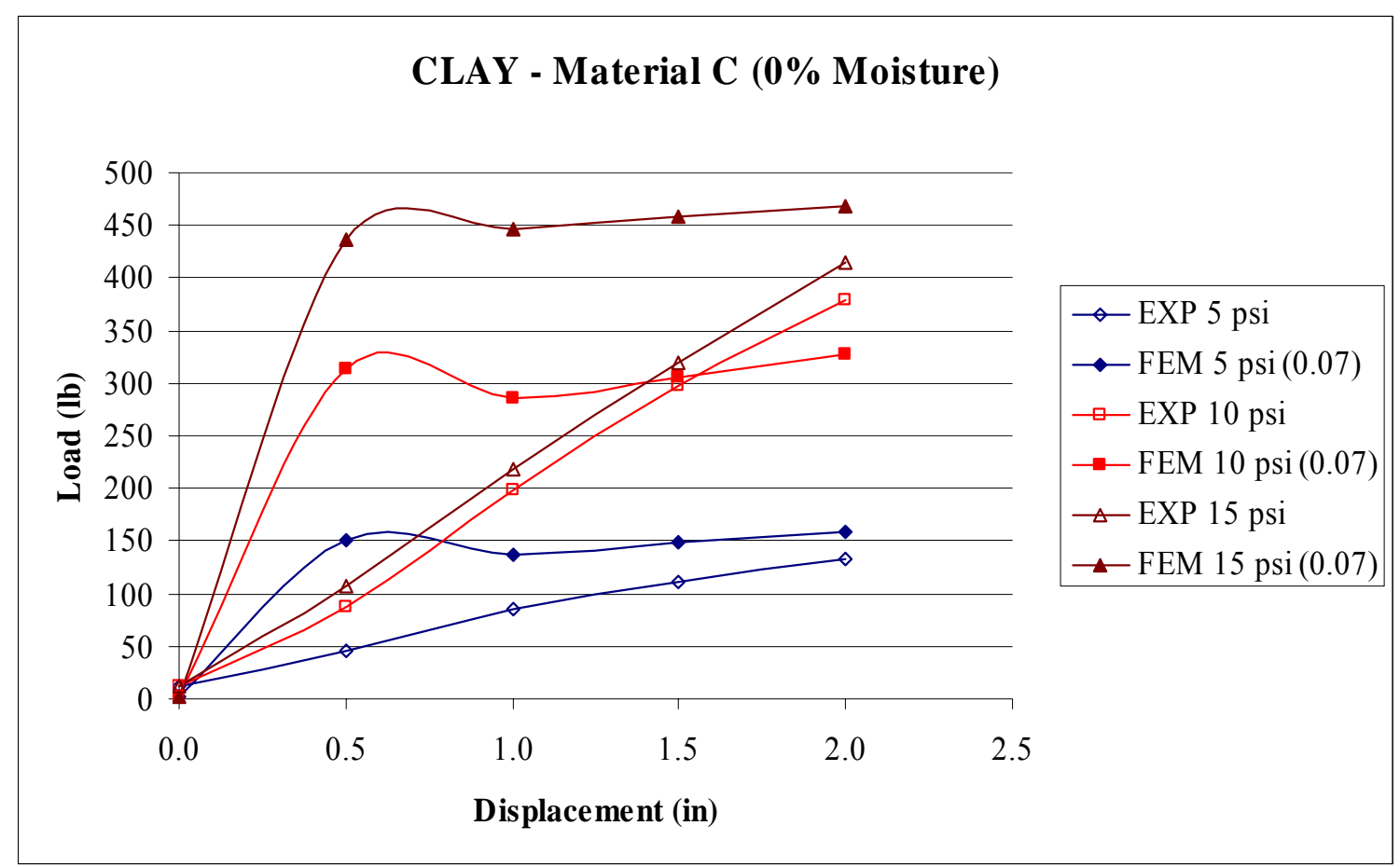

Figure 4.11: Load - displacement relationship for clay - material $\mathrm{C}$ interaction at $0 \%$ moisture under normal pressures of 5 psi, 10 psi, and 15 psi with their respective friction coefficients. 
Figure 4.12 shows the load - displacement curves calculated from the experimental tests and those generated from the finite element analysis for interaction of clay and material $\mathrm{C}$ at $10 \%$ moisture. The figure shows that as normal pressure increases from 5 psi to 10 psi, the friction coefficient remains constant and decreases from 10 psi to 15 psi for clay and material $\mathrm{C}$ at $0 \%$ moisture.

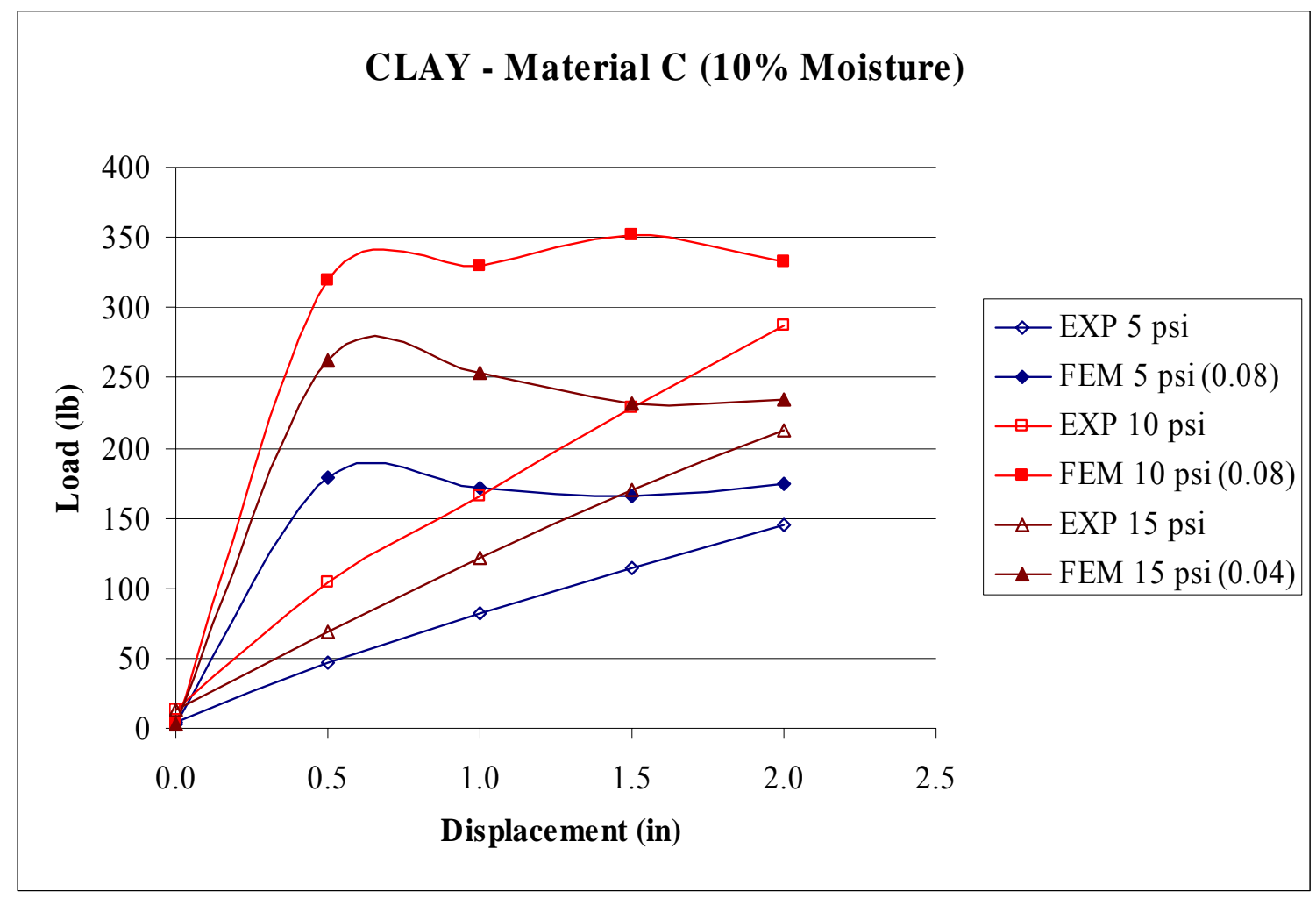

Figure 4.12: Load - displacement relationship for clay - material $C$ interaction at $10 \%$ moisture at 5 psi, 10 psi, and 15 psi with their respective friction coefficient. 


\subsection{Results for Pullout Box B (Large Box)}

Figure 4.13 shows the load - displacement curves calculated from the experimental tests and those generated from the finite element analysis for interaction of sand and material $\mathrm{A}$ at $0 \%$ moisture. The figure shows that as normal pressure increases, the friction coefficient increases. The figure shows a good match between the experimental and finite element analysis curves.

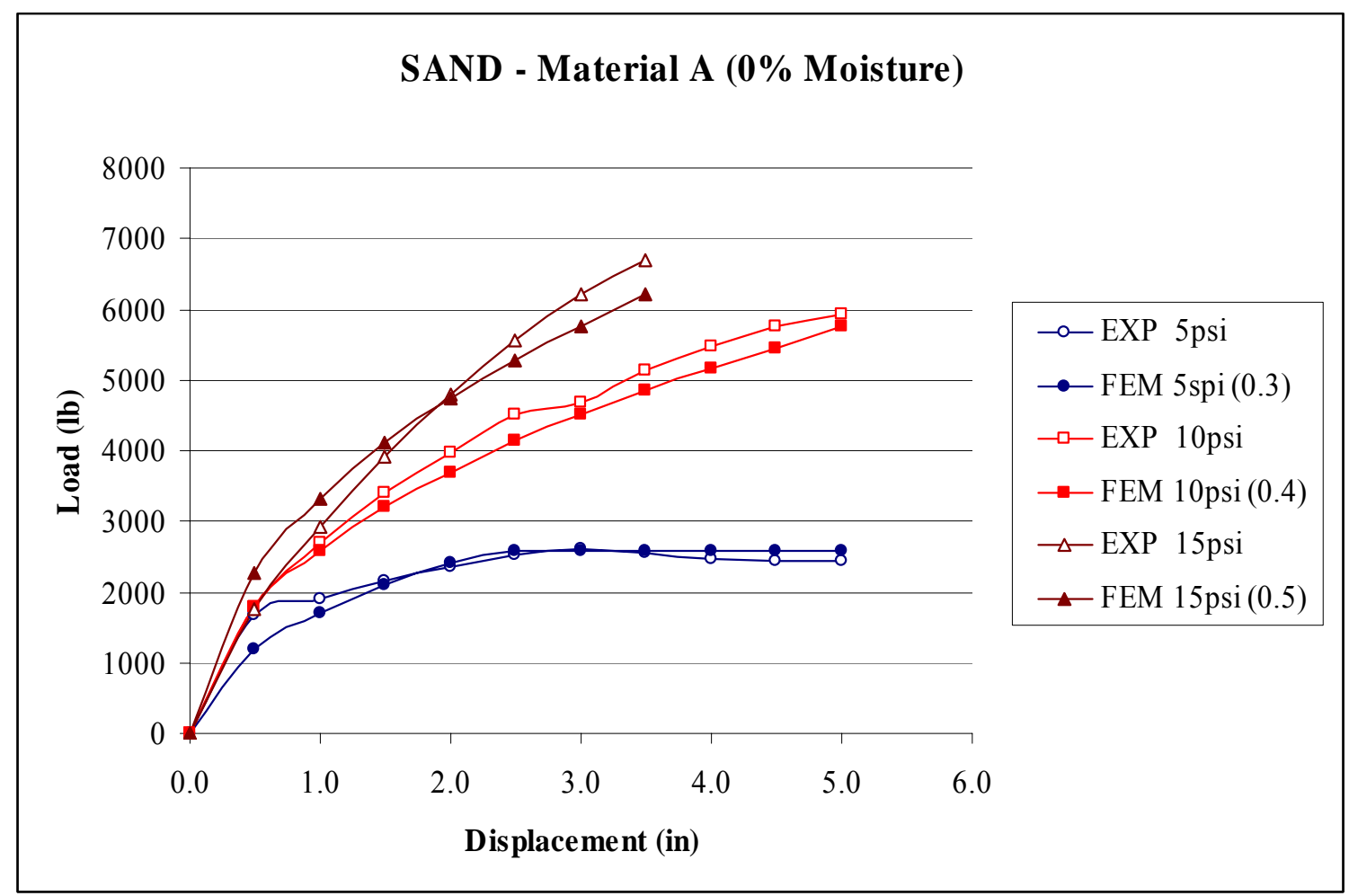

Figure 4.13: Load - displacement relationship for sand - material $A$ interaction at $0 \%$ moisture under normal pressures of 5 psi, 10 psi, and 15 psi with their respective friction coefficients. 
Figure 4.14 shows that the friction coefficient increases as normal pressure increases for sand and material $\mathrm{B}$ interaction at $0 \%$ moisture. The figure shows a slight inconsistency between the experimental and finite element analysis curves. This may be the result of inaccurate experimental results.

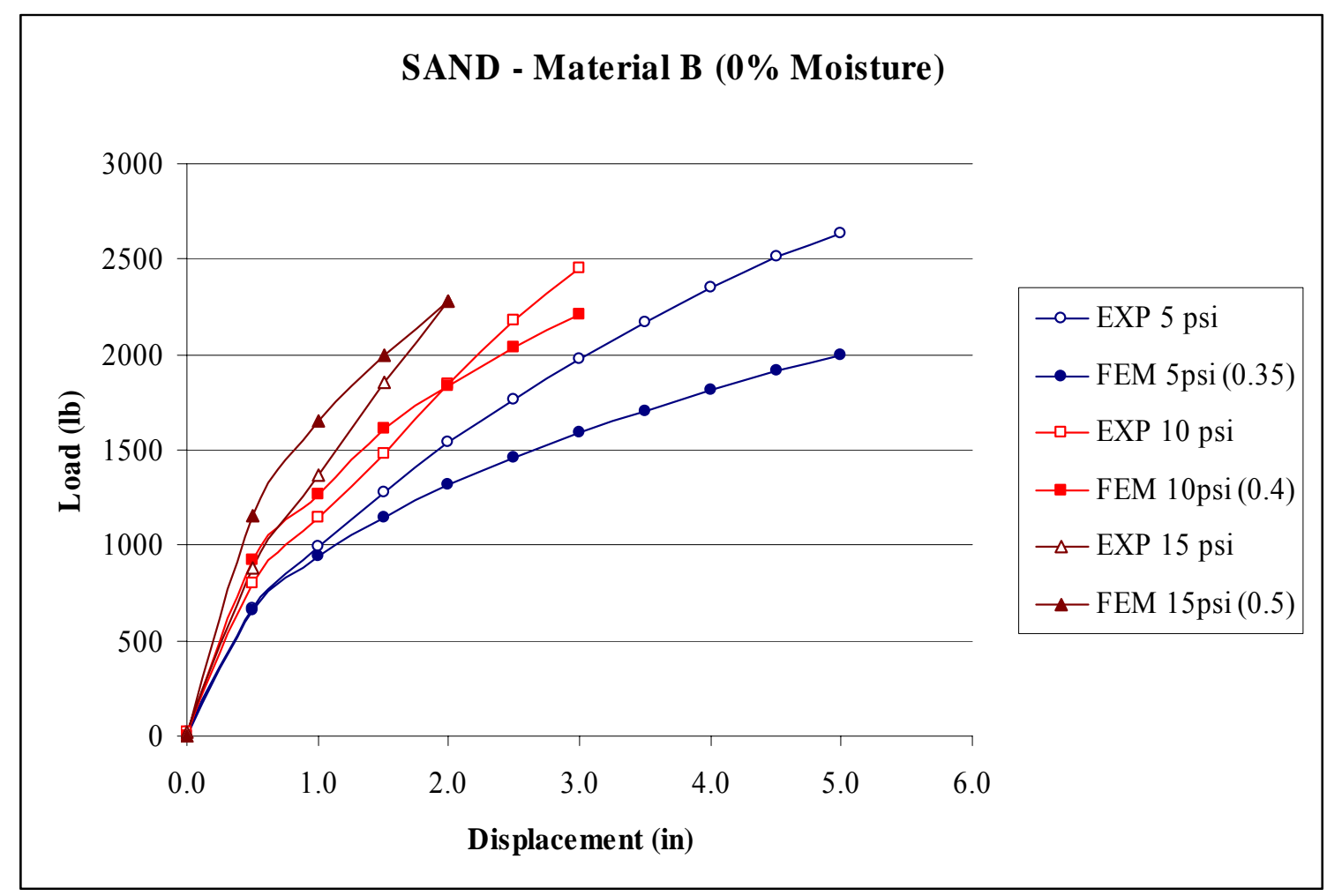

Figure 4.14: Load - displacement relationship for sand - material $B$ interaction at $0 \%$ moisture under normal pressures of $5 \mathrm{psi}, 10 \mathrm{psi}$, and 15 psi with their respective friction coefficients. 
Figure 4.15 shows that the friction coefficient decreases as normal pressure increases for sand and material $\mathrm{C}$ interaction at $0 \%$ moisture.

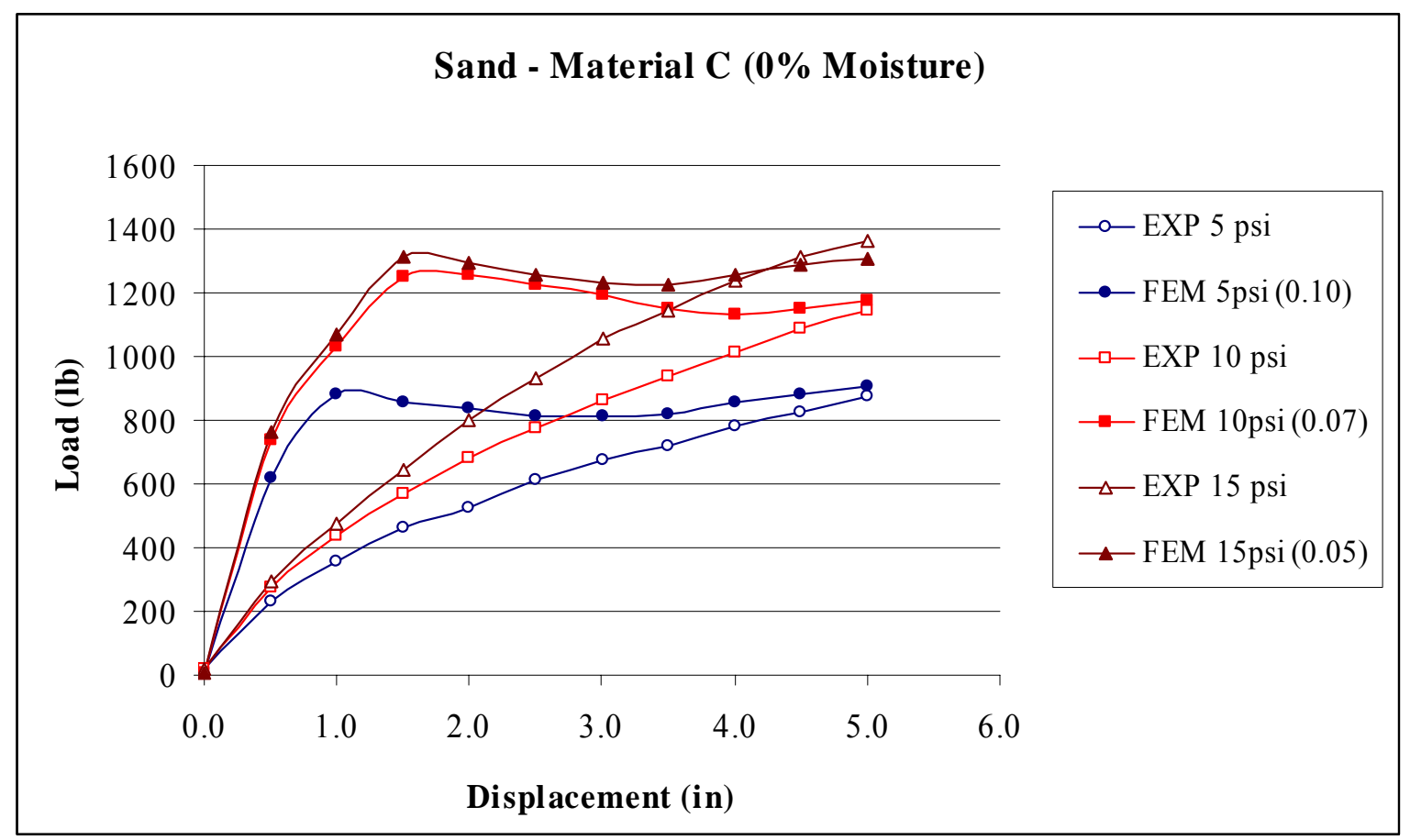

Figure 4.15: Load - displacement relationship for sand - material $C$ interaction at $0 \%$ moisture under normal pressures of $5 \mathrm{psi}, 10 \mathrm{psi}$, and $15 \mathrm{psi}$ with their respective friction coefficients. 
Figure 4.16 shows the load - displacement curves calculated from the experimental tests and those generated from the finite element analysis for interaction of silt and material $\mathrm{A}$ at $0 \%$ moisture. The figure shows that as normal pressure increases the friction coefficient increases. There appears to be a perfect fit between the experimental and finite element results.

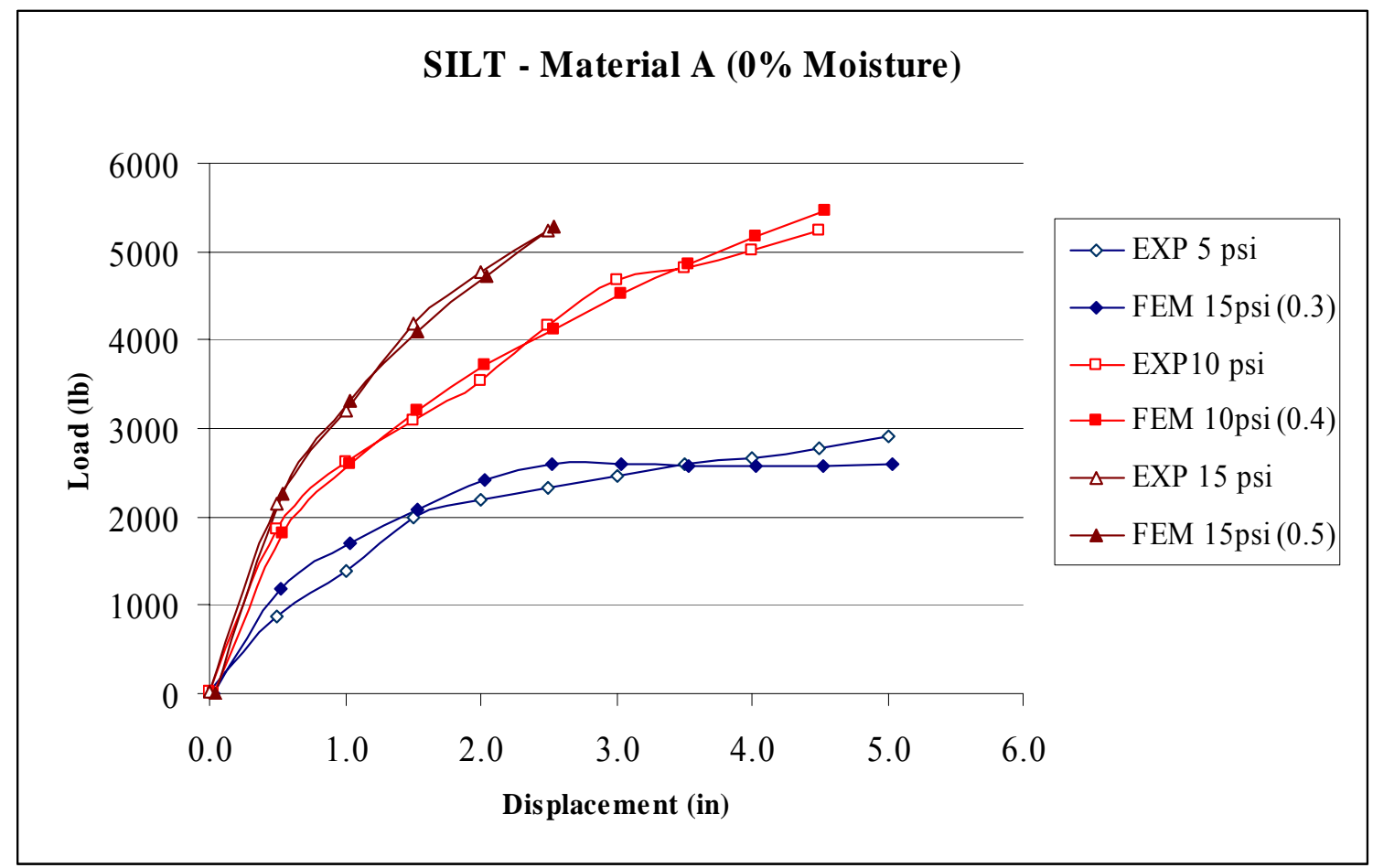

Figure 4.16: Load - displacement relationship for silt - material $A$ interaction at $0 \%$ moisture under normal pressures of 5 psi, 10 psi, and 15 psi with their respective friction coefficients. 
Figure 4.17 shows the load - displacement curves calculated from the experimental tests and those generated from the finite element analysis for interaction of silt and material $\mathrm{A}$ at $10 \%$ moisture. There is a good match between the experimental and finite element analysis data. The figure shows that as normal pressure increases the friction coefficient increases.

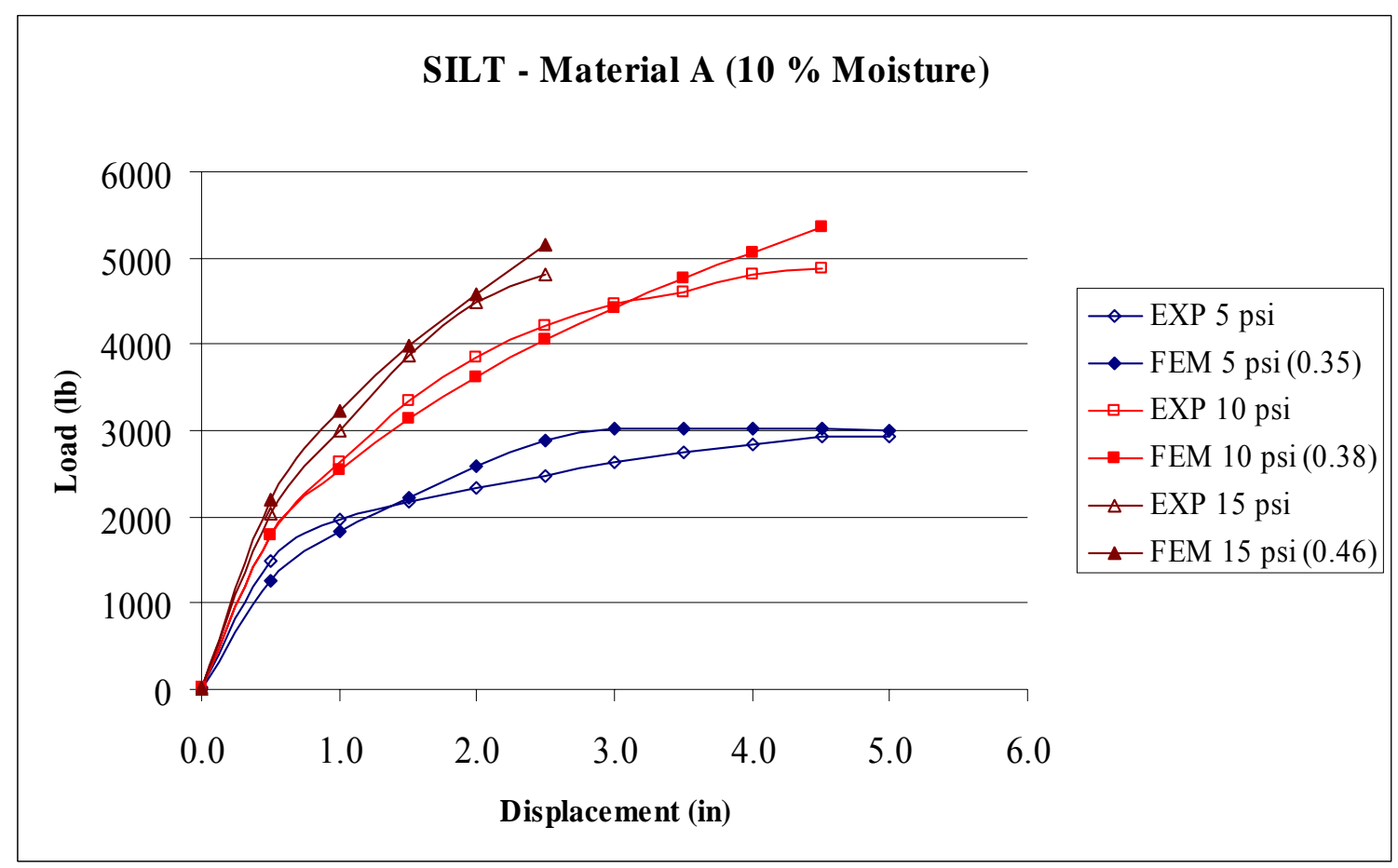

Figure 4.17: Load - displacement relationship for silt - material A interaction at $10 \%$ moisture under normal pressures of 5 psi, 10 psi, and 15 psi with their respective friction coefficients. 
Figure 4.18 shows a good match between the experimental and finite element data. The load - displacement curves show a decrease in friction coefficient as normal pressure increases for silt and material $\mathrm{A}$ at $15 \%$ moisture.

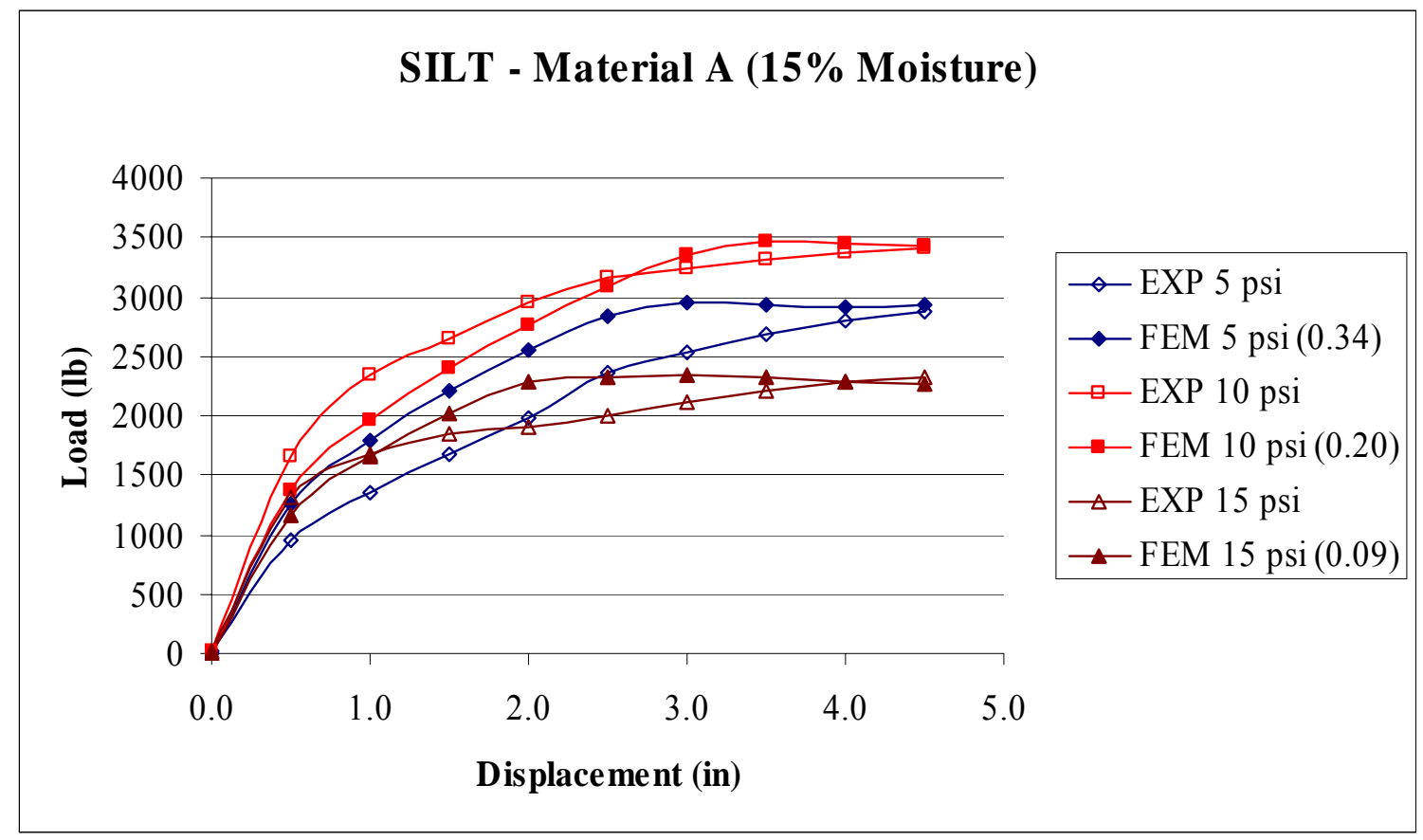

Figure 4.18: Load - displacement relationship for silt - material $A$ interaction at $15 \%$ moisture under normal pressures of $5 \mathrm{psi}, 10 \mathrm{psi}$, and $15 \mathrm{psi}$ with their respective friction coefficients. 
Figure 4.19 shows the load - displacement curves calculated from the experimental tests and those generated from the finite element analysis for interaction of silt and material $\mathrm{B}$ at $0 \%$ moisture. The figure shows that as normal pressure increases the friction coefficient increases. There appears to be a relatively good fit between the experimental and finite element analysis data.

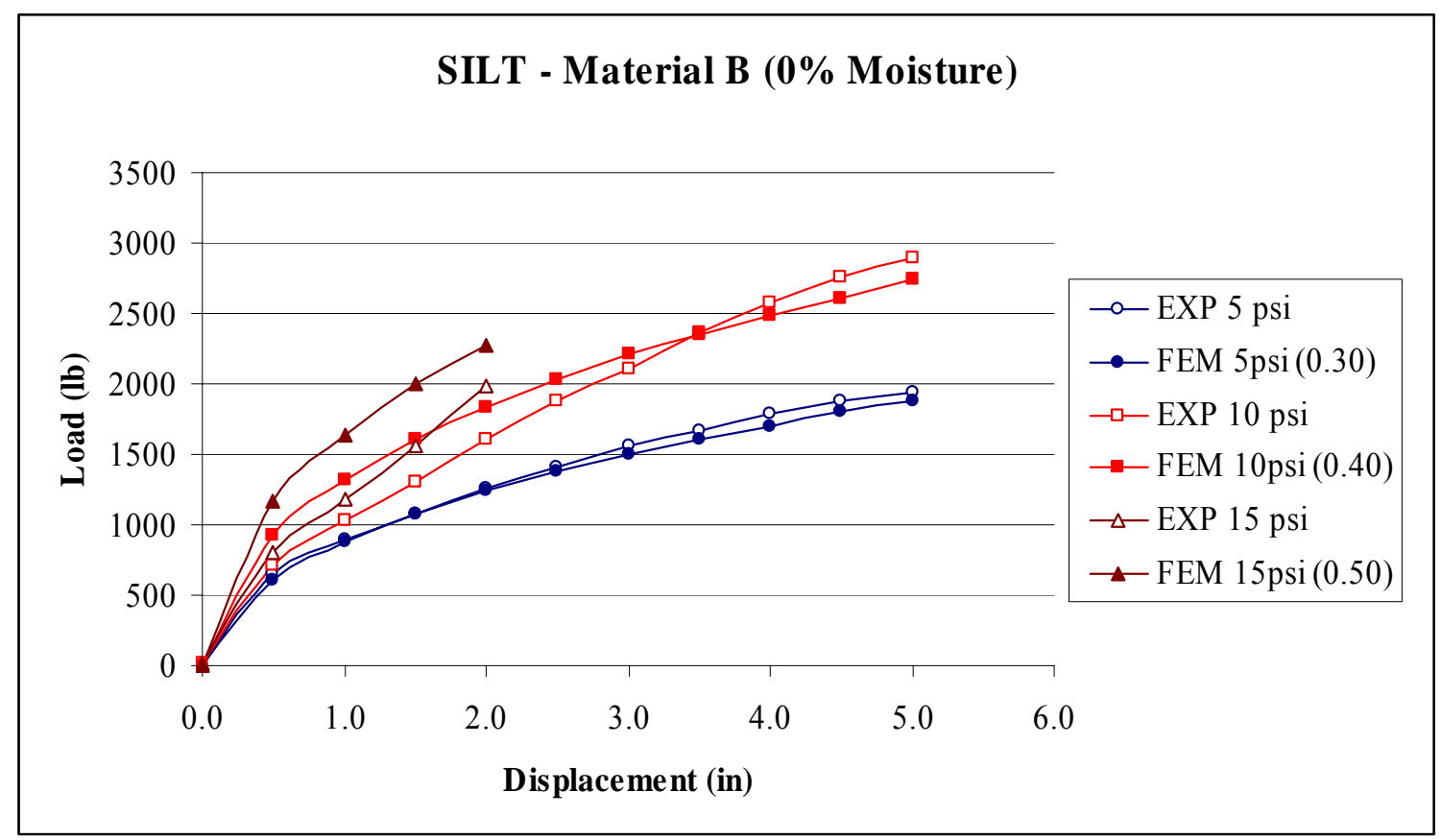

Figure 4.19: Load - displacement relationship for silt - material $\mathrm{B}$ interaction at $0 \%$ moisture under normal pressures of 5 psi, 10 psi, and 15 psi with their respective friction coefficients. 
Figure 4.20 shows the load - displacement curves calculated from the experimental tests and those generated from the finite element analysis for interaction of silt and material $\mathrm{B}$ at $10 \%$ moisture. The figure shows that as normal pressure increases the friction coefficient increases for silt and material B at 10\% moisture. There is a good match between the experimental and finite element analysis curves.

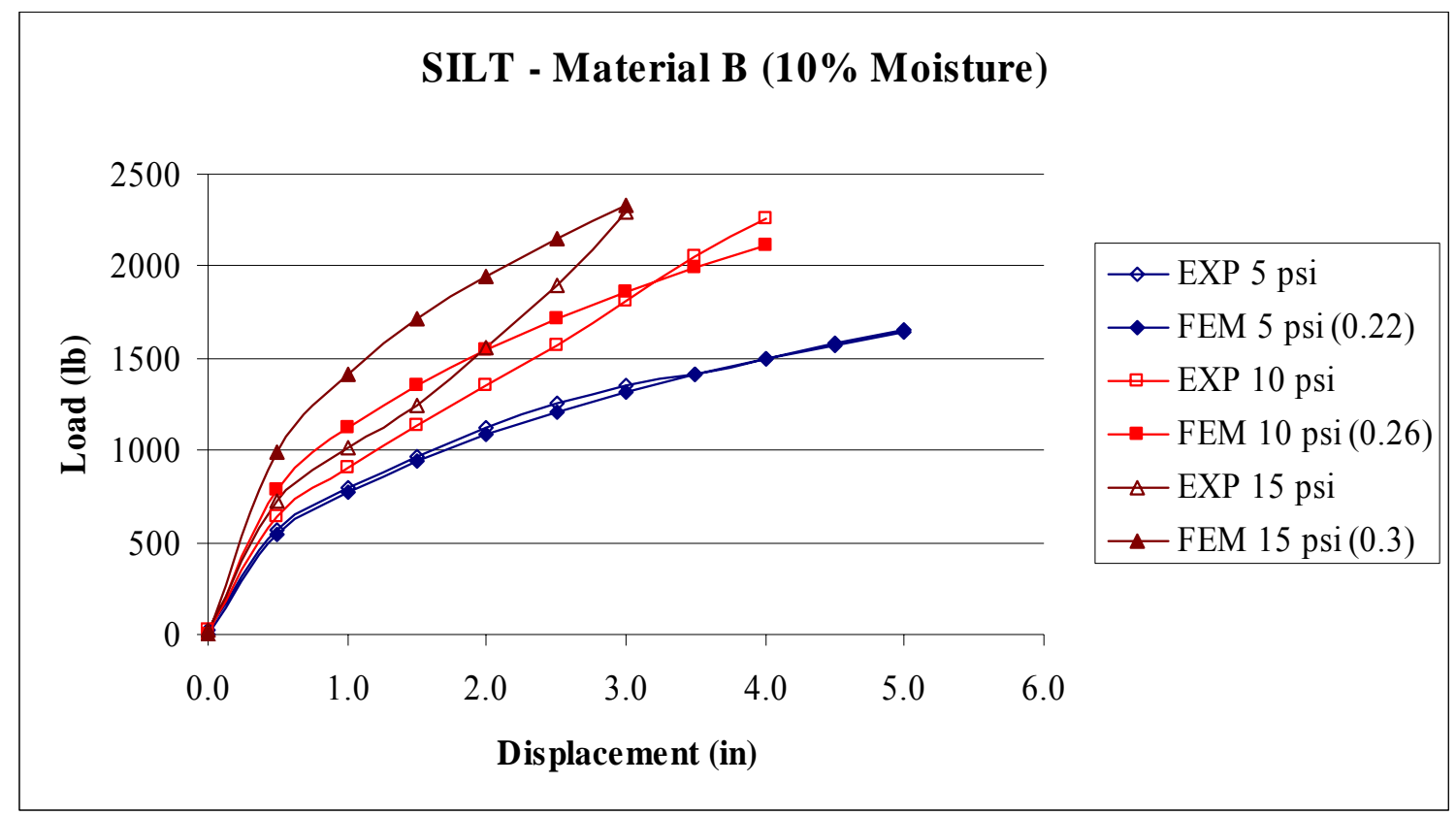

Figure 4.20: Load - displacement relationship for silt - material $B$ interaction at $10 \%$ moisture under normal pressures of 5 psi, 10 psi, and 15 psi with their respective friction coefficients. 
Figure 4.21 shows good match between the experimental and finite element analysis load - displacement curves for material B at 15\% moisture. The figure shows that as normal pressure increases the friction coefficient decreases.

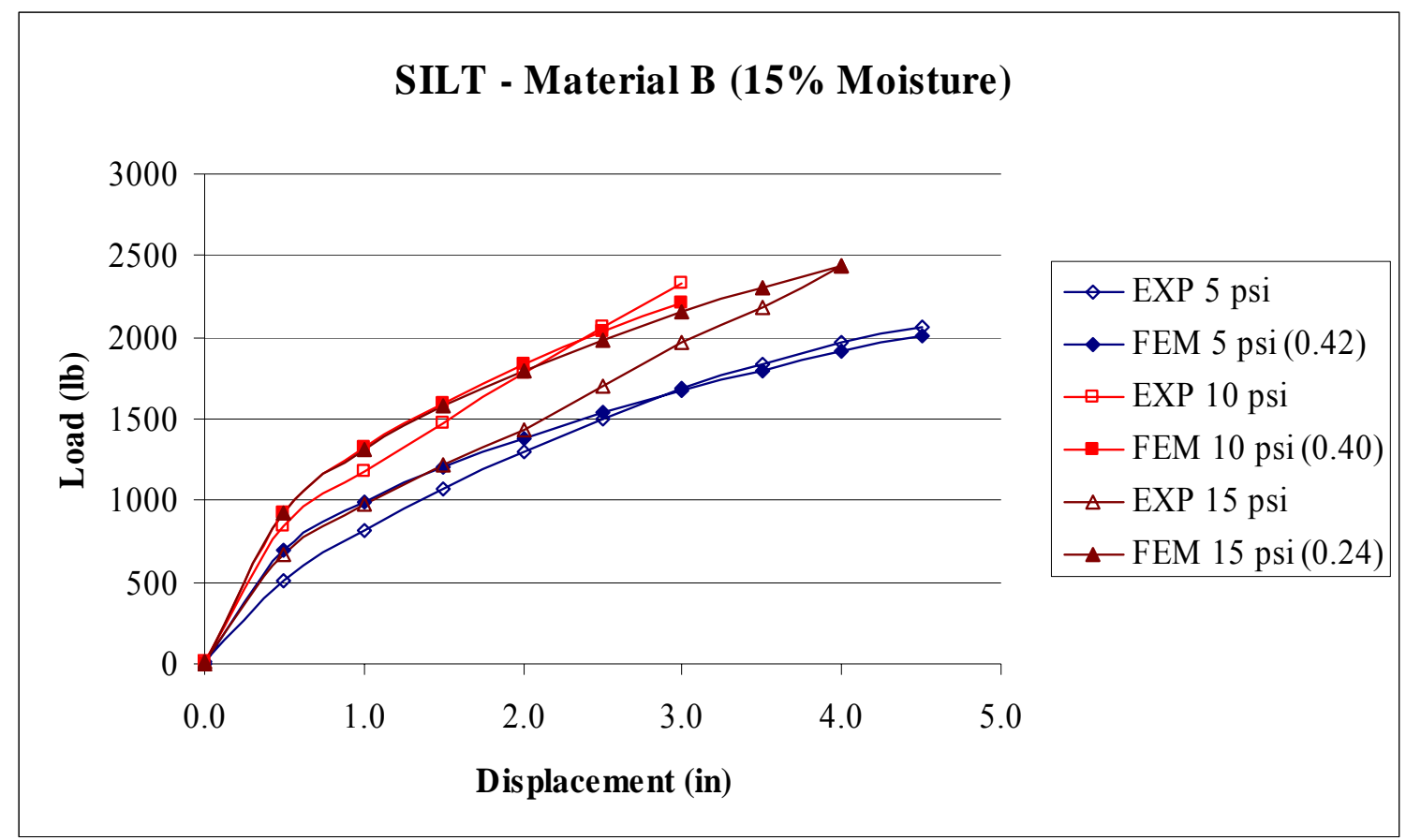

Figure 4.21: Load - displacement relationship for silt - material B interaction at $15 \%$ moisture under normal pressures of $5 \mathrm{psi}, 10 \mathrm{psi}$, and $15 \mathrm{psi}$ with their respective friction coefficients. 
Figure 4.22 shows the load - displacement curves calculated from the experimental tests and those generated from the finite element analysis for interaction of silt and material $\mathrm{C}$ at $0 \%$ moisture. The figure shows that as normal pressure increases from 5 psi to $10 \mathrm{psi}$, the friction coefficient decreases. As the normal pressure increases from 10 psi to $15 \mathrm{psi}$, the friction coefficient increases.

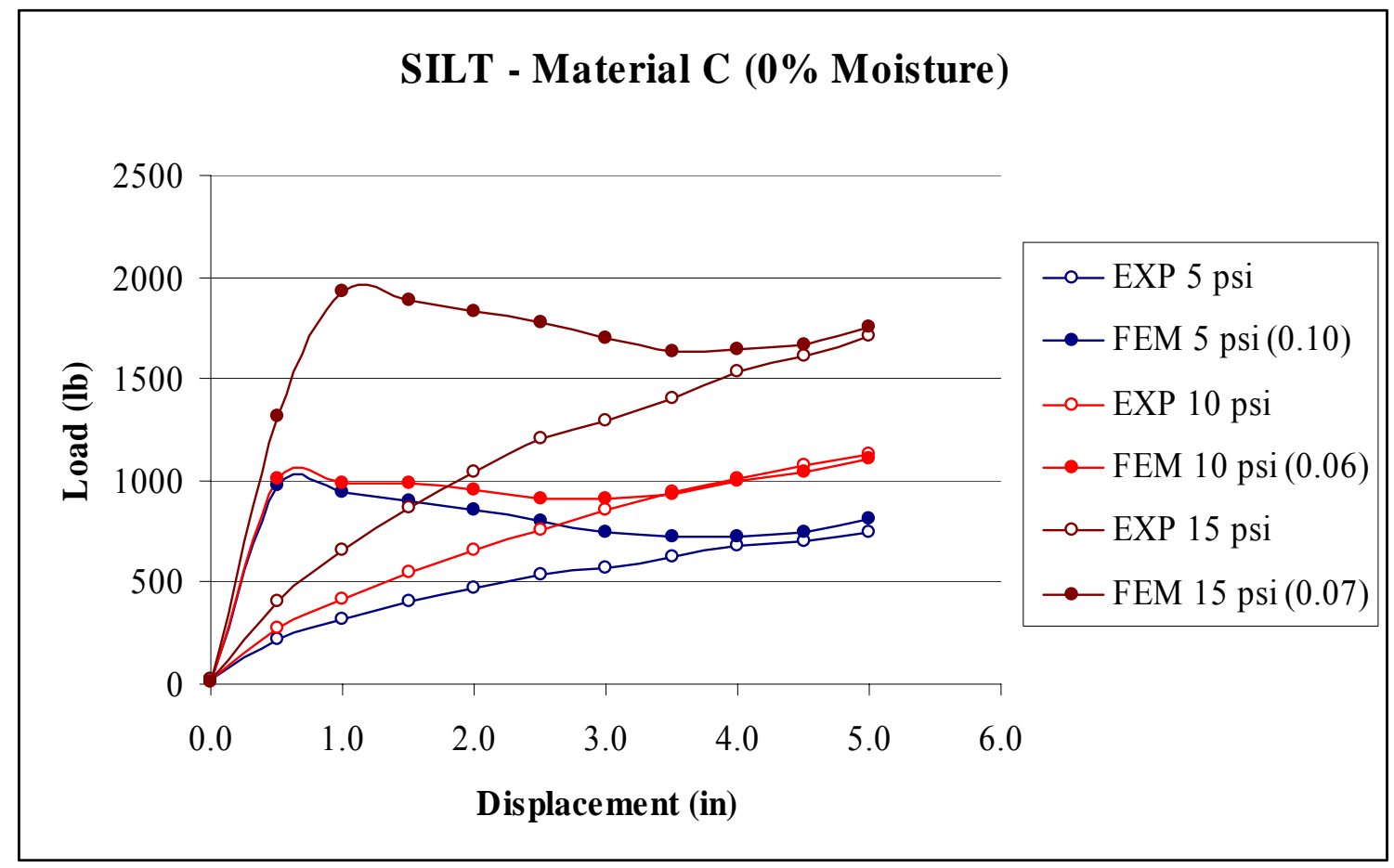

Figure 4.22: Load - displacement relationship for silt - material $\mathrm{C}$ interaction at $0 \%$ moisture under normal pressures of 5 psi, 10 psi, and 15 psi with their respective friction coefficients. 
Figure 4.23 shows the results from the experimental experiments and finite element analysis for silt and material $\mathrm{C}$ interaction at $10 \%$ moisture. The friction coefficient decreases as normal pressure increases.

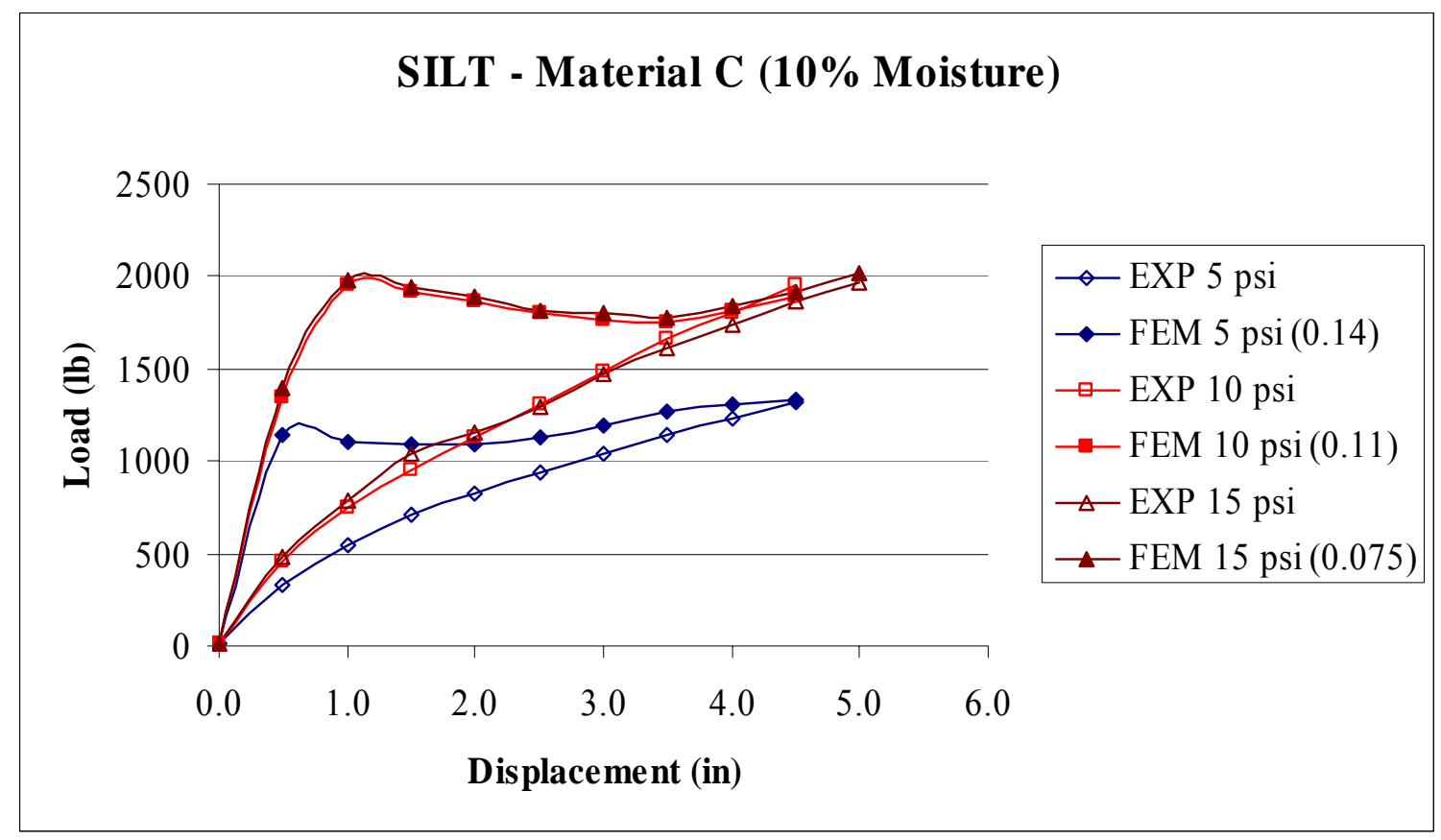

Figure 4.23: Load - displacement relationship for silt - material $\mathrm{C}$ interaction at $10 \%$ moisture under normal pressures of $5 \mathrm{psi}, 10 \mathrm{psi}$, and $15 \mathrm{psi}$ with their respective friction coefficients. 
Figure 4.24 show the load - displacement curves for silt and material C interaction at $15 \%$ moisture. The friction coefficient decreases from 5 psi to 10 psi and remains constant from 10 psi to 15 psi.

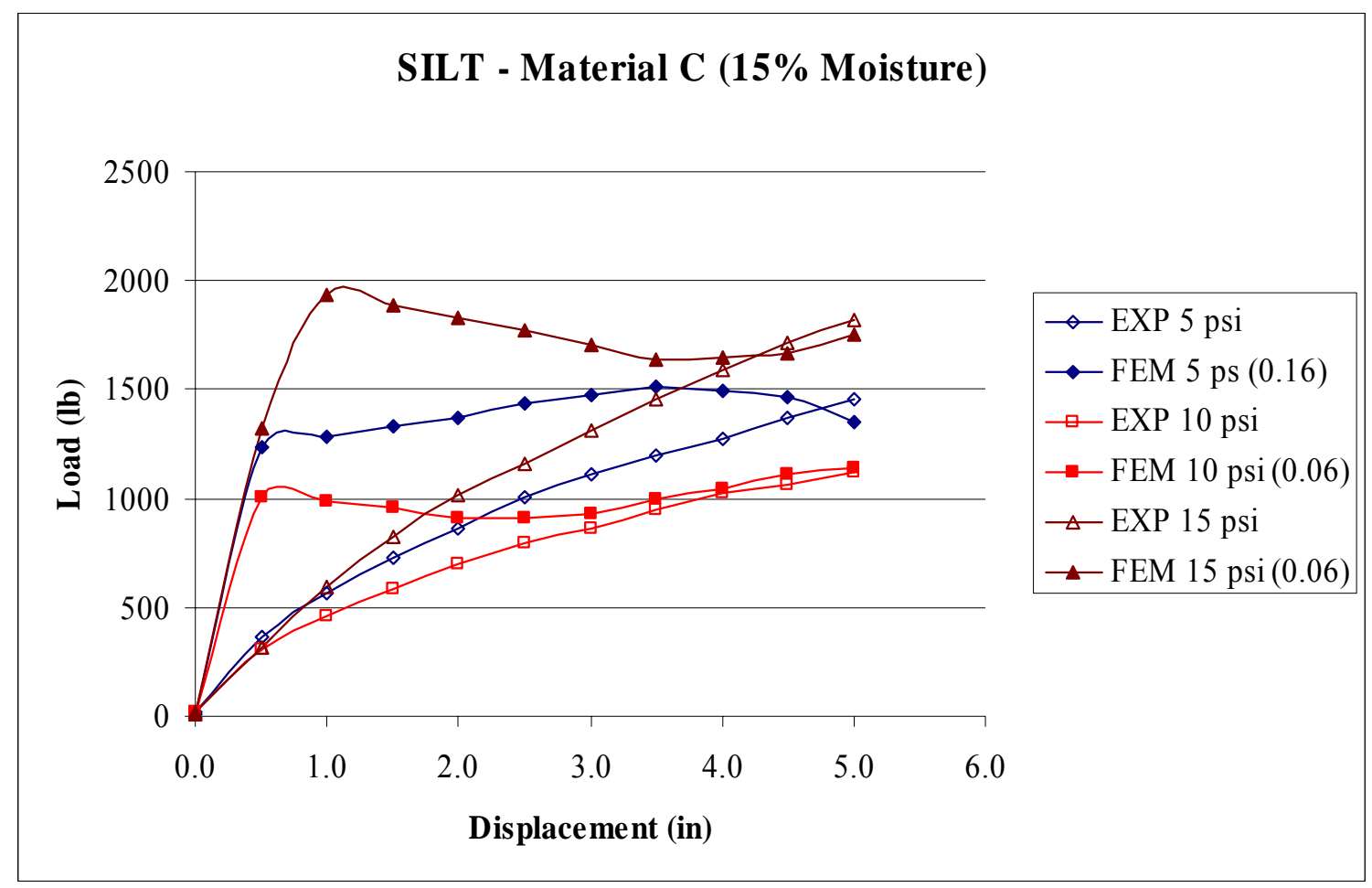

Figure 4.24: Load - displacement relationship for silt - material $C$ interaction at $15 \%$ moisture under normal pressures of 5 psi, 10 psi, and 15 psi with their respective friction coefficients. 
Figure 4.25 show a relatively good match between the experimental and finite element analysis load - displacement curves for clay and material $\mathrm{A}$ interaction at $0 \%$ moisture. The friction coefficient decreases as normal pressure increases in this figure.

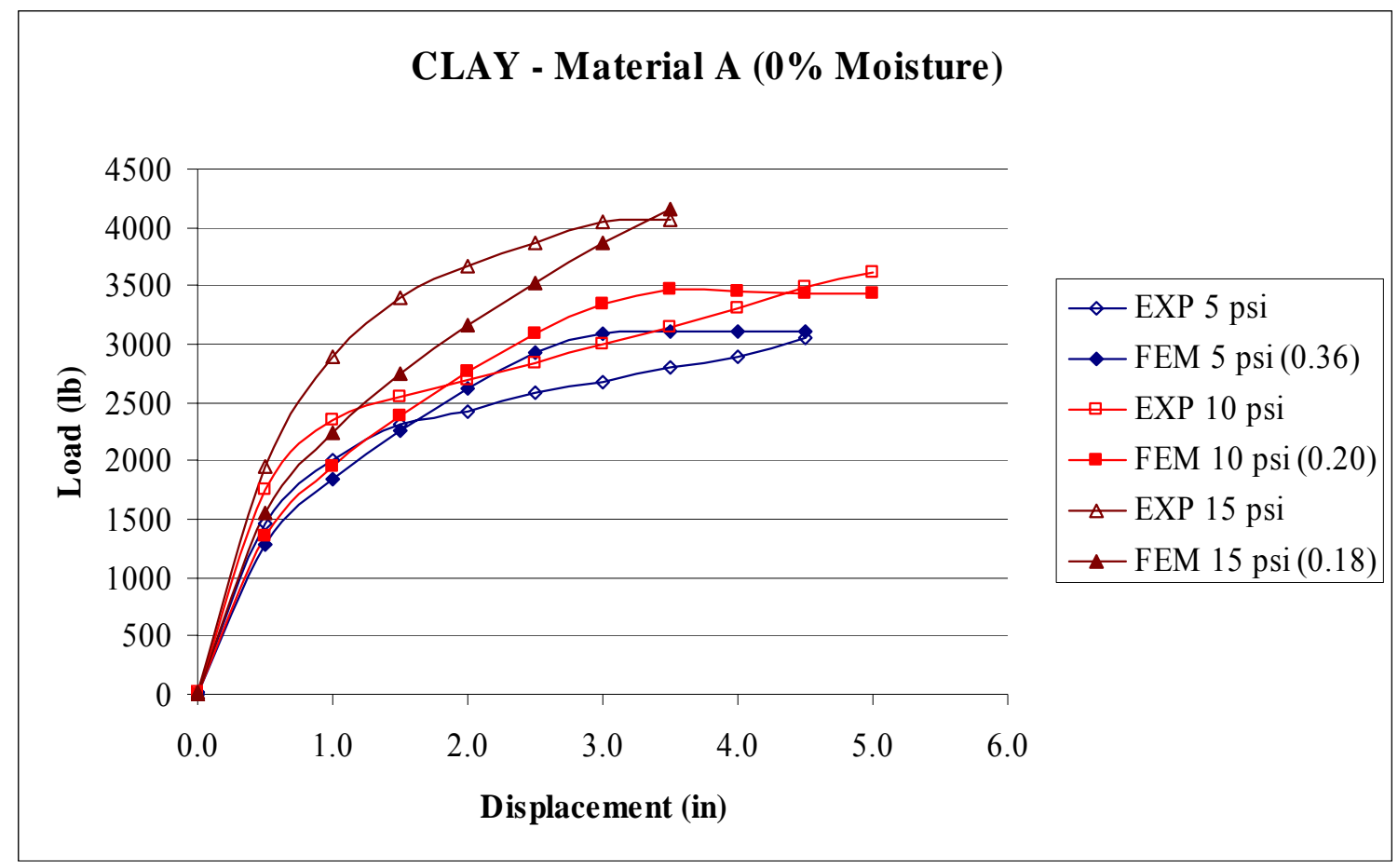

Figure 4.25: Load - displacement relationship for clay - material A interaction at $0 \%$ moisture under normal pressures of $5 \mathrm{psi}, 10 \mathrm{psi}$, and 15 psi with their respective friction coefficients. 
Figure 4.26 shows the load - displacement curves for clay and material A interaction at $10 \%$ moisture. The figure shows a relatively good fit between the experimental and finite element analysis curves. The friction coefficient increases from 5 psi to 10 psi and remains constant from 10 psi to 15 psi.

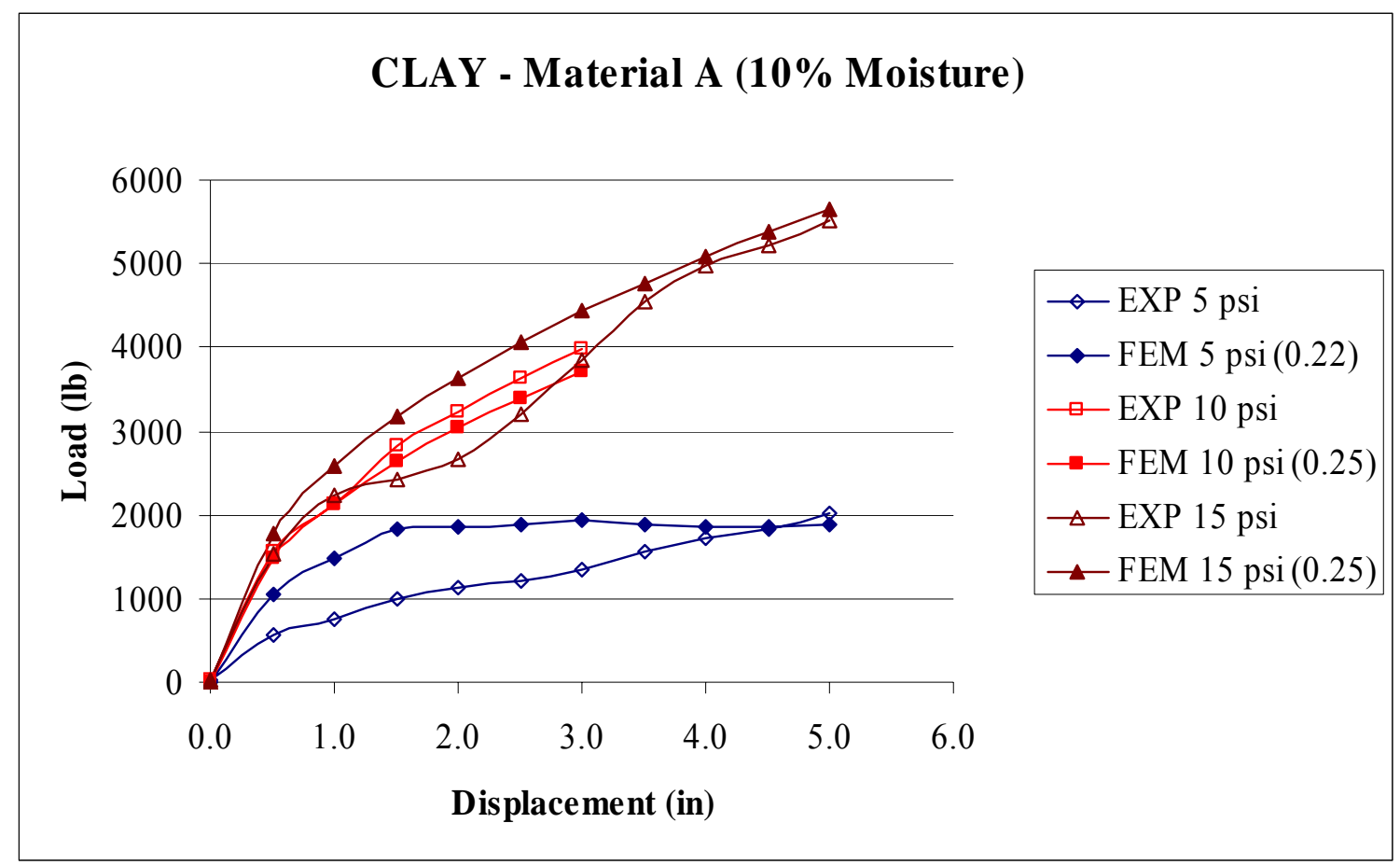

Figure 4.26: Load - displacement relationship for clay - material A interaction at $10 \%$ moisture under normal pressures of 5 psi, 10 psi, and 15 psi with their respective friction coefficients. 
Figure 4.27 shows a good match between the load - displacement curves calculated from the experimental tests and those generated from the finite element analysis. The figure shows that as normal pressure increases the friction coefficient decreases for clay and material $\mathrm{B}$ at $0 \%$ moisture.

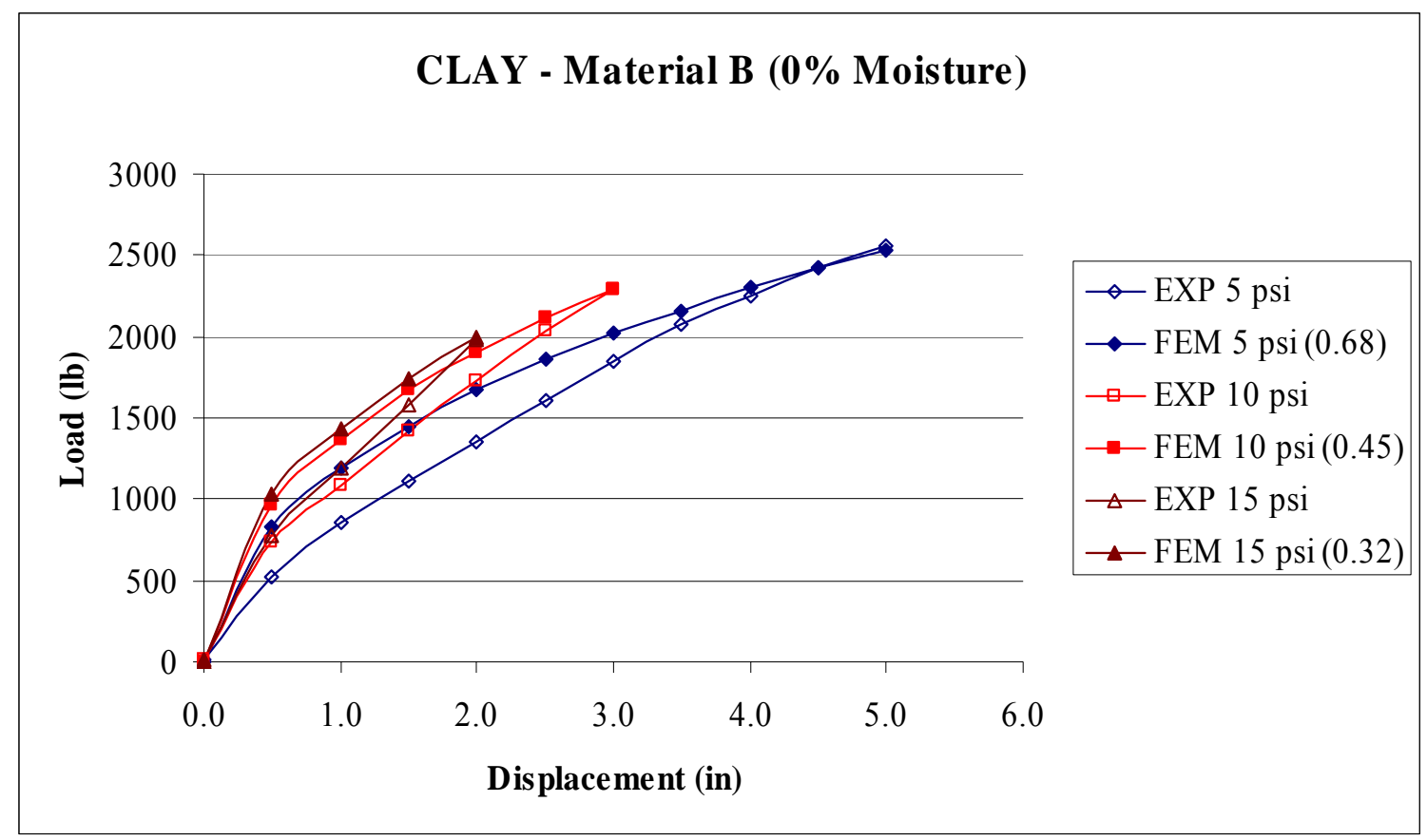

Figure 4.27: Load - displacement relationship for clay - material B interaction at $0 \%$ moisture under normal pressures of $5 \mathrm{psi}, 10 \mathrm{psi}$, and $15 \mathrm{psi}$ with their respective friction coefficients. 
Figure 4.28 shows the load - displacement curves calculated from the experimental tests and those generated from the finite element analysis for interaction of clay and material B at 10\% moisture. The figure shows that as normal pressure increases the friction coefficient decreases. The experimental and finite element analysis curves show a good match.

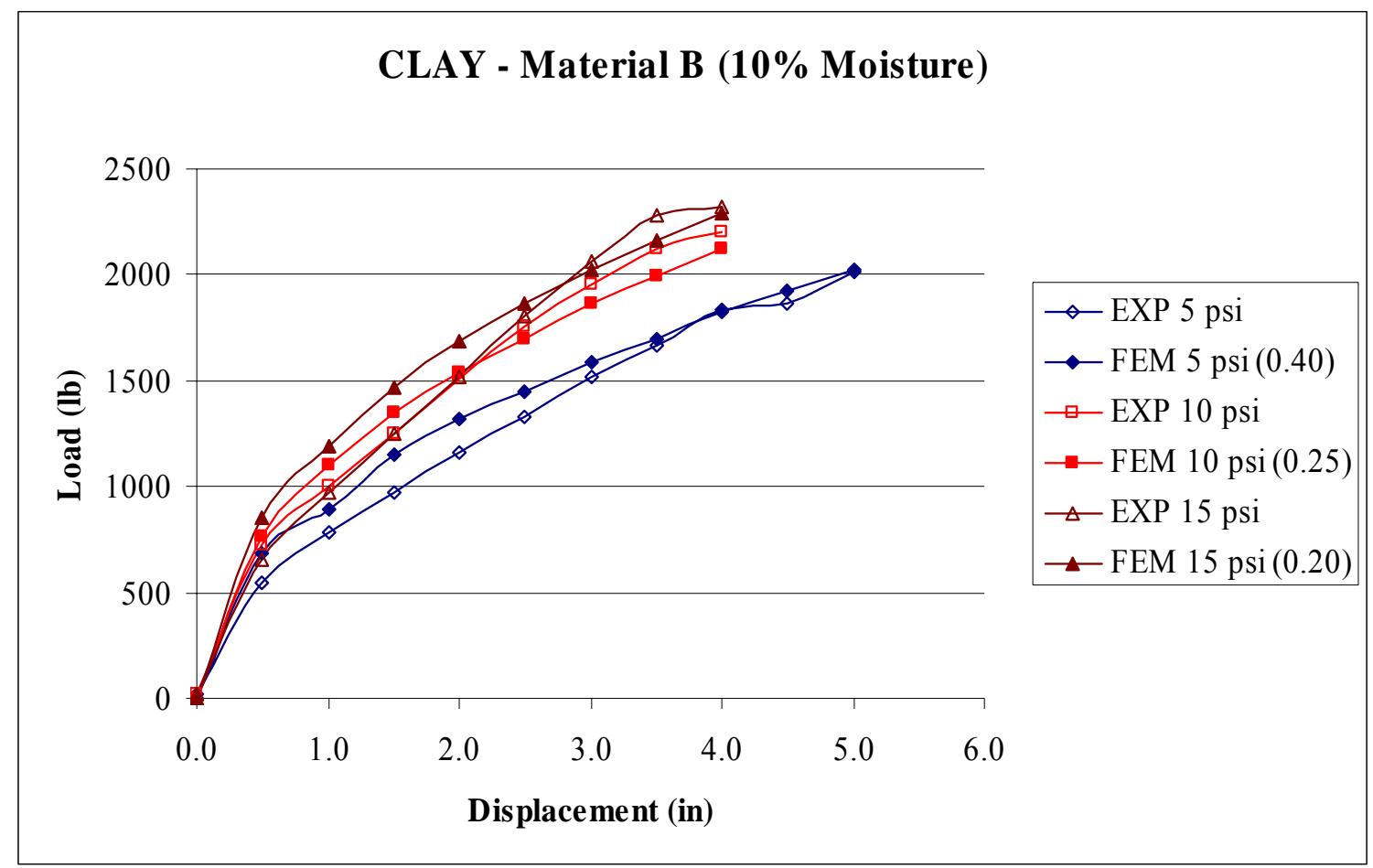

Figure 4.28: Load - displacement relationship for clay - material $B$ interaction at $10 \%$ moisture under normal pressures of 5 psi, 10 psi, and 15 psi with their respective friction coefficients. 
Figure 4.29 shows the load - displacement curves calculated from the experimental tests and those generated from the finite element analysis for interaction of clay and material $\mathrm{C}$ at $0 \%$ moisture. The figure shows that the friction coefficient decreases from 5 psi to 10 psi and then remains constant from 10 psi to 15 psi for clay and material $\mathrm{C}$ at $0 \%$ moisture.

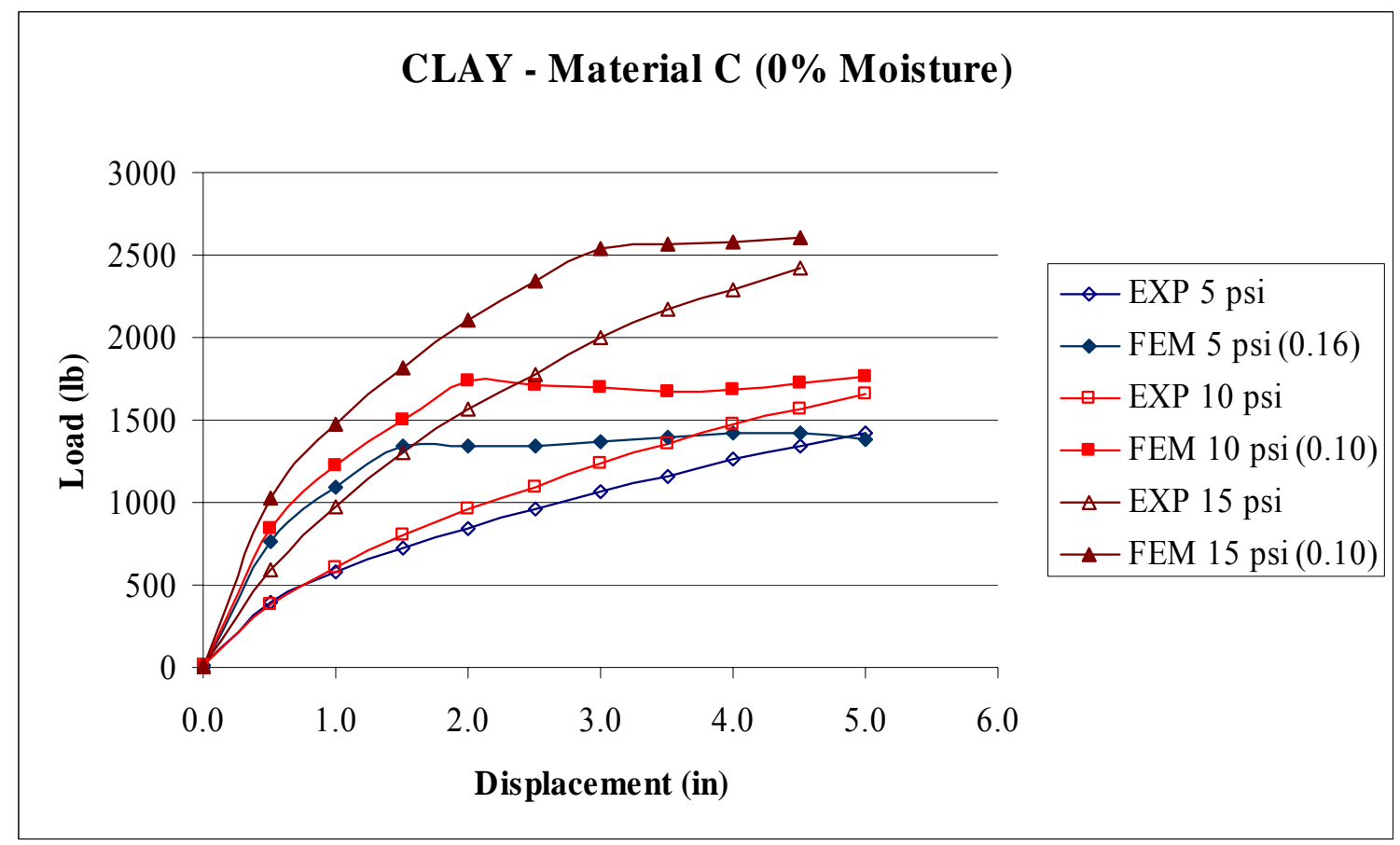

Figure 4.29: Load - displacement relationship for clay - material A interaction at $0 \%$ moisture under normal pressures of 5 psi, 10 psi, and 15 psi with their respective friction coefficients. 
Figure 4.30 shows the load - displacement for the interaction of clay and material $\mathrm{C}$ at $10 \%$ moisture content. As normal pressure increases friction coefficient decreases for clay and material $\mathrm{C}$ at $10 \%$ moisture.

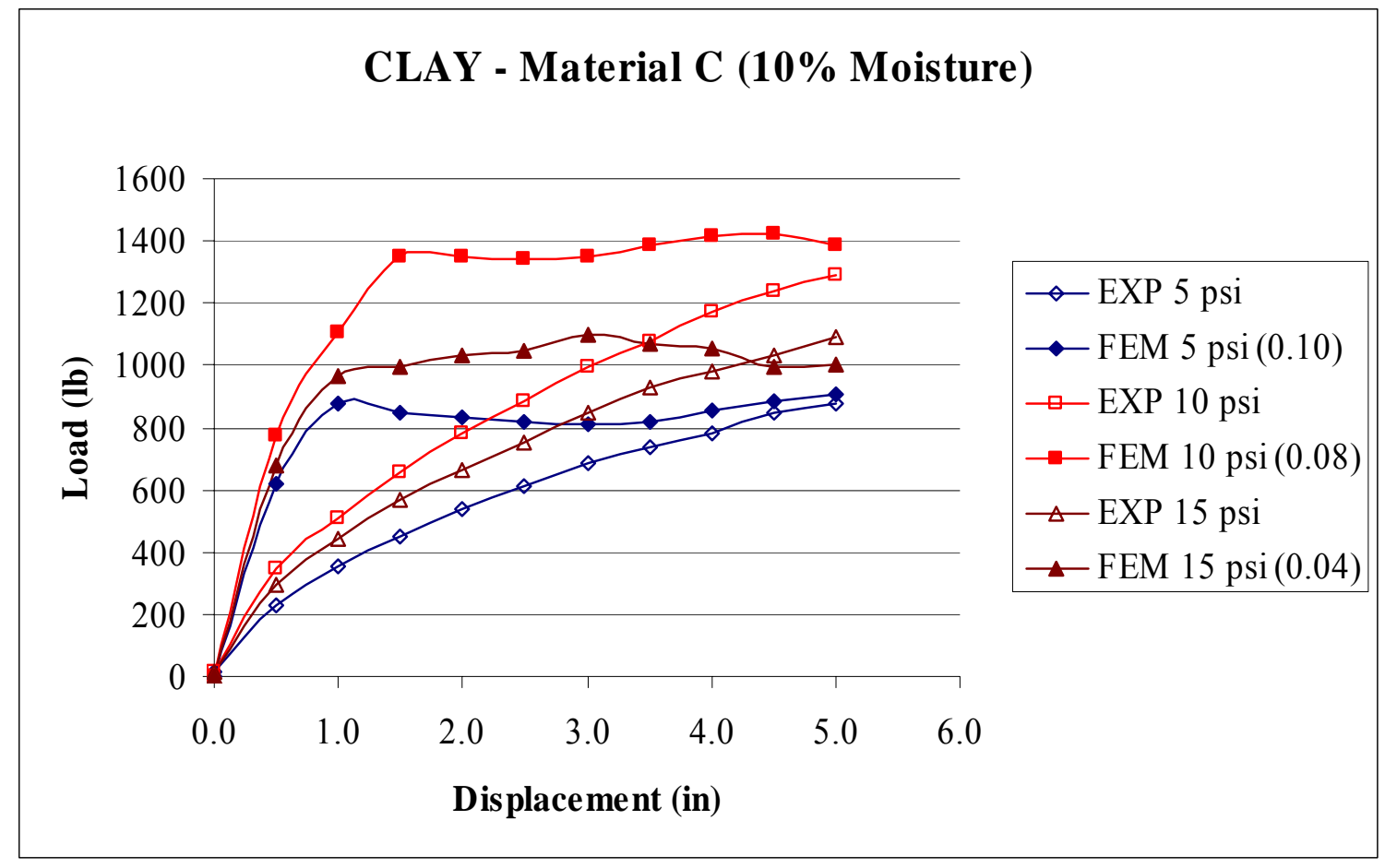

Figure 4.30: Load - displacement relationship for clay - material A interaction at $0 \%$ moisture under normal pressures of 5 psi, 10 psi, and 15 psi with their respective friction coefficients.

Results from finite element analysis for the interaction between soil and geosynthetic material is inconclusive. There is an inconsistency in the load displacement curves calculated from finite element analysis. Further experiments need to be performed on geosynthetic material $\mathrm{C}$ to resolve the inconsistency. 


\subsection{Effect of Moisture Content}

In order to investigate the effect of moisture content on the soil-geosynthetic interaction, moisture contents were varied between $0 \%$ and $15 \%$. Silt with $0 \%, 10 \%$ and $15 \%$ and clay with $0 \%$ and $10 \%$ were used for the purpose of the study. Different combinations of soil geosynthetics were analyzed for small and large box sizes.

\subsubsection{Small Pullout Box}

Figure 4.31 represents the load-displacement relationship for silt and geogrid A under normal pressure of 5 psi at moisture contents of $0 \%, 10 \%$ and $15 \%$. Figure 4.32 shows the load-displacement relationship for silt and geogrid A under normal pressure of 10 psi at moisture contents of $0 \%, 10 \%$ and 15\%. Figure 4.33 represents the loaddisplacement relationship for silt and geogrid A under normal pressure of 15 psi at moisture contents of $0 \%, 10 \%$ and 15\%. Results from figures 4.31, 4.32 and 4.33 show an decrease in the friction with increase in the moisture content for the interaction between silt and geogrid A. 


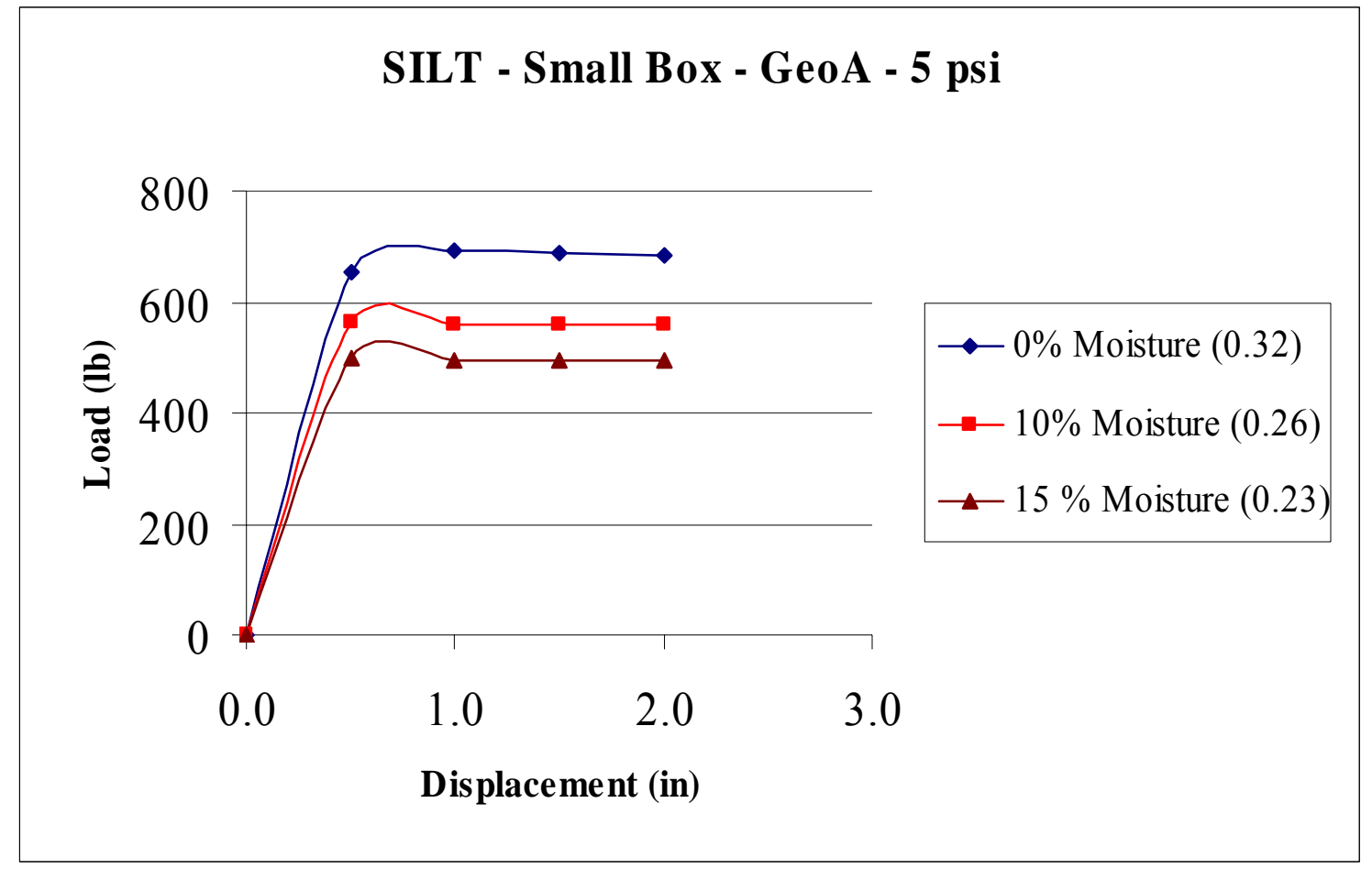

Figure 4.31: Effect of moisture content for silt and geogrid A for normal pressure of 5 psi.

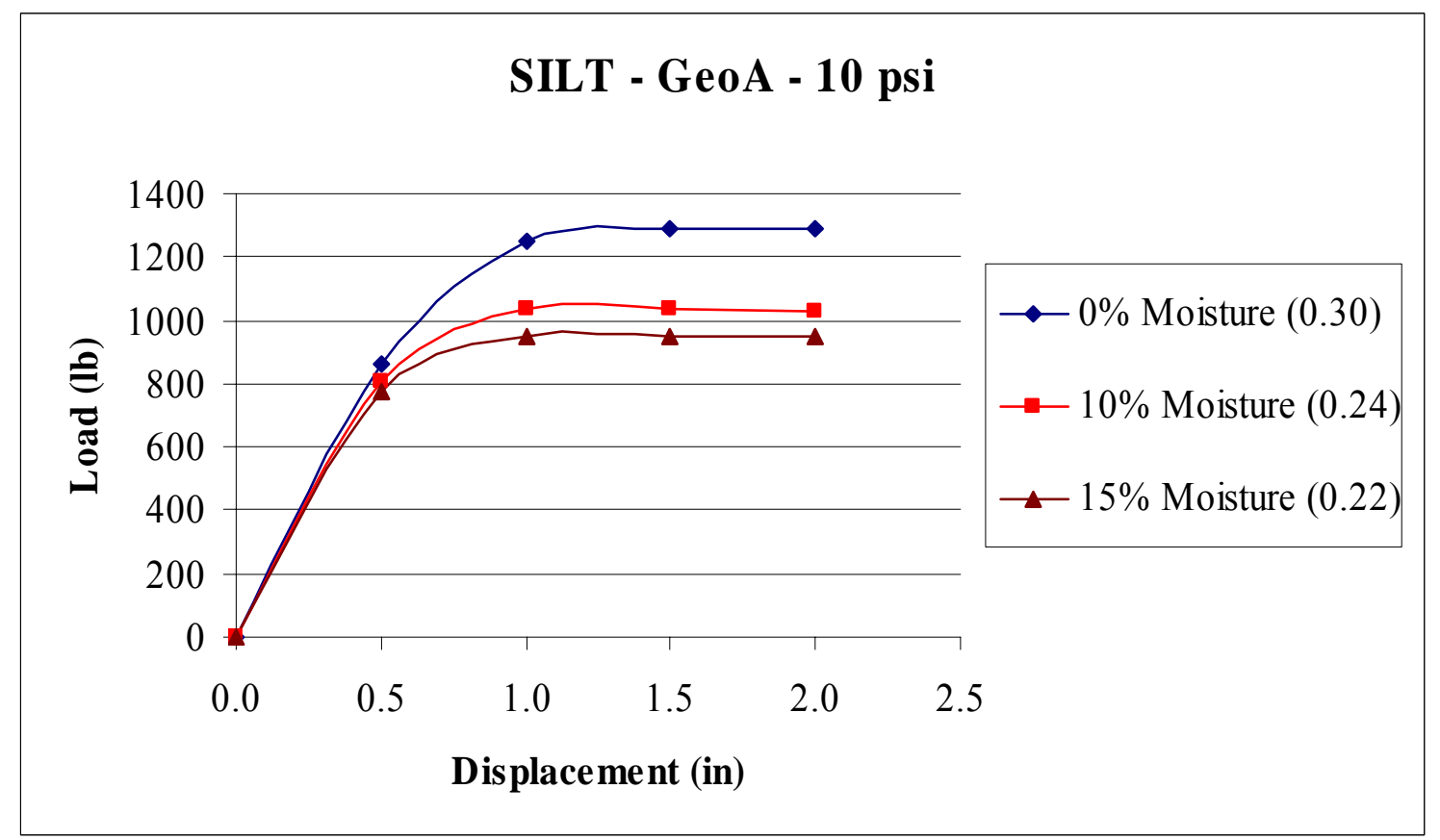

Figure 4.32: Effect of moisture content for silt and geogrid A for normal pressure of 10 psi. 


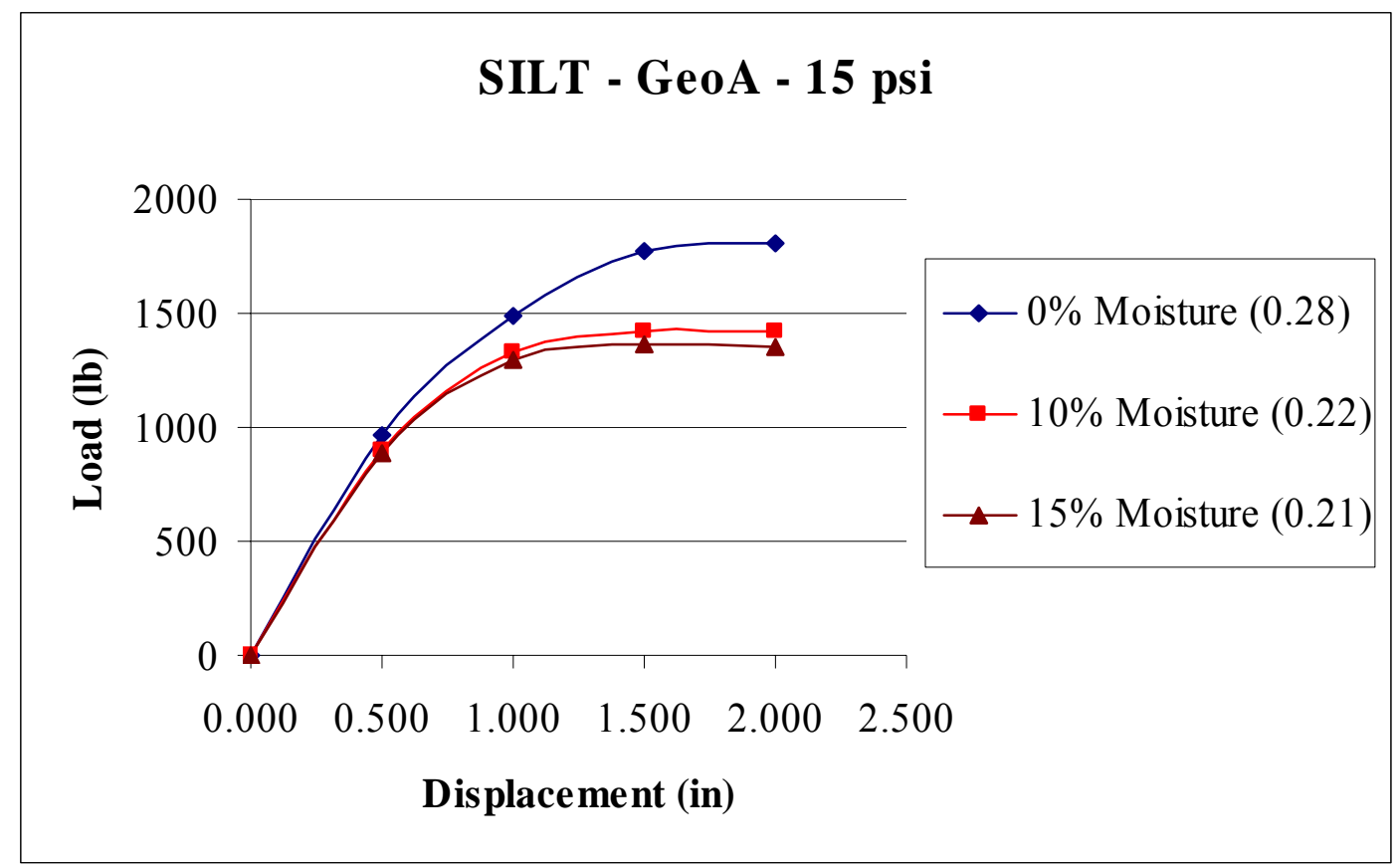

Figure 4.33: Effect of moisture content for silt and geogrid A for normal pressure of 15 psi.

Figure 4.34 represents the load-displacement relationship for silt and geotextile (geosynthetic material C) under normal pressure of 5 psi at moisture contents of $0 \%, 10 \%$ and $15 \%$. Figure 4.35 shows the load-displacement relationship for silt and geotextile (geosynthetic material C) under normal pressure of $10 \mathrm{psi}$ at moisture contents of $0 \%$, $10 \%$ and $15 \%$. Figure 4.36 represents the load-displacement relationship for silt and geotextile (geosynthetic material C) under normal pressure of 15 psi at moisture contents of $0 \%, 10 \%$ and $15 \%$. Results for these tend to decrease or remain constant for silt and material C. 


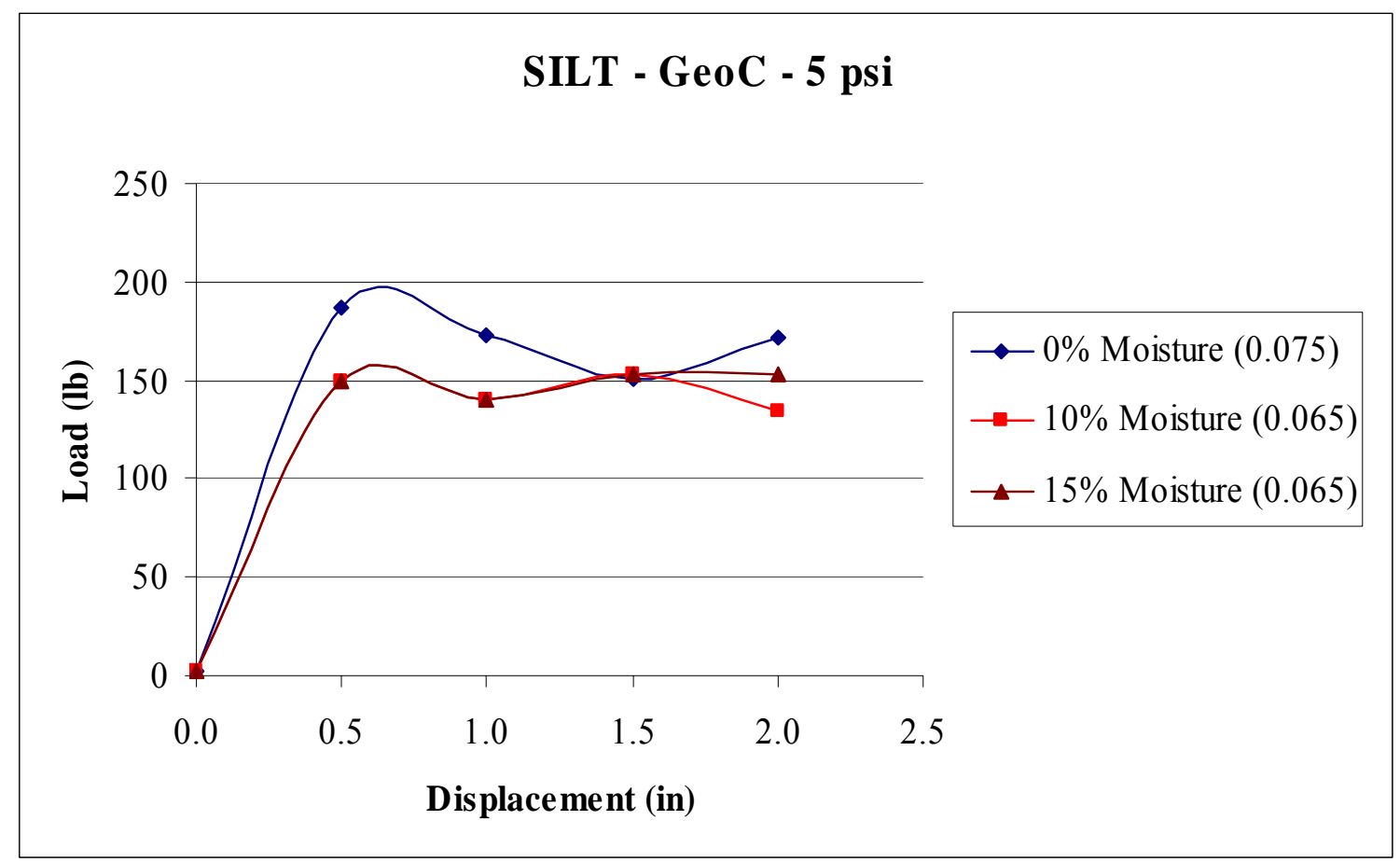

Figure 4.34: Effect of moisture content for silt and geotextile (geosynthetic material C) for normal pressure of 5 psi.

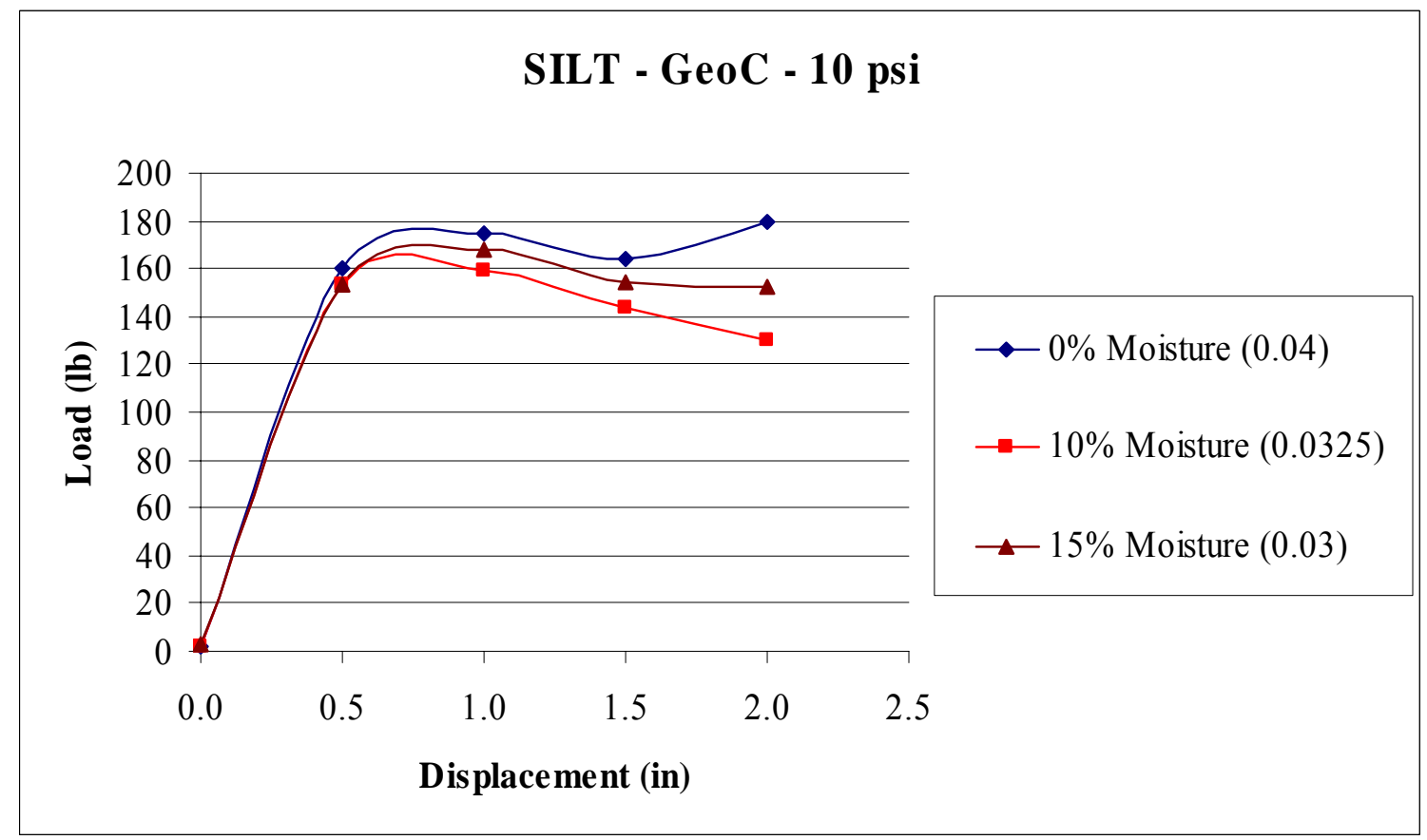

Figure 4.35: Effect of moisture content for silt and geotextile (geosynthetic material C) for normal pressure of $\mathbf{1 0}$ psi. 


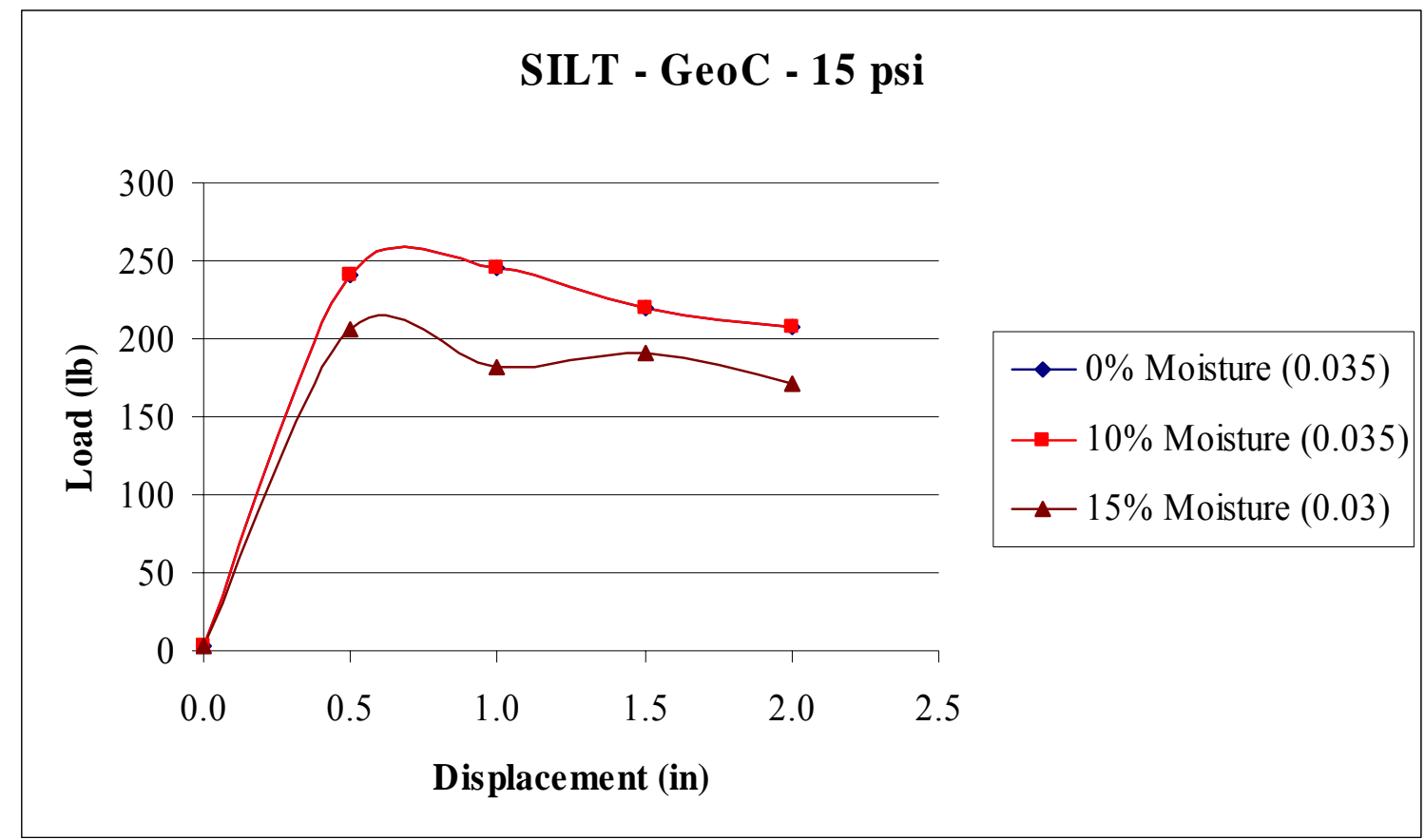

Figure 4.36: Effect of moisture content for silt and geotextile (geosynthetic material C) for normal pressure of 15 psi.

Figures 4.37, 4.38, 4.39 show the load displacement relationship for clay and material A under 5 psi, 10 psi, and 15 psi at $0 \%$ and $10 \%$ moisture. Results from figures 4.37 and 4.39 shows a decrease in the friction with increase in the moisture content. The friction coefficient remains constant for figure 4.38 for the interaction of silt and geogrid A. 


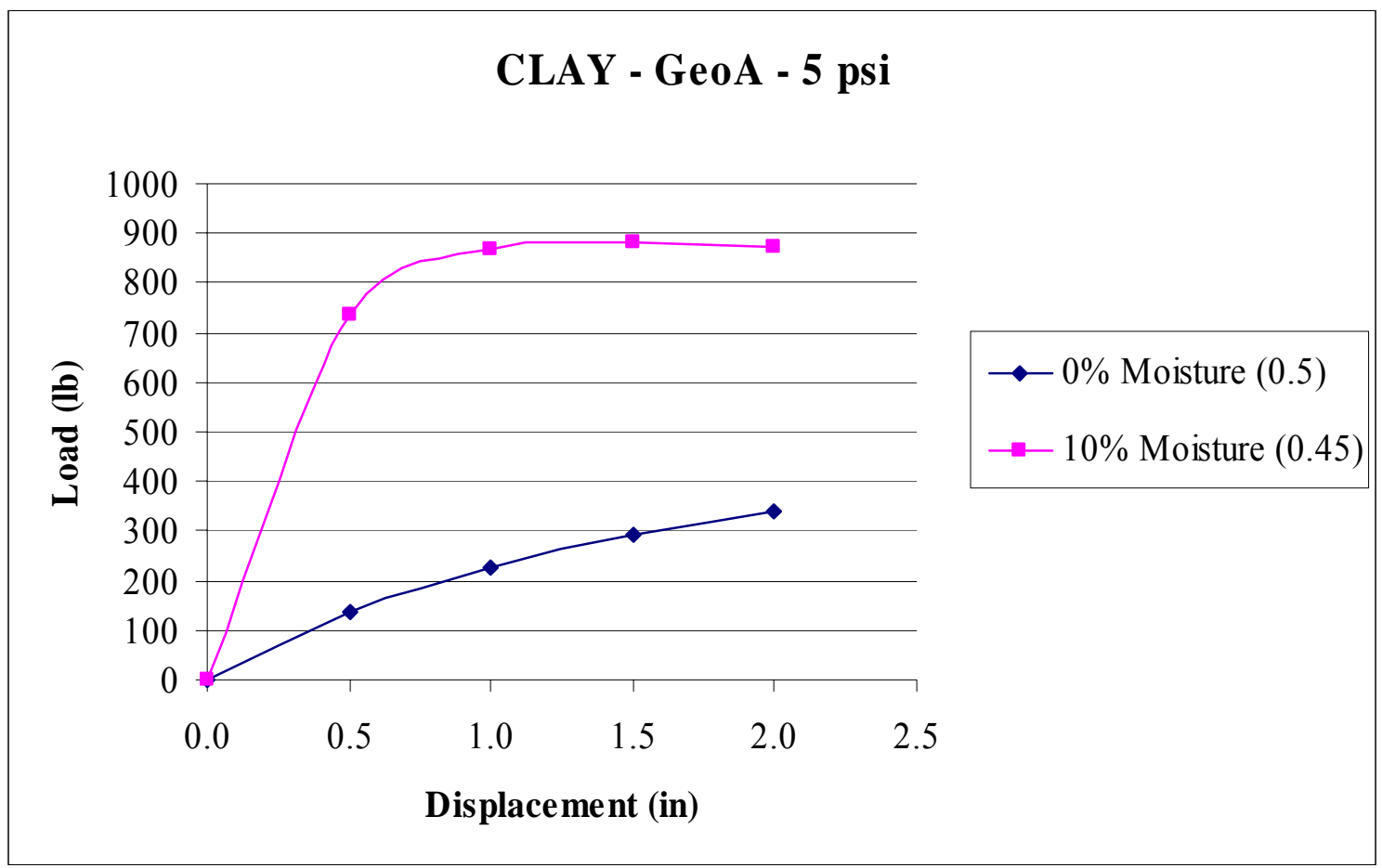

Figure 4.37: Effect of moisture content for clay and geogrid A for normal pressure of 5 psi.

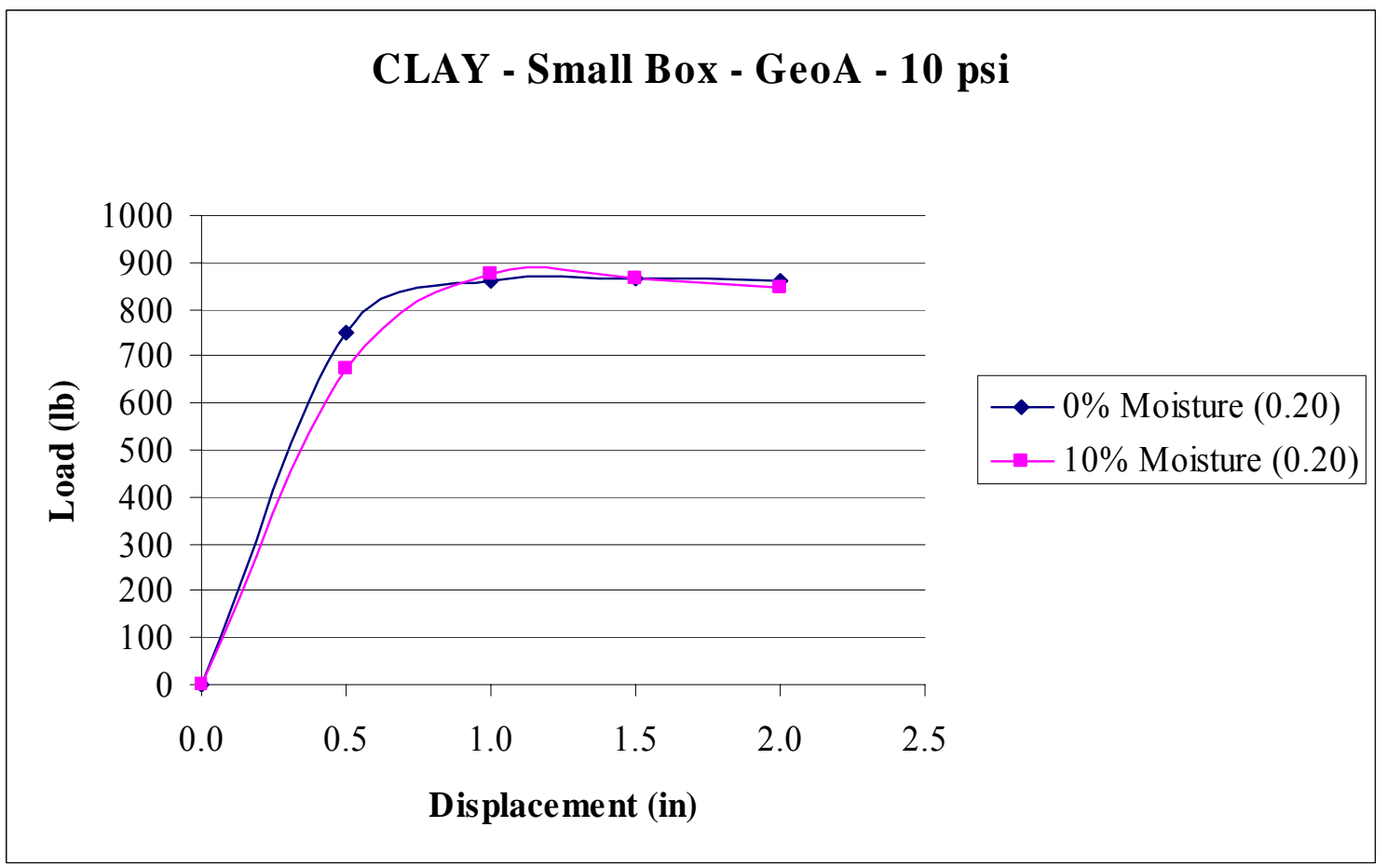

Figure 4.38: Effect of moisture content for clay and geogrid A for normal pressure of 10 psi. 


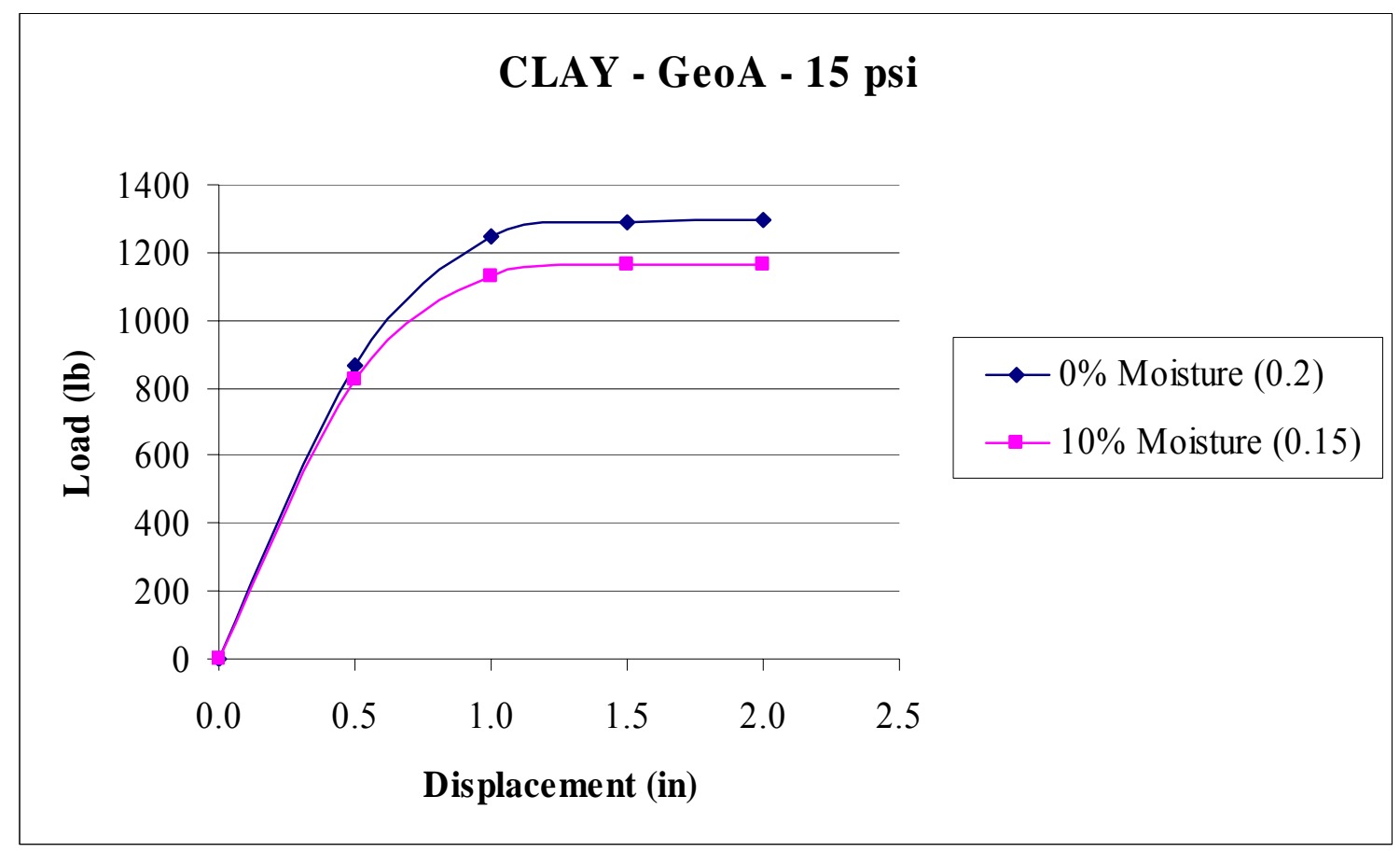

Figure 4.39: Effect of moisture content for clay and geogrid A for normal pressure of 15 psi.

Figures 4.40, 4.41, and 4.42 represent the load-displacement relationship for clay and geotextile (geosynthetic material C) under normal pressures of $5 \mathrm{psi}, 10 \mathrm{psi}$, and 15 psi at moisture contents of $0 \%$ and $10 \%$. The results show that moisture at high normal pressures have small influence on the soil-geosynthetic interaction. Results show an increase in friction coefficient for figure 4.41 and 4.42 and a decrease in friction coefficient in figure 4.43 . 


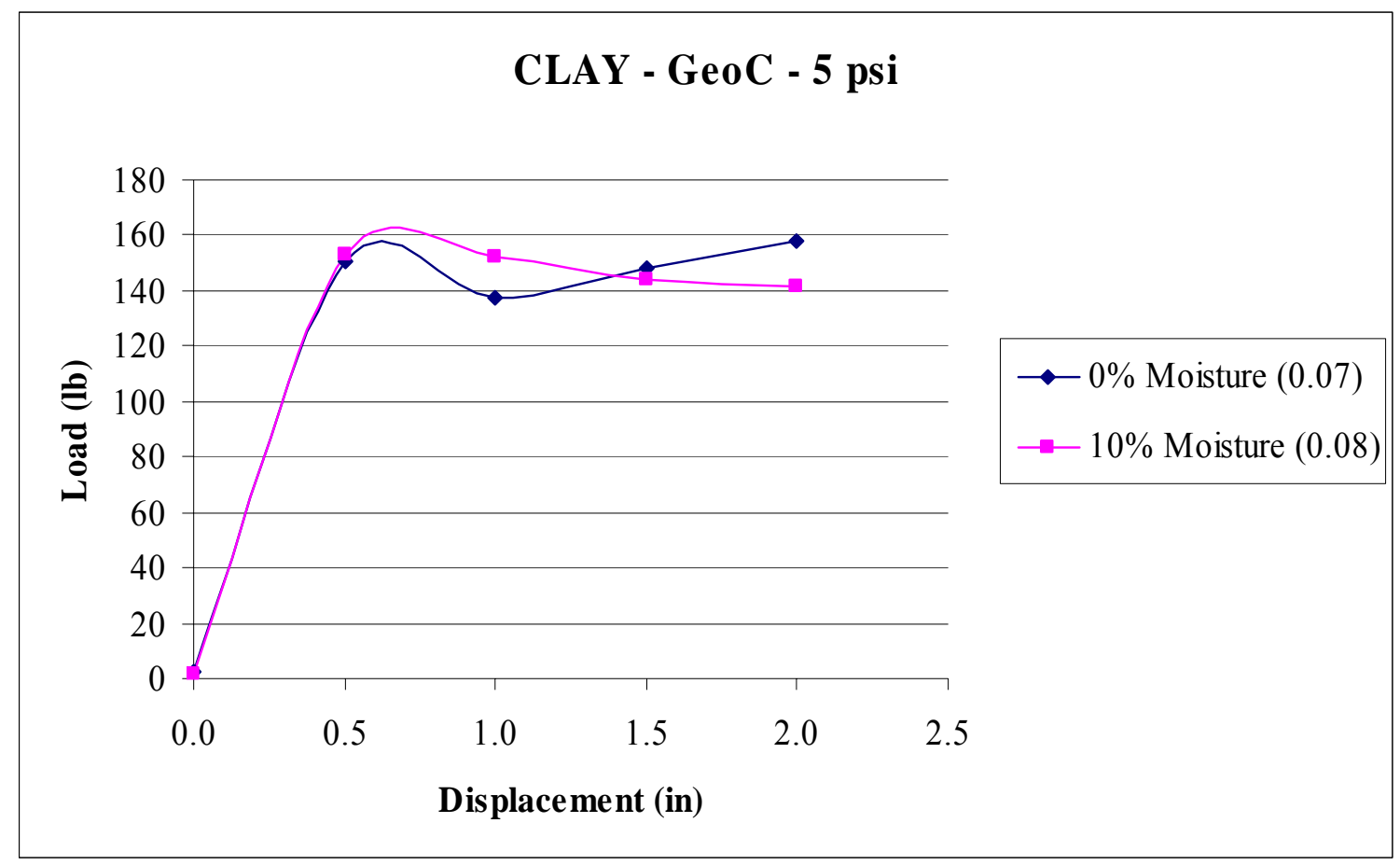

Figure 4.40: Effect of moisture content for clay and geotextile (geosynthetic material C) for normal pressure of 5 psi.

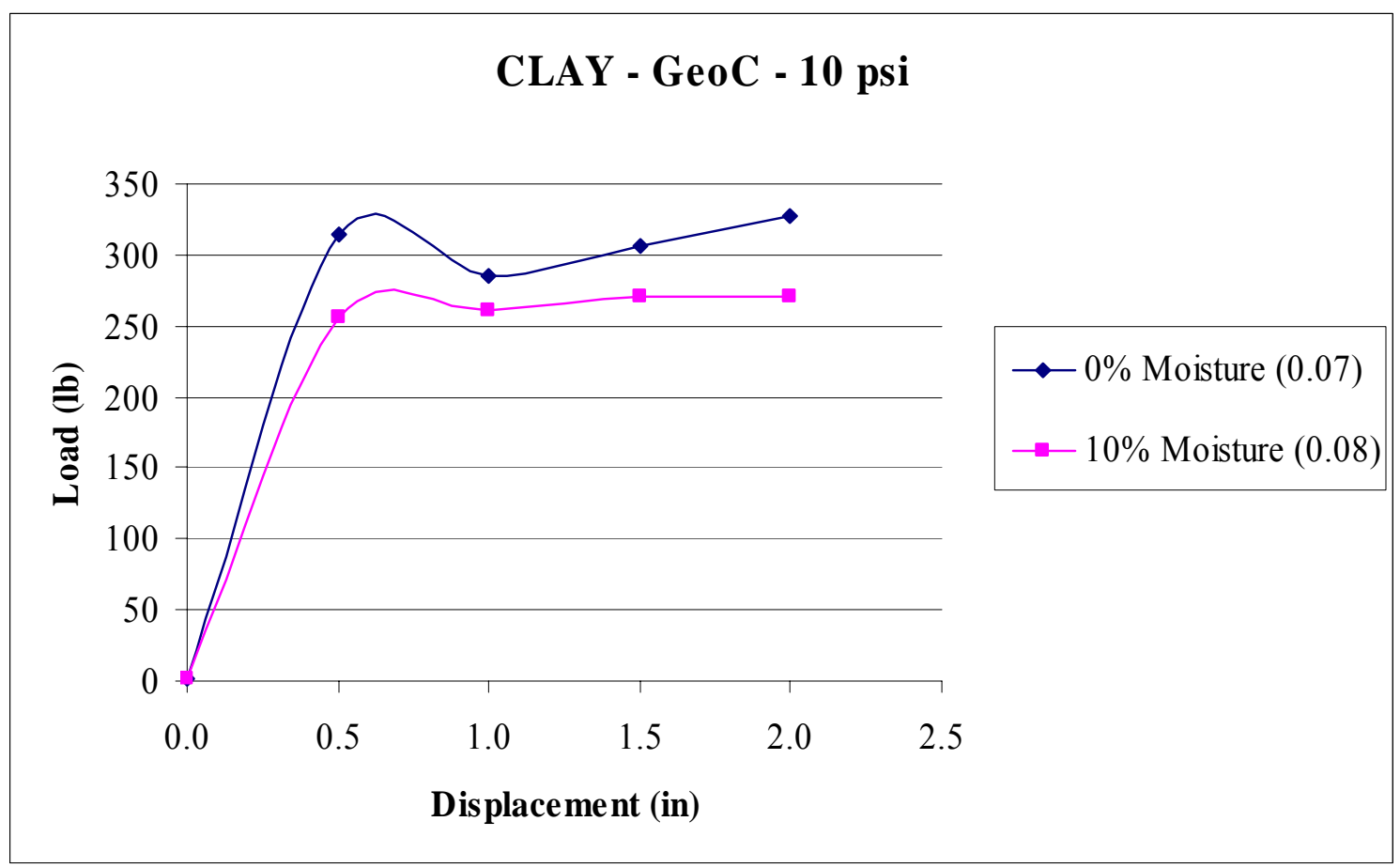

Figure 4.41: Effect of moisture content for clay and geotextile (geosynthetic material C) for normal pressure of 10 psi. 


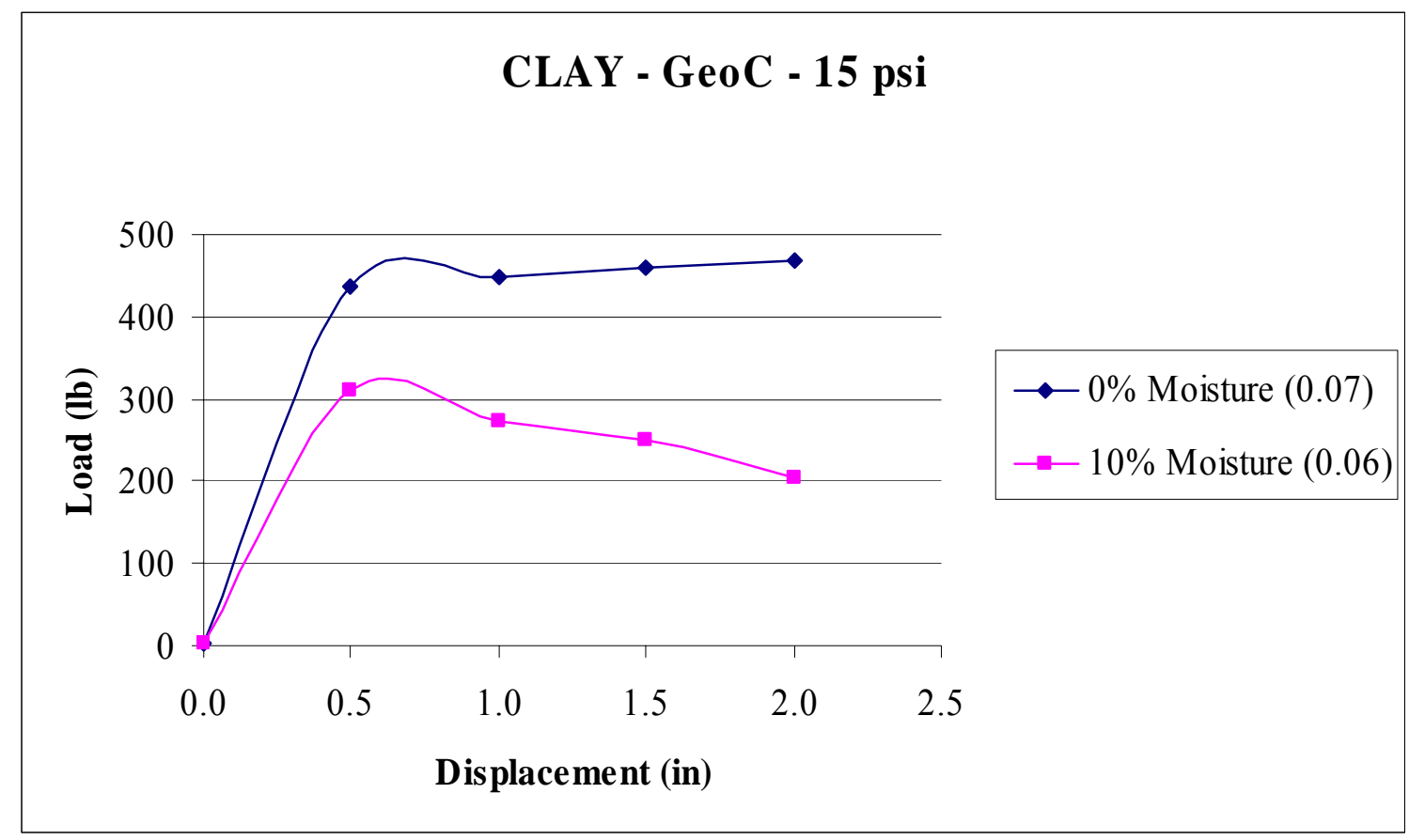

Figure 4.42: Effect of moisture content for clay and geotextile (geosynthetic material C) for normal pressure of 15 psi.

\subsubsection{Large Pullout Box}

Figure 4.43 represents the load-displacement relationship for silt and geogrid A at normal pressure of 5 psi at moisture contents of $0 \%, 10 \%$ and 15\%. Figure 4.44 shows the load-displacement relationship for silt and geogrid A at normal pressure of $10 \mathrm{psi}$ at moisture contents of $0 \%, 10 \%$ and $15 \%$. Figure 4.45 represents the load-displacement relationship for silt and geogrid A at normal pressure of 15 psi at moisture contents of $0 \%, 10 \%$ and $15 \%$. The results from Figures 4.44 and 4.45 show a decrease in the friction coefficient with increase in the moisture content for the interaction of silt and geogrid A for normal pressures of 10 psi and 15 psi. Results from Figure 4.43 show an increase in the friction with increase in the moisture content from $0 \%$ to $10 \%$ and a decrease in friction for $10 \%$ to $15 \%$ for normal pressure of 5 psi. 


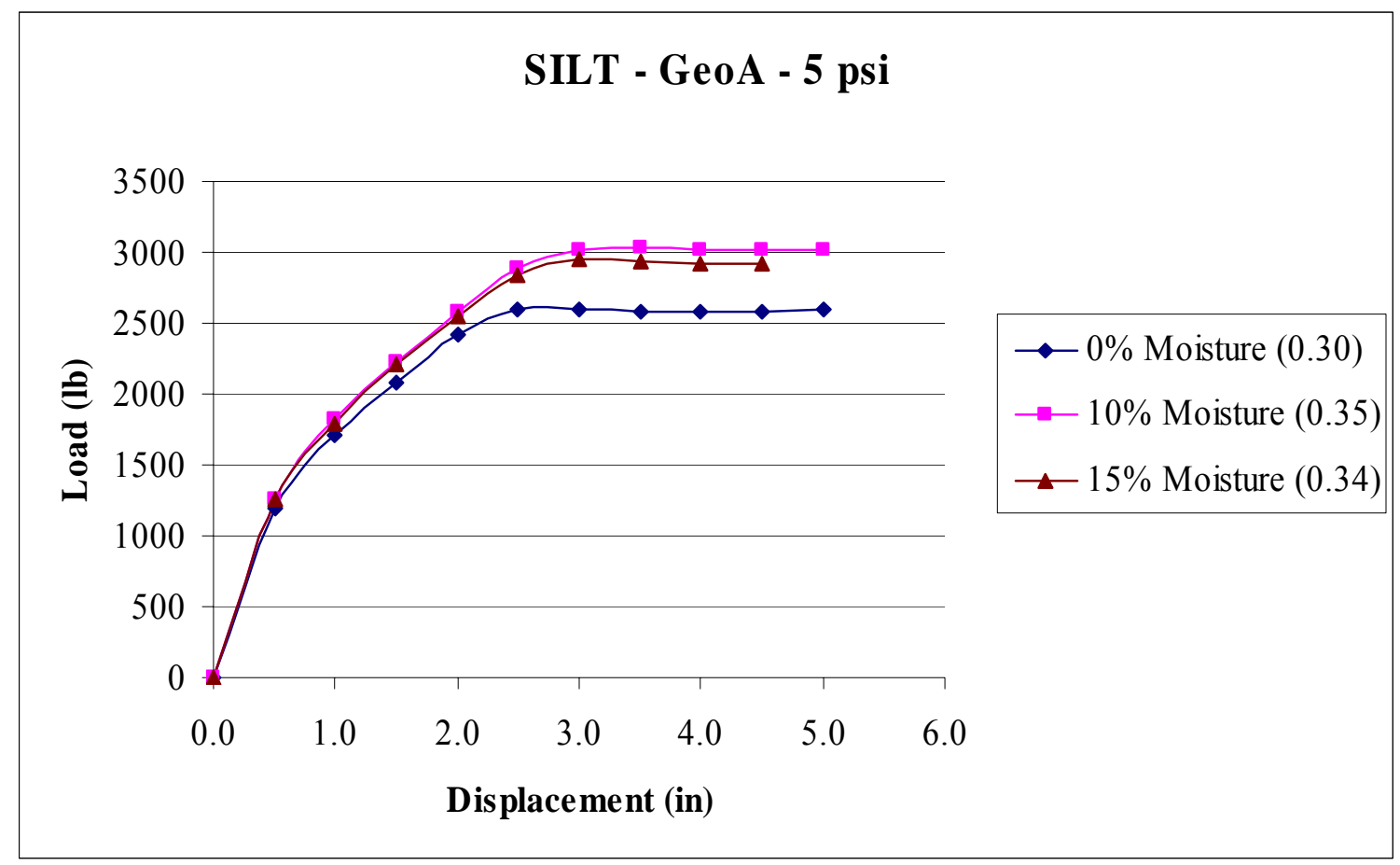

Figure 4.43: Effect of moisture content for silt and geogrid A for normal pressure of 5 psi.

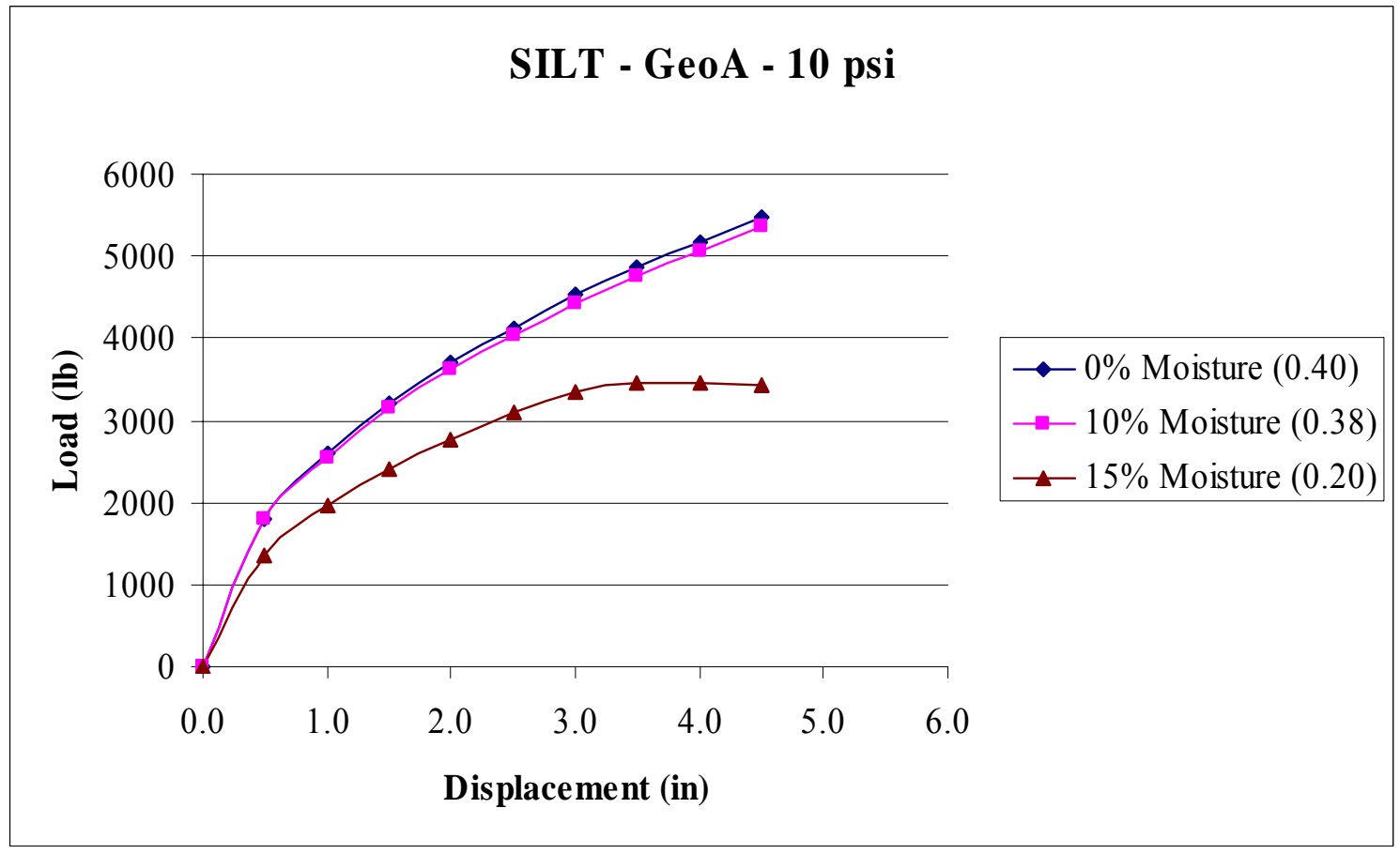

Figure 4.44: Effect of moisture content for silt and geogrid A for normal pressure of 10 psi. 


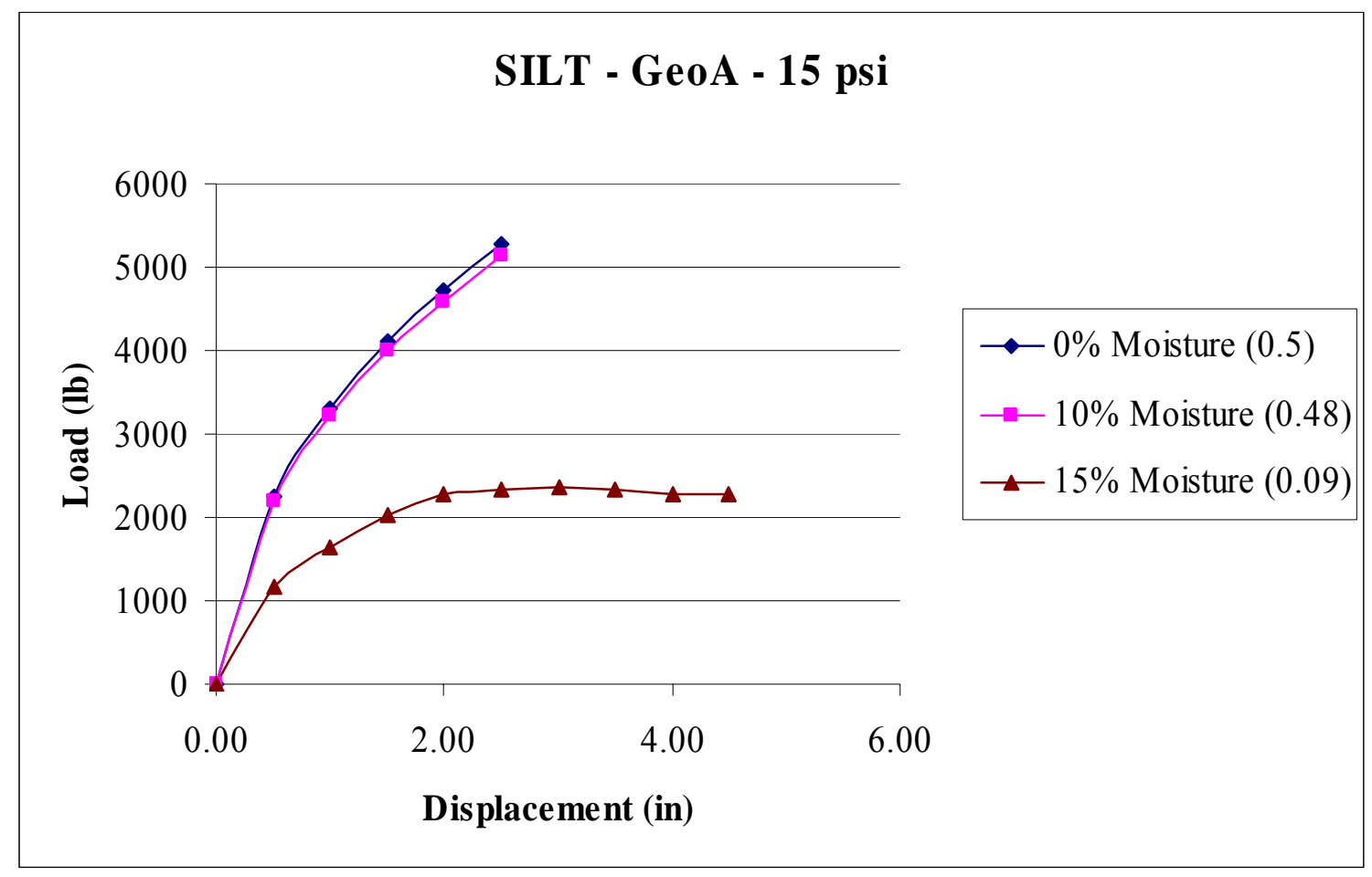

Figure 4.45: Effect of moisture content for silt and geogrid A for normal pressure of 15 psi.

Figure 4.46 represents the load-displacement relationship for silt and geotextile (geosynthetic material C) at normal pressure of 5 psi at moisture contents of $0 \%, 10 \%$ and $15 \%$. Figure 4.47 shows the load-displacement relationship for silt and geotextile (geosynthetic material $\mathrm{C}$ ) at normal pressure of $10 \mathrm{psi}$ at moisture contents of $0 \%, 10 \%$ and $15 \%$. Figure 4.48 represents the load-displacement relationship for silt and geotextile (geosynthetic material C) at normal pressure of 15 psi at moisture contents of $0 \%, 10 \%$ and $15 \%$. Figures 4.47 and 4.48 shows an increase from $0 \%$ to $10 \%$ moisture then a decrease in the friction coefficient from $10 \%$ to $15 \%$ moisture content. Figure 4.46 shows an increase in the frictional properties with an increase in the moisture content. 


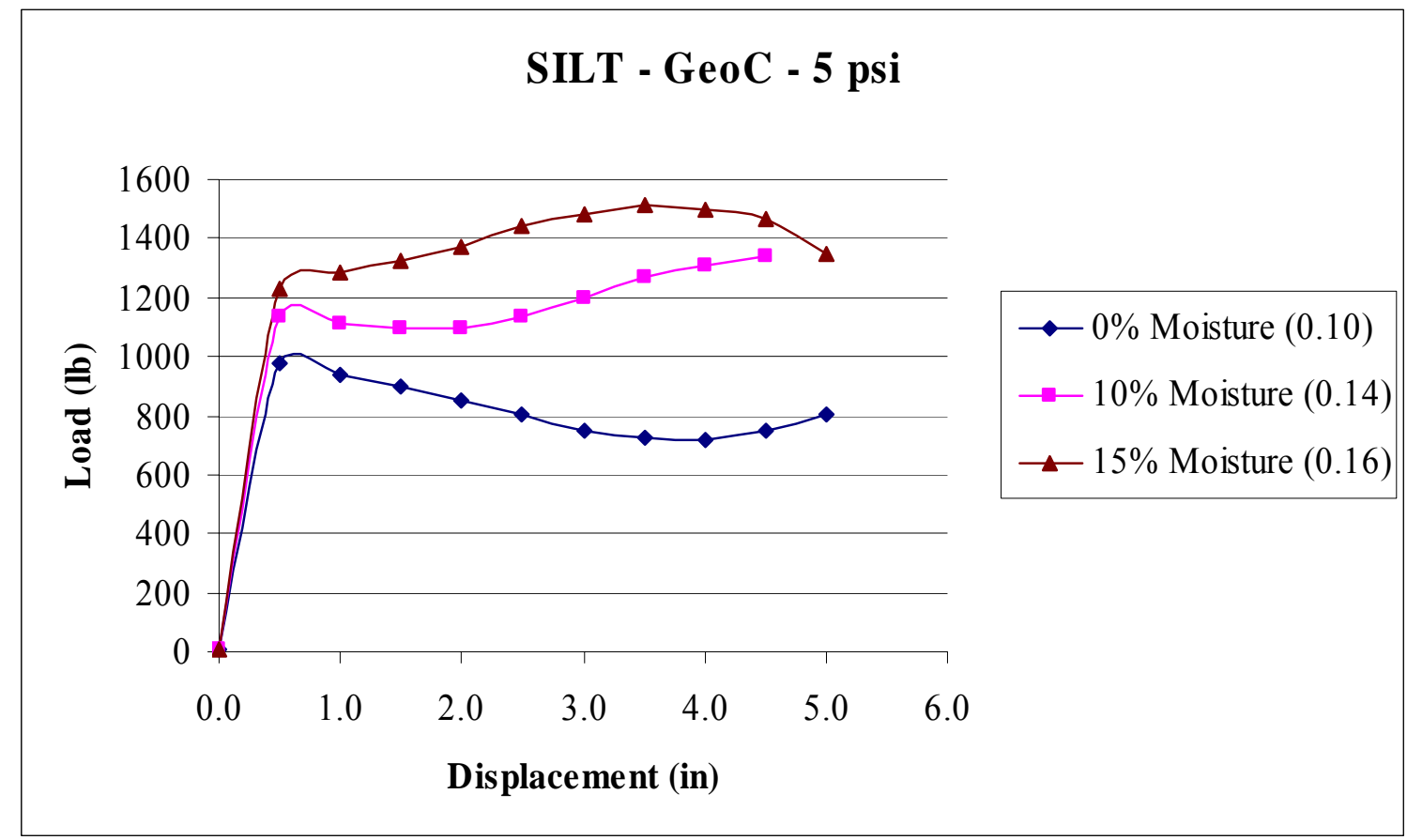

Figure 4.46: Effect of moisture content for silt and geotextile (geosynthetic material C) for normal pressure of 5 psi.

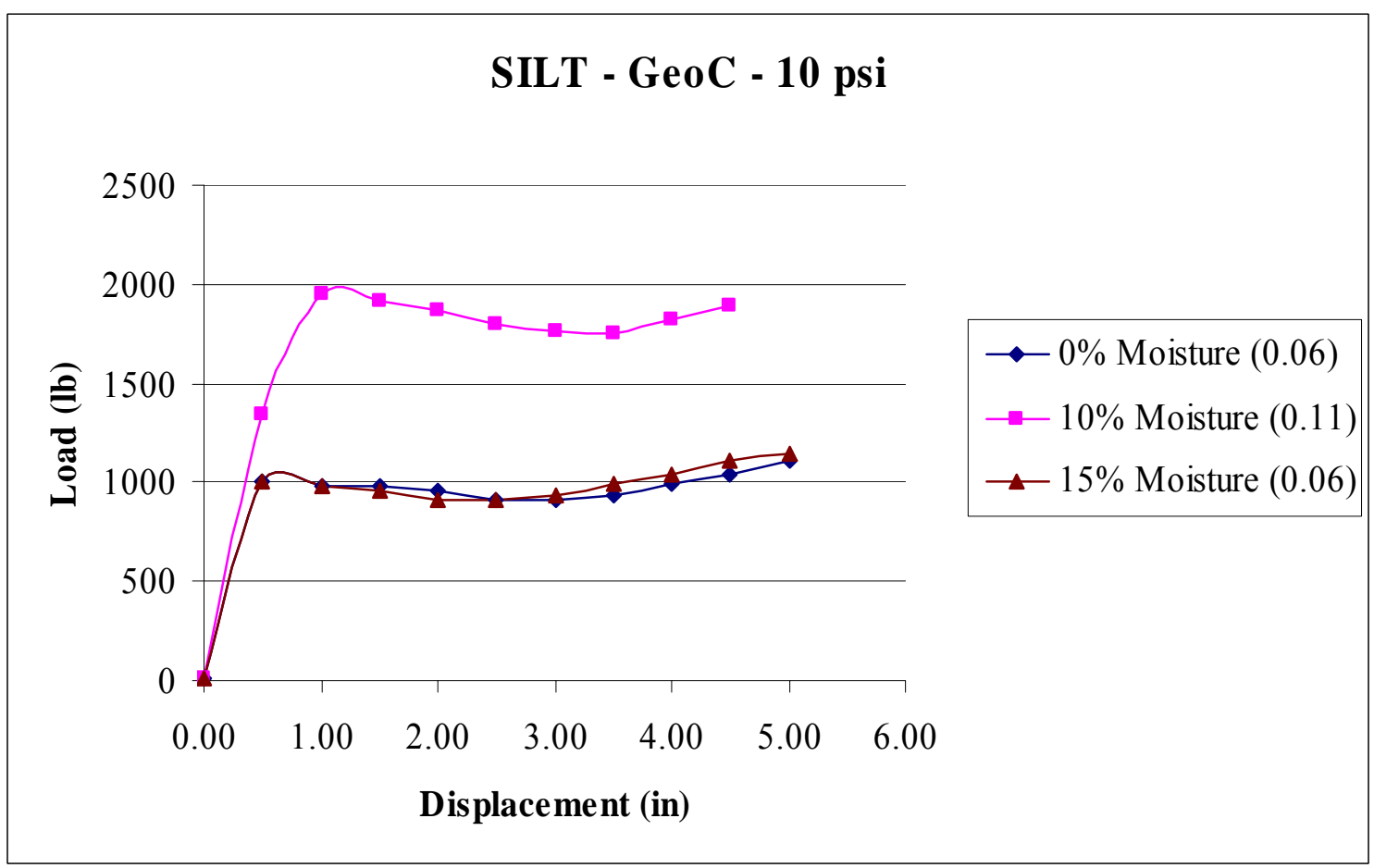

Figure 4.47: Effect of moisture content for silt and geotextile (geosynthetic material C) for normal pressure of $\mathbf{1 0}$ psi. 


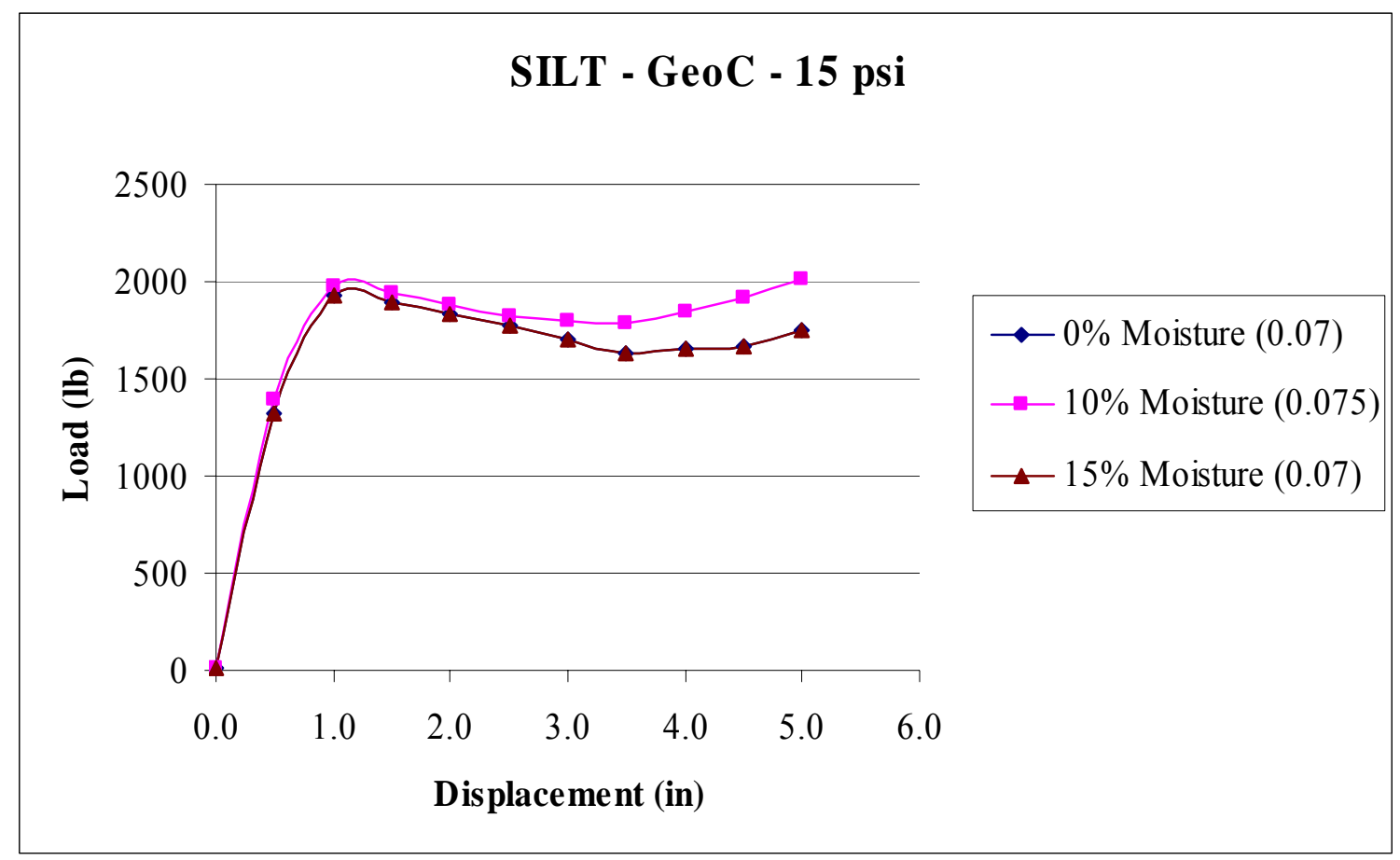

Figure 4.48: Effect of moisture content for silt and geotextile (geosynthetic material C) for normal pressure of 15 psi.

Figures 4.49, 4.50, and 4.51 represent the load-displacement relationship for clay and geogrid A under normal pressure of 5 psi, 10 psi, and 15 psi at moisture contents of $0 \%$ and $10 \%$. Figure 4.49 shows a decrease in the friction with increase in the moisture content for the interaction of silt and geogrid A. Results from Figures 4.50 and 4.51 show an increase in friction coefficient as moisture content increases. 


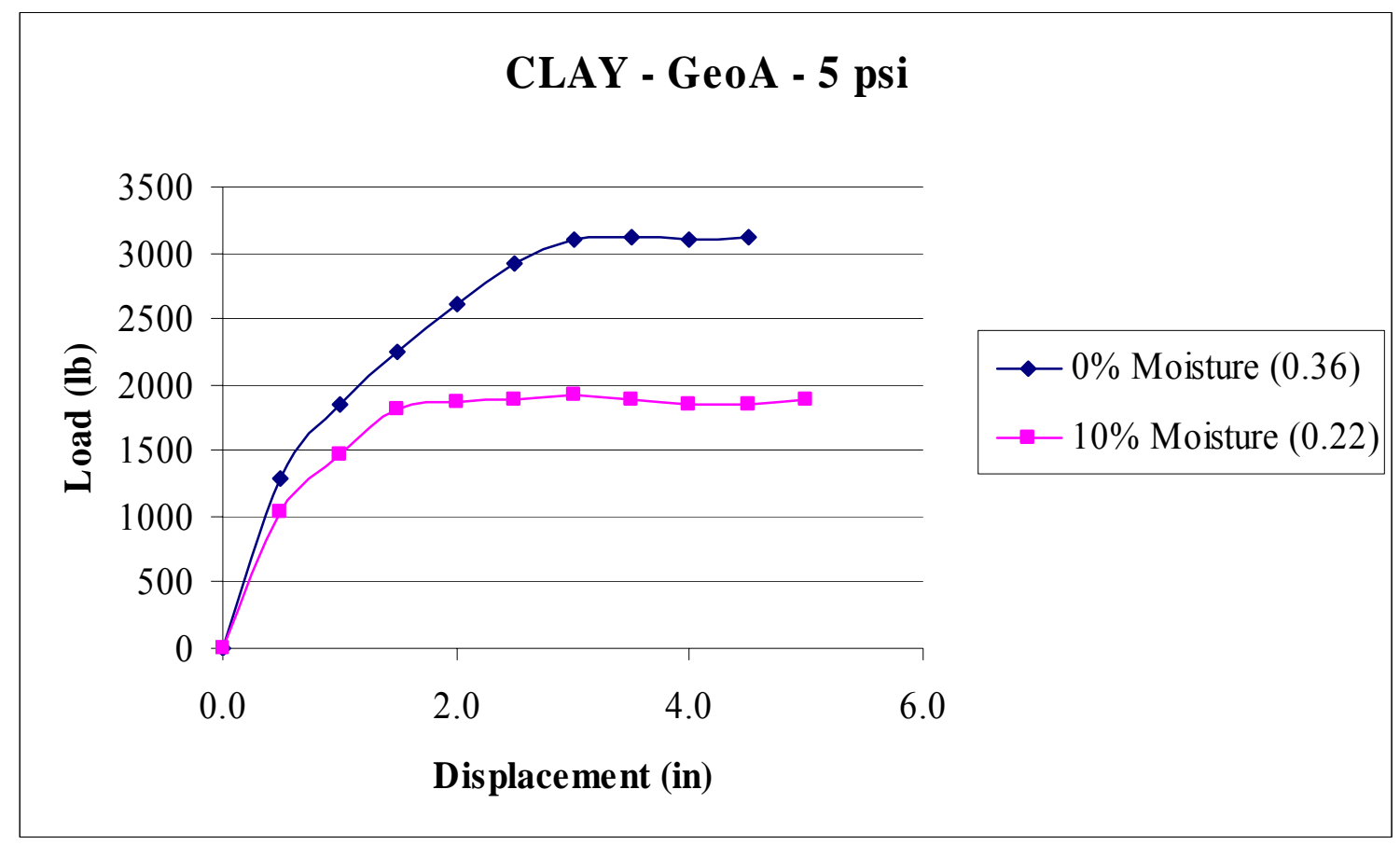

Figure 4.49: Effect of moisture content for clay and geogrid A for normal pressure of 5 psi.

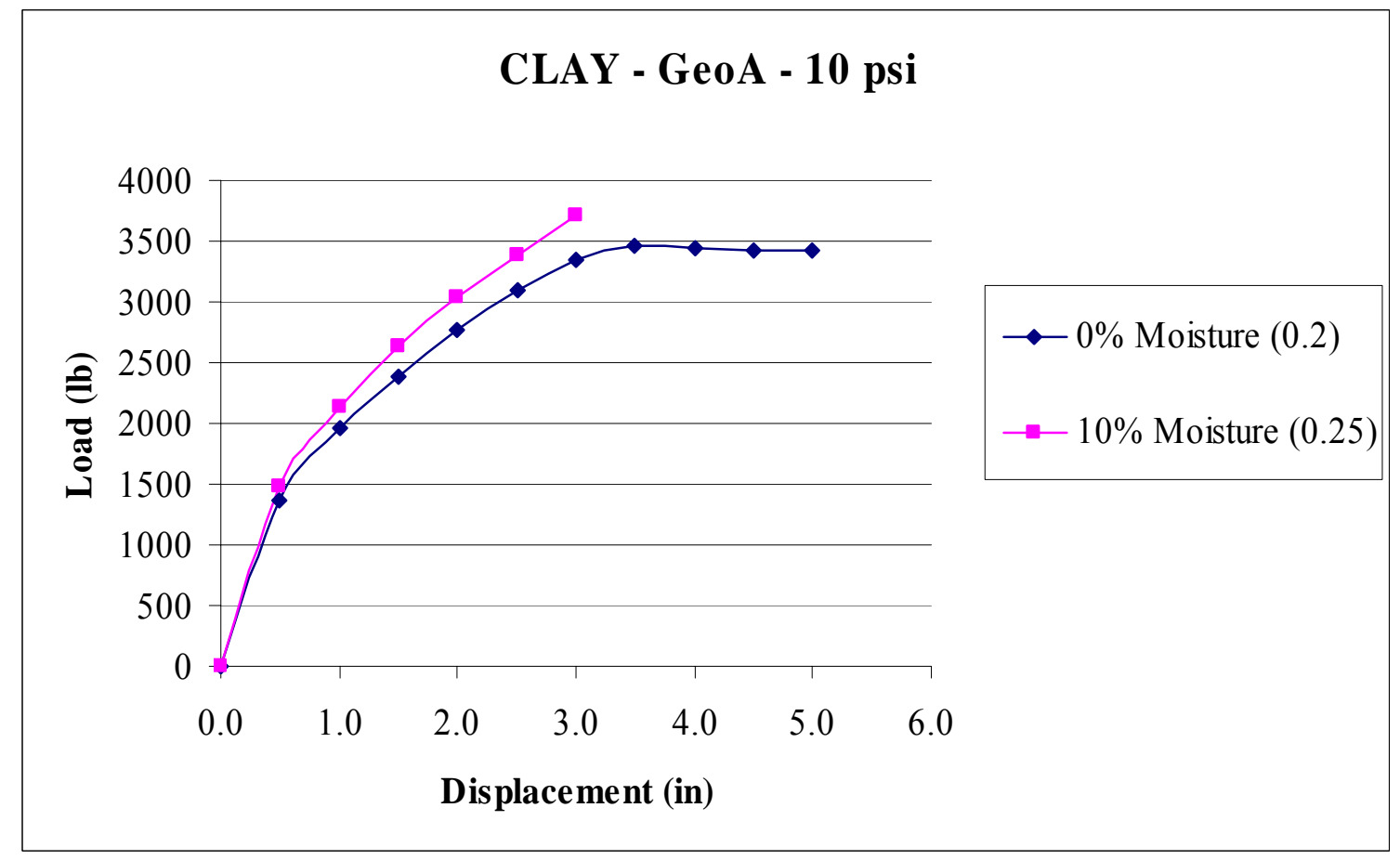

Figure 4.50: Effect of moisture content for clay and geogrid A for normal pressure of 10 psi. 


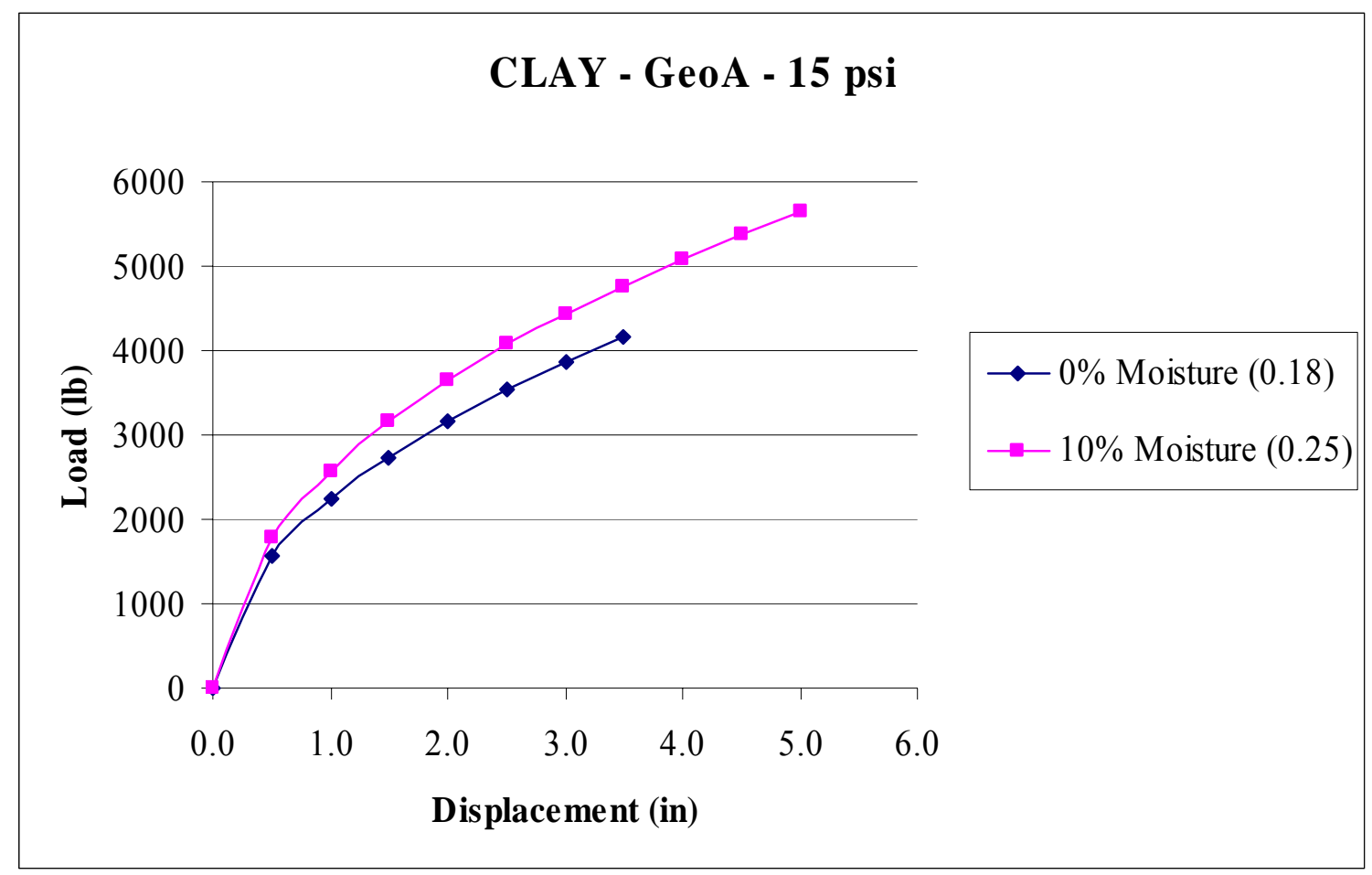

Figure 4.51: Effect of moisture content for clay and geogrid A for normal pressure of 15 psi.

Figure 4.52, 4.53, and 4.54 represent the load-displacement relationship for clay and geotextile (geosynthetic material C) under normal pressures of $5 \mathrm{psi}, 10 \mathrm{psi}$, and 15 psi at moisture contents of $0 \%$ and 10\%. Results show the friction coefficient decreases as moisture content increases for each of the figures. 


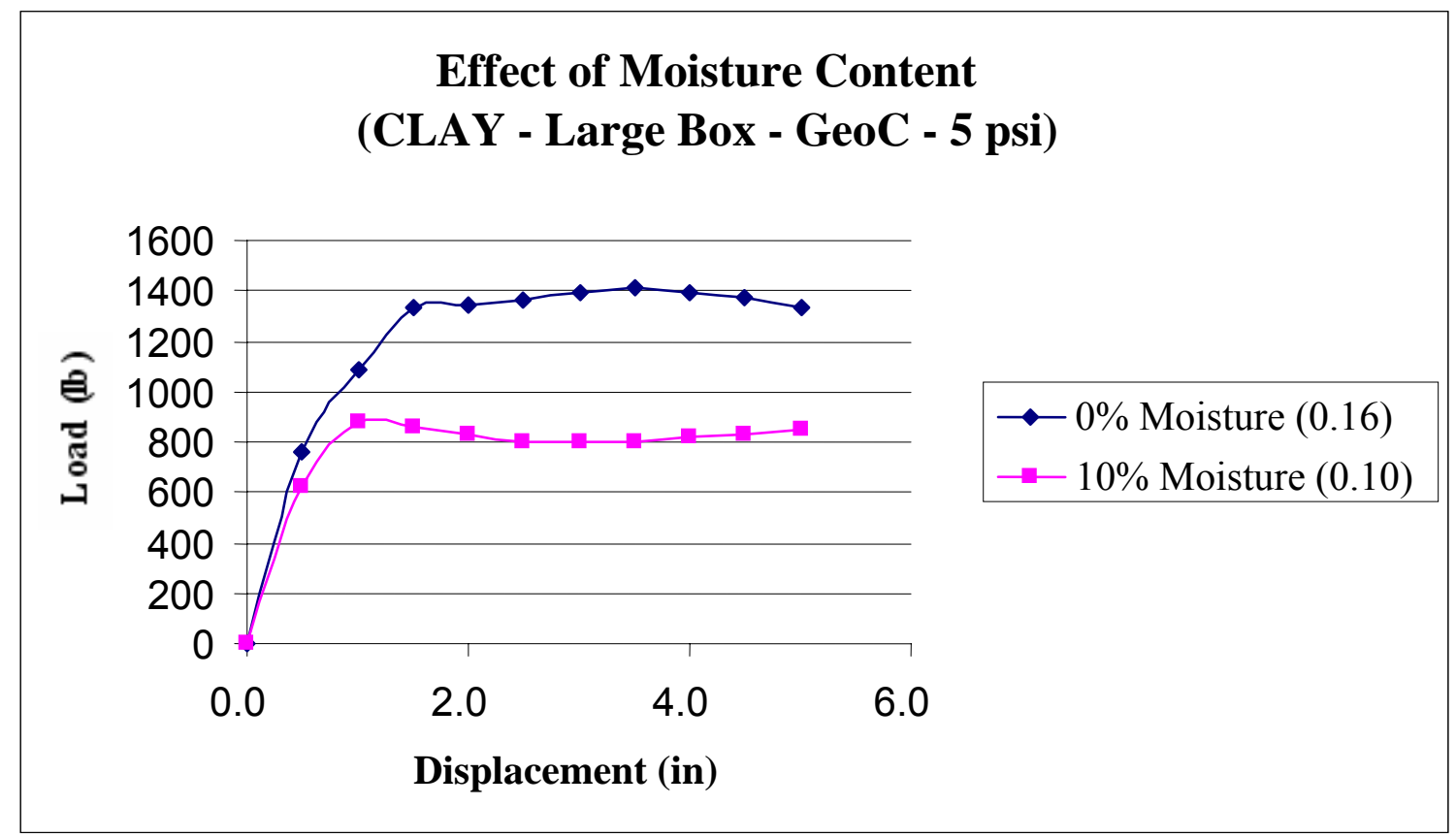

Figure 4.52: Effect of moisture content for clay and geotextile (geosynthetic material C) for normal pressure of $\mathbf{5}$ psi.

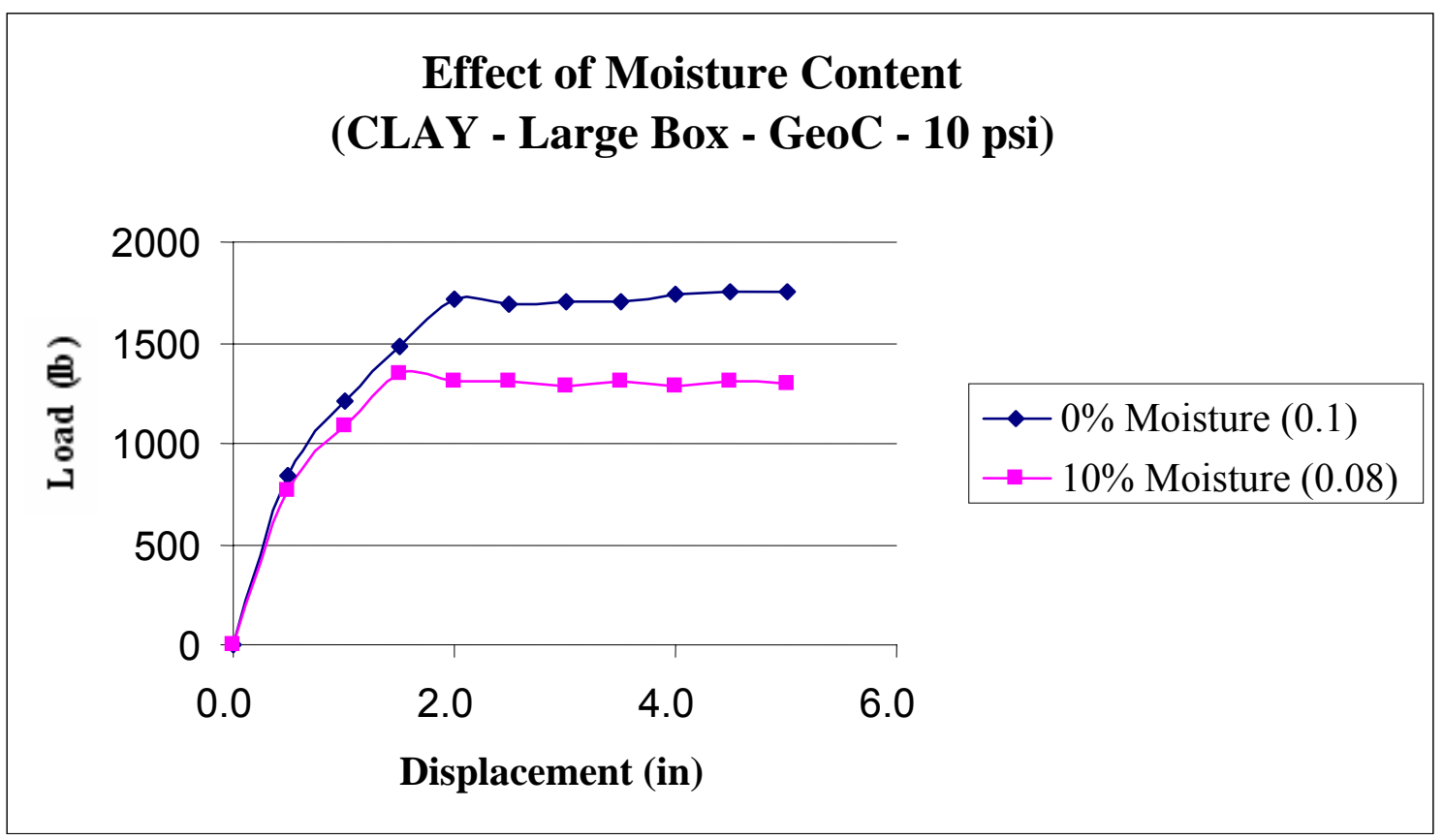

Figure 4.53: Effect of moisture content for clay and geotextile (geosynthetic material C) for normal pressure of $\mathbf{1 0}$ psi. 


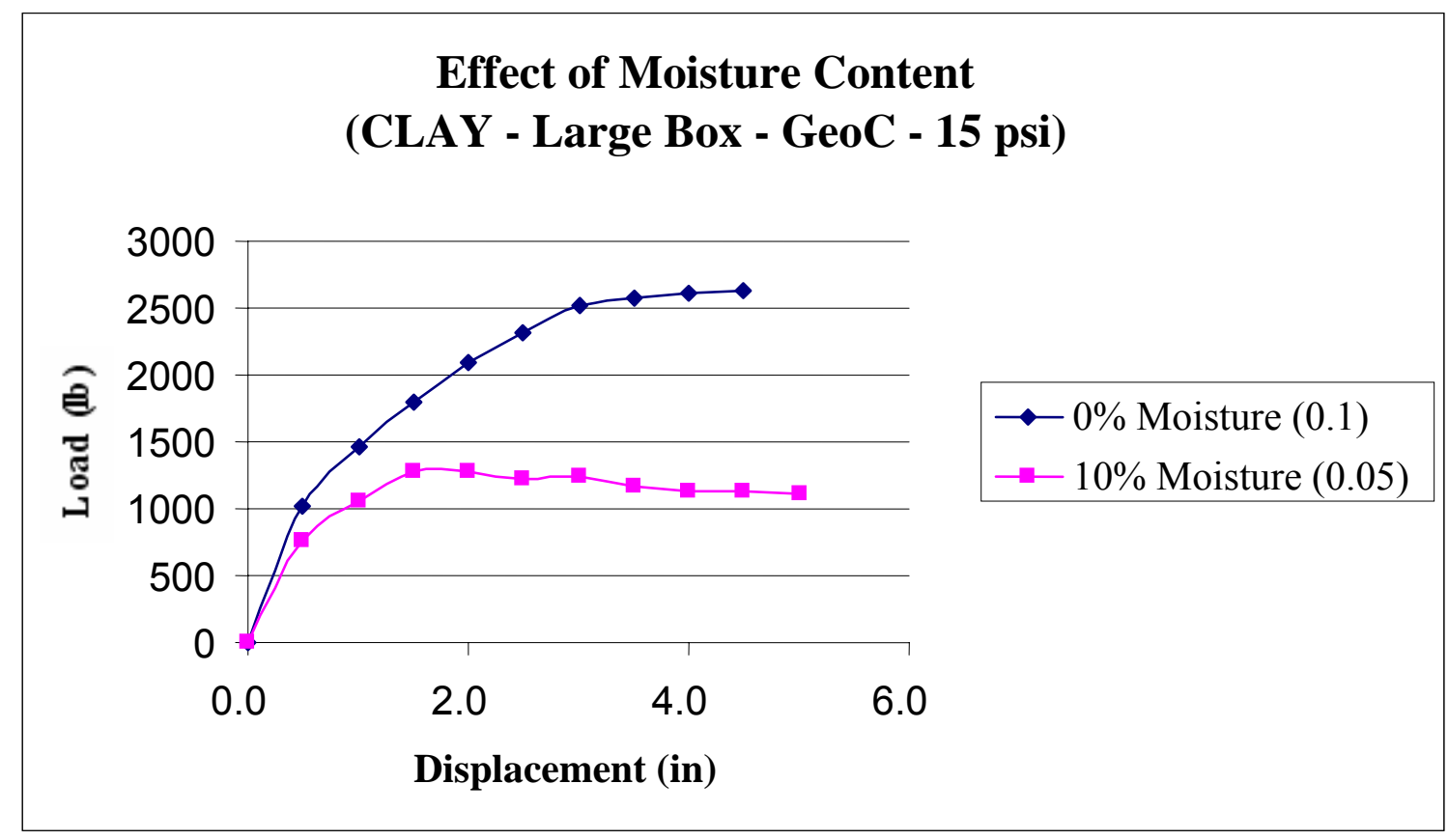

Figure 4.54: Effect of moisture content for clay and geotextile (geosynthetic material C) for normal pressure of 15 psi.

\subsection{Effect of Box Size}

The effect of pullout box size on the analysis seems to change with types of soils tested. The friction coefficient decreases from the small box to the large box for the analysis done for sand - geosynthetic interaction. The friction coefficient for silt is greater for the large pullout box except at high moisture contents and normal pressure for Material A. The large pullout box has lower friction coefficients than that of the small pullout box for clay - Material A interaction except at high moisture content and normal pressure. The friction coefficient is higher in the large pullout box for clay - Material C interaction.

The results for the friction coefficients for each case were placed in tables for easy analysis and comparison. The tables also show the percent differences in the friction coefficient as normal pressure increases and moisture content increases. For example, a decrease in the friction coefficient as normal pressure increase and moisture content 
increases would result in a negative percent difference. The percent difference in pullout box size was calculated comparing the large box to the small box therefore; a decrease in friction coefficient from large pullout box to small pullout box would result in a negative percent difference. This was done to show how much the friction coefficient increases or decreases with the increase of normal pressure, moisture content, and box size. The results can be shown in tables 4.1,4.2, 4.3, 4.4, and 4.5. Friction angle was calculated from the friction coefficient used during the finite element analysis. This can be seen in tables 4.6, 4.7, and 4.8. The friction angle calculated from the friction coefficient was then compared to the measured friction angle found in previous laboratory experiments (Ingram, 2006). The comparison of friction angles measured and calculated can be seen in table 4.9. These tables are show in the following pages. 
Table 4.1: Percent difference in friction coefficient for a change in normal pressure and change in box size for sand

\begin{tabular}{|c|c|c|c|c|c|c|c|}
\hline $\begin{array}{l}\text { Geosynthetic } \\
\text { Material }\end{array}$ & $\begin{array}{c}\text { Moisture } \\
\text { Content } \\
(\%)\end{array}$ & $\begin{array}{l}\text { Normal } \\
\text { Pressure } \\
\text { (psi) }\end{array}$ & $\begin{array}{c}\text { Friction } \\
\text { Coefficient } \\
\text { (FC) - Large } \\
\text { Box }\end{array}$ & $\begin{array}{c}\text { Friction } \\
\text { Coefficient } \\
\text { (FC) - Small } \\
\text { Box }\end{array}$ & $\begin{array}{l}\text { Percent Difference } \\
\text { in FC for Normal } \\
\text { Pressure - Large } \\
\text { Box }\end{array}$ & $\begin{array}{c}\text { Percent Difference } \\
\text { in FC for Normal } \\
\text { Pressure - Small } \\
\text { Box }\end{array}$ & $\begin{array}{c}\text { Percent } \\
\text { Difference in } \\
\text { FC for Box } \\
\text { Size }\end{array}$ \\
\hline \multirow{3}{*}{$A$} & \multirow{3}{*}{0} & 5 & 0.3 & 0.35 & \multirow[t]{2}{*}{$33.33 \%$} & \multirow[t]{2}{*}{$14.29 \%$} & $16.67 \%$ \\
\hline & & 10 & 0.4 & 0.4 & & & $0.00 \%$ \\
\hline & & 15 & 0.5 & 0.6 & $25.00 \%$ & $50.00 \%$ & $20.00 \%$ \\
\hline \multirow{3}{*}{ B } & \multirow{3}{*}{0} & 5 & 0.35 & - & \multirow{2}{*}{$14.29 \%$} & \multirow{2}{*}{-} & - \\
\hline & & 10 & 0.4 & - & & & - \\
\hline & & 15 & 0.5 & - & $25.00 \%$ & - & - \\
\hline \multirow{3}{*}{ C } & \multirow{3}{*}{0} & 5 & 0.1 & 0.09 & \multirow{2}{*}{$-30.00 \%$} & \multirow{2}{*}{$0.00 \%$} & $-10.00 \%$ \\
\hline & & 10 & 0.07 & 0.09 & & & $28.57 \%$ \\
\hline & & 15 & 0.05 & 0.4 & $-28.57 \%$ & $344.44 \%$ & $700.00 \%$ \\
\hline
\end{tabular}


Table 4.2: Percent difference in friction coefficient for a change in normal pressure and change in box size for silt

\begin{tabular}{|c|c|c|c|c|c|c|c|}
\hline \multicolumn{8}{|c|}{ SILT } \\
\hline $\begin{array}{c}\text { Geosynthetic } \\
\text { Material }\end{array}$ & $\begin{array}{c}\text { Moisture } \\
\text { Content }(\%)\end{array}$ & $\begin{array}{l}\text { Normal } \\
\text { Pressure } \\
\quad \text { (psi) }\end{array}$ & $\begin{array}{c}\text { Friction } \\
\text { Coefficient (FC) } \\
\text { Large Box }\end{array}$ & \begin{tabular}{|c|} 
Friction \\
Coefficient (FC) \\
- Small Box
\end{tabular} & $\begin{array}{l}\text { Percent Difference in } \\
\text { FC for Normal } \\
\text { Pressure - Large Box }\end{array}$ & $\begin{array}{l}\text { Percent Difference in } \\
\text { FC for Normal } \\
\text { Pressure - Small Box }\end{array}$ & $\begin{array}{l}\text { Percent Difference in } \\
\text { FC for Box Size }\end{array}$ \\
\hline \multirow{9}{*}{ A } & \multirow{3}{*}{0} & 5 & 0.3 & 0.32 & \multirow[t]{2}{*}{$33.33 \%$} & \multirow[t]{2}{*}{$-6.25 \%$} & $6.67 \%$ \\
\hline & & 10 & 0.4 & 0.3 & & & $-25.00 \%$ \\
\hline & & 15 & 0.5 & 0.28 & $25.00 \%$ & $-6.67 \%$ & $-44.00 \%$ \\
\hline & \multirow{3}{*}{10} & 5 & 0.35 & 0.26 & \multirow[t]{2}{*}{$8.57 \%$} & $-7.69 \%$ & $-25.71 \%$ \\
\hline & & 10 & 0.38 & 0.24 & & \multirow[b]{2}{*}{$-8.33 \%$} & $-36.84 \%$ \\
\hline & & 15 & 0.46 & 0.22 & $21.05 \%$ & & $-52.17 \%$ \\
\hline & \multirow{3}{*}{15} & 5 & 0.34 & 0.23 & $-41.18 \%$ & $-4.35 \%$ & $-32.35 \%$ \\
\hline & & 10 & 0.2 & 0.22 & & & $10.00 \%$ \\
\hline & & 15 & 0.09 & 0.21 & $-55.00 \%$ & $-4.55 \%$ & $133.33 \%$ \\
\hline \multirow{9}{*}{ B } & \multirow{3}{*}{0} & 5 & 0.3 & - & \multirow[t]{2}{*}{$33.33 \%$} & \multirow[t]{2}{*}{-} & - \\
\hline & & 10 & 0.4 & - & & & - \\
\hline & & 15 & 0.5 & - & $25.00 \%$ & - & - \\
\hline & \multirow{3}{*}{10} & 5 & 0.22 & - & \multirow[t]{2}{*}{$18.18 \%$} & \multirow[t]{2}{*}{-} & - \\
\hline & & 10 & 0.26 & - & & & - \\
\hline & & 15 & 0.3 & - & $15.38 \%$ & - & - \\
\hline & \multirow{3}{*}{15} & 5 & 0.42 & - & \multirow[t]{2}{*}{$-4.76 \%$} & \multirow[t]{2}{*}{-} & - \\
\hline & & 10 & 0.4 & - & & & - \\
\hline & & 15 & 0.24 & - & $-40.00 \%$ & - & - \\
\hline \multirow{9}{*}{ C } & \multirow{3}{*}{0} & 5 & 0.1 & 0.075 & \multirow[t]{2}{*}{$-40.00 \%$} & \multirow[t]{2}{*}{$-46.67 \%$} & $-25.00 \%$ \\
\hline & & 10 & 0.06 & 0.04 & & & $-33.33 \%$ \\
\hline & & 15 & 0.07 & 0.035 & $16.67 \%$ & $-12.50 \%$ & $-50.00 \%$ \\
\hline & \multirow{3}{*}{10} & 5 & 0.14 & 0.065 & \multirow[t]{2}{*}{$-21.43 \%$} & \multirow[t]{2}{*}{$-46.15 \%$} & $-53.57 \%$ \\
\hline & & 10 & 0.11 & 0.035 & & & $-68.18 \%$ \\
\hline & & 15 & 0.075 & 0.035 & $-31.82 \%$ & $0.00 \%$ & $-53.33 \%$ \\
\hline & \multirow{3}{*}{15} & 0 & 0.16 & 0.065 & $-62.50 \%$ & $-53.85 \%$ & $-59.38 \%$ \\
\hline & & 10 & 0.06 & 0.03 & & & $-50.00 \%$ \\
\hline & & 15 & 0.06 & 0.03 & $0.00 \%$ & $0.00 \%$ & $-50.00 \%$ \\
\hline
\end{tabular}

*FC $=$ friction coefficient 
Table 4.3: Percent difference in friction coefficient for change in moisture content for silt

\begin{tabular}{|c|c|c|c|c|c|c|c|c|c|c|}
\hline \multicolumn{11}{|c|}{ SILT } \\
\hline $\begin{array}{c}\text { Geosynthetic } \\
\text { Material }\end{array}$ & $\begin{array}{c}\text { Moisture } \\
\text { Content (\%) }\end{array}$ & $\begin{array}{l}\text { Normal } \\
\text { Pressure } \\
\text { (psi) }\end{array}$ & $\begin{array}{c}\text { Friction } \\
\text { Coefficient (FC) } \\
\text { Large Box }\end{array}$ & \begin{tabular}{|c|} 
Friction \\
Coefficient (FC) \\
- Small Box
\end{tabular} & $\begin{array}{l}\text { Percent Difference in } \\
\text { FC for Moisture } \\
\text { Content - Large Box (5 } \\
\text { psi) }\end{array}$ & $\begin{array}{l}\text { Percent Difference in } \\
\text { FC for Moisture } \\
\text { Content - Large Box } \\
(10 \mathrm{psi})\end{array}$ & $\begin{array}{c}\text { Percent Difference in } \\
\text { FC for Moisture } \\
\text { Content - Large Box } \\
\text { (15 psi) }\end{array}$ & $\begin{array}{l}\text { Percent Difference in } \\
\text { FC for Moisture } \\
\text { Content - Small Box } \\
\text { (5 psi) }\end{array}$ & $\begin{array}{l}\text { Percent Difference in } \\
\text { FC for Moisture } \\
\text { Content - Small Box } \\
\text { (10 psi) }\end{array}$ & $\begin{array}{l}\text { Percent Difference in } \\
\text { FC for Moisture } \\
\text { Content - Smal Box } \\
\text { (15 psi) }\end{array}$ \\
\hline \multirow{9}{*}{ A } & \multirow{3}{*}{0} & 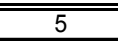 & 0.3 & $\overline{c 0.32}$ & \multirow{4}{*}{$16.67 \%$} & \multirow{4}{*}{$-5.00 \%$} & \multirow{4}{*}{$-8.00 \%$} & \multirow{4}{*}{$-18.75 \%$} & \multirow{5}{*}{$-20.00 \%$} & \multirow{5}{*}{$-21.43 \%$} \\
\hline & & 10 & 0.4 & 0.3 & & & & & & \\
\hline & & $\frac{15}{15}$ & 0.5 & 0.28 & & & & & & \\
\hline & \multirow{3}{*}{10} & 5 & 0.35 & 0.26 & & & & & & \\
\hline & & 10 & 0.38 & 0.24 & \multirow{5}{*}{$-2.86 \%$} & \multirow{5}{*}{$-47.37 \%$} & \multirow{5}{*}{$-80.43 \%$} & & & \\
\hline & & 15 & 0.46 & 0.22 & & & & \multirow{4}{*}{$-11.54 \%$} & \multirow{4}{*}{$-8.33 \%$} & \multirow{4}{*}{$-4.55 \%$} \\
\hline & \multirow{3}{*}{15} & 5 & 0.34 & 0.23 & & & & & & \\
\hline & & $\frac{5}{10}$ & 0.2 & 0.22 & & & & & & \\
\hline & & 15 & 0.09 & 0.21 & & & & & & \\
\hline \multirow{9}{*}{ B } & \multirow{3}{*}{0} & 5 & 0.3 & - & \multirow{4}{*}{$-26.67 \%$} & \multirow{4}{*}{$-35.00 \%$} & \multirow{4}{*}{$-40.00 \%$} & \multirow{4}{*}{ - } & \multirow{4}{*}{ - } & \multirow{4}{*}{-} \\
\hline & & 10 & 0.4 & - & & & & & & \\
\hline & & 15 & 0.5 & - & & & & & & \\
\hline & \multirow{3}{*}{10} & 5 & 0.22 & - & & & & & & \\
\hline & & 10 & 0.26 & - & \multirow{5}{*}{$90.91 \%$} & \multirow{5}{*}{$53.85 \%$} & & & & \\
\hline & & 15 & 0.3 & - & & & & & & \\
\hline & \multirow{3}{*}{15} & 5 & 0.42 & - & & & & & & \\
\hline & & 10 & 0.4 & - & & & $-20.00 \%$ & - & - & - \\
\hline & & 15 & 0.24 & - & & & & & & \\
\hline & & 5 & 0.1 & 0.075 & & & & & & \\
\hline & 0 & 10 & 0.06 & 0.04 & & & & & & \\
\hline & & $\frac{15}{15}$ & 0.07 & 0.035 & $40.00 \%$ & $83.33 \%$ & $7.14 \%$ & $40.00 \%$ & $-12.50 \%$ & $0.00 \%$ \\
\hline & & 5 & 0.14 & 0.065 & & & & & & \\
\hline c & 10 & 10 & 0.11 & 0.035 & & & & & & \\
\hline & & 15 & 0.075 & 0.035 & & & & & & \\
\hline & & 5 & 0.16 & 0.065 & & & & & & \\
\hline & 15 & $\frac{5}{10}$ & $\begin{array}{l}0.10 \\
0.06\end{array}$ & 0.003 & $14.29 \%$ & $-45.45 \%$ & $-20.00 \%$ & $14.29 \%$ & $-14.29 \%$ & $-14.29 \%$ \\
\hline & & 15 & 0.06 & 0.03 & & & & & & \\
\hline
\end{tabular}

$* \mathrm{FC}=$ friction coefficient 
Table 4.4: Percent difference in friction coefficient for a change in normal pressure and change in box size for clay

\begin{tabular}{|c|c|c|c|c|c|c|c|}
\hline $\begin{array}{c}\text { Geosynthetic } \\
\text { Material }\end{array}$ & $\begin{array}{c}\text { Moisture } \\
\text { Content (\%) }\end{array}$ & $\begin{array}{l}\text { Normal } \\
\text { Pressure } \\
\text { (psi) }\end{array}$ & \begin{tabular}{|c|} 
Friction \\
Coefficient (FC) - \\
Large Box
\end{tabular} & $\begin{array}{c}\text { Friction } \\
\text { Coefficient (FC) - } \\
\text { Small Box }\end{array}$ & $\begin{array}{l}\text { Percent Difference in } \\
\text { FC for Normal } \\
\text { Pressure - Large Box }\end{array}$ & $\begin{array}{c}\text { Percent Difference in } \\
\text { FC for Normal Pressure } \\
\text { - Small Box }\end{array}$ & $\begin{array}{l}\text { Percent Difference in } \\
\text { FC for Box Size }\end{array}$ \\
\hline \multirow{6}{*}{$A$} & \multirow{3}{*}{0} & 5 & 0.36 & 0.5 & \multirow[t]{2}{*}{$-44.44 \%$} & \multirow[t]{2}{*}{$-60.00 \%$} & $38.89 \%$ \\
\hline & & 10 & 0.2 & 0.2 & & & $0.00 \%$ \\
\hline & & 15 & 0.18 & 0.2 & $-10.00 \%$ & $0.00 \%$ & $11.11 \%$ \\
\hline & \multirow{3}{*}{10} & 5 & 0.22 & 0.45 & \multirow[t]{2}{*}{$13.64 \%$} & \multirow[t]{2}{*}{$-55.56 \%$} & $104.55 \%$ \\
\hline & & 10 & 0.25 & 0.2 & & & $-20.00 \%$ \\
\hline & & 15 & 0.25 & 0.18 & $0.00 \%$ & $-10.00 \%$ & $-28.00 \%$ \\
\hline \multirow{6}{*}{ B } & \multirow{3}{*}{0} & 5 & 0.68 & - & \multirow[t]{2}{*}{$-33.82 \%$} & \multirow[t]{2}{*}{ - } & - \\
\hline & & 10 & 0.45 & - & & & - \\
\hline & & 15 & 0.32 & - & $-28.89 \%$ & - & - \\
\hline & \multirow{3}{*}{10} & 5 & 0.4 & - & \multirow[t]{2}{*}{$-37.50 \%$} & \multirow{2}{*}{-} & - \\
\hline & & 10 & 0.25 & - & & & - \\
\hline & & 15 & 0.2 & - & $-20.00 \%$ & - & - \\
\hline \multirow{6}{*}{ C } & \multirow{3}{*}{0} & 5 & 0.16 & 0.07 & \multirow[t]{2}{*}{$-37.50 \%$} & \multirow[t]{2}{*}{$0.00 \%$} & $-56.25 \%$ \\
\hline & & 10 & 0.1 & 0.07 & & & $-30.00 \%$ \\
\hline & & 15 & 0.1 & 0.07 & $0.00 \%$ & $0.00 \%$ & $-30.00 \%$ \\
\hline & \multirow{3}{*}{10} & 5 & 0.1 & 0.08 & \multirow[t]{2}{*}{$-20.00 \%$} & \multirow[t]{2}{*}{$0.00 \%$} & $-20.00 \%$ \\
\hline & & 10 & 0.08 & 0.08 & & & $0.00 \%$ \\
\hline & & 15 & 0.04 & 0.04 & $-50.00 \%$ & $-50.00 \%$ & $0.00 \%$ \\
\hline
\end{tabular}

$* \mathrm{FC}=$ friction coefficient 
Table 4.5: Friction coefficient and percent difference in moisture content for clay under each condition.

\begin{tabular}{|c|c|c|c|c|c|c|c|c|c|c|}
\hline \multicolumn{11}{|c|}{ CLAY } \\
\hline $\begin{array}{c}\text { Geosynthetic } \\
\text { Material }\end{array}$ & \begin{tabular}{|c|} 
Moisture \\
Content (\%)
\end{tabular} & $\begin{array}{l}\text { Normal } \\
\text { Pressure } \\
\text { (psi) }\end{array}$ & $\begin{array}{c}\text { Friction } \\
\text { Coefficient (FC) } \\
\text { Large Box }\end{array}$ & \begin{tabular}{|c|} 
Friction \\
Coefficient (FC) - \\
Small Box
\end{tabular} & $\begin{array}{c}\text { Percent Difference in } \\
\text { FC for Moisture } \\
\text { Content - Large Box } \\
\text { (5 psi) }\end{array}$ & $\begin{array}{l}\text { Percent Difference in } \\
\text { FC for Moisture } \\
\text { Content - Large Box (10 } \\
\text { psi) }\end{array}$ & $\begin{array}{c}\text { Percent Difference in } \\
\text { FC for Moisture } \\
\text { Content - Large Box } \\
\text { (15 psi) }\end{array}$ & $\begin{array}{c}\text { Percent Difference in } \\
\text { FC for Moisture } \\
\text { Content - Small Box } \\
\text { (5 psi) }\end{array}$ & $\begin{array}{c}\text { Percent Difference in } \\
\text { FC for Moisture } \\
\text { Content - Small Box } \\
\text { (10 psi) }\end{array}$ & $\begin{array}{c}\text { Percent Difference in } \\
\text { FC for Moisture } \\
\text { Content - Smal Box } \\
\text { (15 psi) }\end{array}$ \\
\hline \multirow{6}{*}{ A } & \multirow{3}{*}{0} & $\overline{5}$ & 0.36 & 0.5 & \multirow{6}{*}{$-38.89 \%$} & \multirow{6}{*}{$25.00 \%$} & \multirow{6}{*}{$38.89 \%$} & \multirow{6}{*}{$-10.00 \%$} & \multirow{6}{*}{$10.00 \%$} & \multirow{6}{*}{$-10.00 \%$} \\
\hline & & 10 & 0.2 & 0.2 & & & & & & \\
\hline & & 15 & 0.18 & 0.2 & & & & & & \\
\hline & \multirow{3}{*}{10} & 5 & 0.22 & 0.45 & & & & & & \\
\hline & & 10 & 0.25 & 0.22 & & & & & & \\
\hline & & 15 & 0.25 & 0.18 & & & & & & \\
\hline \multirow{6}{*}{ B } & \multirow{3}{*}{0} & 5 & 0.68 & - & \multirow{6}{*}{$-41.18 \%$} & \multirow{6}{*}{$-44.44 \%$} & \multirow{6}{*}{$-37.50 \%$} & \multirow{6}{*}{-} & \multirow{6}{*}{-} & \multirow{6}{*}{-} \\
\hline & & 10 & 0.45 & - & & & & & & \\
\hline & & 15 & 0.32 & - & & & & & & \\
\hline & \multirow{3}{*}{10} & 5 & 0.4 & - & & & & & & \\
\hline & & 10 & 0.25 & - & & & & & & \\
\hline & & 15 & 0.2 & - & & & & & & \\
\hline \multirow{6}{*}{$C$} & \multirow{3}{*}{0} & 5 & 0.16 & 0.07 & \multirow{6}{*}{$-37.50 \%$} & \multirow{6}{*}{$-20.00 \%$} & \multirow{6}{*}{$-60.00 \%$} & \multirow{6}{*}{$-57.14 \%$} & \multirow{6}{*}{$14.29 \%$} & \multirow{6}{*}{$-42.86 \%$} \\
\hline & & 10 & 0.1 & 0.07 & & & & & & \\
\hline & & 15 & 0.1 & 0.07 & & & & & & \\
\hline & \multirow{3}{*}{10} & 5 & 0.1 & 0.03 & & & & & & \\
\hline & & 10 & 0.18 & 0.08 & & & & & & \\
\hline & & 15 & 0.04 & 0.04 & & & & & & \\
\hline
\end{tabular}

*FC $=$ friction coefficient 
Table 4.6: Friction coefficient and calculated friction angle for sand

\begin{tabular}{|c|c|c|c|c|c|c|}
\hline $\begin{array}{c}\text { Geosynthetic } \\
\text { Material }\end{array}$ & $\begin{array}{c}\text { Moisture } \\
\text { Content } \\
(\%)\end{array}$ & $\begin{array}{l}\text { Normal } \\
\text { Pressure } \\
\text { (psi) }\end{array}$ & $\begin{array}{c}\text { Friction } \\
\text { Coefficient } \\
\text { (Large } \\
\text { Box) }\end{array}$ & $\begin{array}{c}\text { Friction Angle } \\
\text { (Large Box) }\end{array}$ & $\begin{array}{c}\text { Friction } \\
\text { Coefficient } \\
\text { (Small Box) }\end{array}$ & $\begin{array}{c}\text { Friction } \\
\text { Angle (Small } \\
\text { Box) }\end{array}$ \\
\hline \multirow{6}{*}{ A } & \multirow{6}{*}{0} & \multirow{2}{*}{5} & \multirow[b]{2}{*}{0.3} & 16.70 & \multirow[b]{2}{*}{0.35} & 19.29 \\
\hline & & & & 0.00 & & 0.00 \\
\hline & & \multirow{2}{*}{10} & \multirow[b]{2}{*}{0.4} & 21.80 & \multirow[b]{2}{*}{0.4} & 21.80 \\
\hline & & & & 0.00 & & 0.00 \\
\hline & & \multirow{2}{*}{15} & \multirow[b]{2}{*}{0.5} & 26.57 & \multirow[b]{2}{*}{0.6} & 30.96 \\
\hline & & & & 0.00 & & 0.00 \\
\hline \multirow{6}{*}{ B } & \multirow{6}{*}{0} & \multirow{2}{*}{5} & & 19.29 & \multirow[b]{2}{*}{-} & - \\
\hline & & & 0.35 & 0.00 & & - \\
\hline & & \multirow{2}{*}{10} & \multirow[b]{2}{*}{0.4} & 21.80 & \multirow[b]{2}{*}{-} & - \\
\hline & & & & 0.00 & & - \\
\hline & & \multirow{2}{*}{15} & \multirow[b]{2}{*}{0.5} & 26.57 & \multirow[b]{2}{*}{-} & - \\
\hline & & & & 0.00 & & - \\
\hline \multirow{6}{*}{ C } & \multirow{6}{*}{0} & \multirow{2}{*}{5} & \multirow[b]{2}{*}{0.1} & 5.71 & \multirow[b]{2}{*}{0.09} & 5.14 \\
\hline & & & & 0.00 & & 0.00 \\
\hline & & \multirow{2}{*}{10} & & 4.00 & \multirow[b]{2}{*}{0.09} & 5.14 \\
\hline & & & 0.07 & 0.00 & & 0.00 \\
\hline & & \multirow{2}{*}{15} & & 2.86 & \multirow[b]{2}{*}{0.4} & 21.80 \\
\hline & & & 0.05 & 0.00 & & 0.00 \\
\hline
\end{tabular}


Table 4.7: Friction coefficient and calculated friction angle for silt

\begin{tabular}{|c|c|c|c|c|c|c|}
\hline $\begin{array}{l}\text { Geosynthetic } \\
\text { Material }\end{array}$ & $\begin{array}{c}\text { Moisture } \\
\text { Content } \\
(\%)\end{array}$ & $\begin{array}{l}\text { Normal } \\
\text { Pressure } \\
\text { (psi) }\end{array}$ & $\begin{array}{c}\text { Friction } \\
\text { Coefficient } \\
\text { (Large } \\
\text { Box) } \\
\end{array}$ & $\begin{array}{c}\text { Friction } \\
\text { Angle (Large } \\
\text { Box) }\end{array}$ & $\begin{array}{c}\text { Friction } \\
\text { Coefficient } \\
\text { (Small } \\
\text { Box) } \\
\end{array}$ & $\begin{array}{c}\text { Friction } \\
\text { Angle (Small } \\
\text { Box) }\end{array}$ \\
\hline \multirow{9}{*}{$A$} & \multirow{3}{*}{0} & 5 & 0.3 & 16.70 & 0.32 & 17.74 \\
\hline & & 10 & 0.4 & 21.80 & 0.3 & 16.70 \\
\hline & & 15 & 0.5 & 26.57 & 0.28 & 15.64 \\
\hline & \multirow{3}{*}{10} & 5 & 0.35 & 19.29 & 0.26 & 14.57 \\
\hline & & 10 & 0.38 & 20.81 & 0.24 & 13.50 \\
\hline & & 15 & 0.46 & 24.70 & 0.22 & 12.41 \\
\hline & \multirow{3}{*}{15} & 5 & 0.34 & 18.78 & 0.23 & 12.95 \\
\hline & & 10 & 0.2 & 11.31 & 0.22 & 12.41 \\
\hline & & 15 & 0.09 & 5.14 & 0.21 & 11.86 \\
\hline \multirow{9}{*}{ B } & \multirow{3}{*}{0} & 5 & 0.3 & 16.70 & - & - \\
\hline & & 10 & 0.4 & 21.80 & - & - \\
\hline & & 15 & 0.5 & 26.57 & - & - \\
\hline & \multirow{3}{*}{10} & 5 & 0.22 & 12.41 & - & - \\
\hline & & 10 & 0.26 & 14.57 & - & - \\
\hline & & 15 & 0.3 & 16.70 & - & - \\
\hline & \multirow{3}{*}{15} & 5 & 0.42 & 22.78 & - & - \\
\hline & & 10 & 0.4 & 21.80 & - & - \\
\hline & & 15 & 0.24 & 13.50 & - & - \\
\hline \multirow{9}{*}{ C } & \multirow{3}{*}{0} & 5 & 0.1 & 5.71 & 0.075 & 4.29 \\
\hline & & 10 & 0.06 & 3.43 & 0.04 & 2.29 \\
\hline & & 15 & 0.07 & 4.00 & 0.035 & 2.00 \\
\hline & \multirow{3}{*}{10} & 5 & 0.14 & 7.97 & 0.065 & 3.72 \\
\hline & & 10 & 0.11 & 6.28 & 0.035 & 2.00 \\
\hline & & 15 & 0.075 & 4.29 & 0.035 & 2.00 \\
\hline & \multirow{3}{*}{15} & 5 & 0.16 & 9.09 & 0.065 & 3.72 \\
\hline & & 10 & 0.06 & 3.43 & 0.03 & 1.72 \\
\hline & & 15 & 0.06 & 3.43 & 0.03 & 1.72 \\
\hline
\end{tabular}


Table 4.8: Friction coefficient and calculated friction angle for clay

\begin{tabular}{|c|c|c|c|c|c|c|}
\hline $\begin{array}{c}\text { Geosynthetic } \\
\text { Material }\end{array}$ & $\begin{array}{c}\text { Moisture } \\
\text { Content } \\
(\%)\end{array}$ & $\begin{array}{l}\text { Normal } \\
\text { Pressure } \\
\text { (psi) }\end{array}$ & $\begin{array}{c}\text { Friction } \\
\text { Coefficient } \\
\text { (Large Box) }\end{array}$ & $\begin{array}{c}\text { Friction } \\
\text { Angle (Large } \\
\text { Box) }\end{array}$ & $\begin{array}{c}\text { Friction } \\
\text { Coefficient } \\
\text { (Small } \\
\text { Box) }\end{array}$ & $\begin{array}{l}\text { Friction Angle } \\
\text { (Small Box) }\end{array}$ \\
\hline \multirow{6}{*}{$A$} & \multirow{3}{*}{0} & 5 & 0.36 & 19.80 & 0.5 & 26.57 \\
\hline & & 10 & 0.2 & 11.31 & 0.2 & 11.31 \\
\hline & & 15 & 0.18 & 10.20 & 0.2 & 11.31 \\
\hline & \multirow{3}{*}{10} & 5 & 0.22 & 12.41 & 0.45 & 24.23 \\
\hline & & 10 & 0.25 & 14.04 & 0.2 & 11.31 \\
\hline & & 15 & 0.25 & 14.04 & 0.18 & 10.20 \\
\hline \multirow{6}{*}{ B } & \multirow{3}{*}{0} & 5 & 0.68 & 34.22 & - & - \\
\hline & & 10 & 0.45 & 24.23 & - & - \\
\hline & & 15 & 0.32 & 17.74 & - & - \\
\hline & \multirow{3}{*}{10} & 5 & 0.4 & 21.80 & - & - \\
\hline & & 10 & 0.25 & 14.04 & - & - \\
\hline & & 15 & 0.2 & 11.31 & - & - \\
\hline \multirow{6}{*}{ C } & \multirow{3}{*}{0} & 5 & 0.16 & 9.09 & 0.07 & 4.00 \\
\hline & & 10 & 0.1 & 5.71 & 0.07 & 4.00 \\
\hline & & 15 & 0.1 & 5.71 & 0.07 & 4.00 \\
\hline & \multirow{3}{*}{10} & 5 & 0.1 & 5.71 & 0.03 & 1.72 \\
\hline & & 10 & 0.08 & 4.57 & 0.08 & 4.57 \\
\hline & & 15 & 0.05 & 2.86 & 0.06 & 3.43 \\
\hline
\end{tabular}


Table 4.9: Comparison of measured friction angle and calculated friction angle (Ingram, 2006)

\begin{tabular}{|c|c|c|c|c|c|c|}
\hline $\begin{array}{c}\text { Geosynthetic } \\
\text { Material }\end{array}$ & Soil Type & $\begin{array}{c}\text { Water } \\
\text { Content } \\
(\%)\end{array}$ & $\begin{array}{c}\text { Measured } \\
\text { Friction Angle } \\
\text { (Small Box) }\end{array}$ & $\begin{array}{l}\text { Calculated } \\
\text { Friction Angle } \\
\text { (Small Box) }\end{array}$ & $\begin{array}{c}\text { Measured } \\
\text { Friction Angle } \\
\text { (Large Box) }\end{array}$ & $\begin{array}{l}\text { Calculated } \\
\text { Friction Angle } \\
\text { (Large Box) }\end{array}$ \\
\hline \multirow{6}{*}{$A$} & Sand & 0 & 26.01 & 21.8 & 18.82 & 21.8 \\
\hline & \multirow[b]{3}{*}{ Silt } & 0 & 19.21 & 15.64 & 10.1 & 21.8 \\
\hline & & 10 & 15.46 & 14.57 & 7.87 & 19.29 \\
\hline & & 15 & 16.78 & 12.95 & 2.93 & 11.31 \\
\hline & \multirow[b]{2}{*}{ Clay } & 0 & 16.29 & 11.31 & 6.63 & 11.31 \\
\hline & & 10 & 7.9 & 11.31 & 11.2 & 14.04 \\
\hline \multirow{6}{*}{ B } & Sand & 0 & 12.21 & - & 8.8 & 19.29 \\
\hline & \multirow[b]{3}{*}{ Silt } & 0 & 4.22 & - & 1.87 & 16.7 \\
\hline & & 10 & 5 & - & 4.99 & 12.41 \\
\hline & & 15 & 4.06 & - & 1.79 & 21.8 \\
\hline & \multirow[b]{2}{*}{ Clay } & 0 & 4.6 & - & 0.55 & 17.74 \\
\hline & & 10 & 1.94 & - & 2.24 & 11.31 \\
\hline \multirow{6}{*}{ C } & Sand & 0 & 2.11 & 5.71 & 4.04 & 5.14 \\
\hline & \multirow[b]{3}{*}{ Silt } & 0 & 0.33 & 2 & 1.87 & 3.43 \\
\hline & & 10 & 1.1 & 2 & 2.1 & 4.29 \\
\hline & & 15 & 0.29 & 1.72 & 1.59 & 3.43 \\
\hline & \multirow[b]{2}{*}{ Clay } & 0 & 4.31 & 4 & 5.88 & 9.09 \\
\hline & & 10 & 2.39 & 1.72 & 1.69 & 5.71 \\
\hline
\end{tabular}




\subsection{Effect of cohesion}

Cohesion is a molecular attraction between a particular soil and a given interface. Cohesion occurs when water is combined with soils such as clay and silt. Cohesion may have some influence on the friction coefficient. Cohesion was added to the analysis of clay to determine the difference in results in the load displacement curves with and without being considered. Cohesion was determined from experiments performed during previous laboratory tests conducted at West Virginia University (Ingram, 2006). Section 3.8 describes the technique used to include the effect of cohesion and the equations used to find the Drucker-Prager cohesion and angle of friction. Table 4.10 shows the cohesion and angle of frictions used with corresponding Drucker-Prager cohesion and angle of friction.

Table 4.10: Angle of friction and cohesion developed in the laboratory and corresponding angle of friction and cohesion used in ABAQUS.

\begin{tabular}{|c|c|c|c|c|c|}
\hline Box & Material & $\begin{array}{l}\text { Angle of } \\
\text { Friction }(\Phi) \\
\text { (degrees) }\end{array}$ & $\begin{array}{l}\text { Cohesion (c) } \\
\text { (kPa) }\end{array}$ & $\begin{array}{c}\text { Drucker-Prager } \\
\text { Angle of } \\
\text { Friction }(\beta) \\
\text { (degrees) }\end{array}$ & $\begin{array}{l}\text { Stress in uniaxial } \\
\text { compression }\left(\sigma^{\circ}\right) \\
(p s i)\end{array}$ \\
\hline \multirow{2}{*}{ 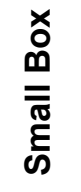 } & Geo_A & 7.9 & 11.36 & 13.35 & 12.36 \\
\hline & Geo_C & 2.39 & 0.7705 & 4.13 & 0.789 \\
\hline \multirow{3}{*}{$\begin{array}{l}x \\
0 \\
0 \\
0 \\
\stackrel{0}{\pi} \\
\frac{1}{\pi}\end{array}$} & Geo_A & 11.2 & 8.607 & 18.486 & 9.686 \\
\hline & Geo_B & 2.24 & 8.6901 & 3.872 & 8.891 \\
\hline & Geo_C & 1.69 & 3.201 & 2.924 & 3.257 \\
\hline
\end{tabular}


Figures 4.55 through 4.58 show the comparison between analysis containing cohesion and without cohesion. Analysis was done with clay at $10 \%$ moisture for material A and material C in Pullout box A and Pullout box B using the same coefficient of friction. Material A (geogrid) had little or no effect with the addition of cohesion. When cohesion was added to clay and material $\mathrm{C}$ interaction there were some differences noted in the load-displacement curves. The effect of cohesion becomes a much greater factor with the use of geotextiles than with geogrids.

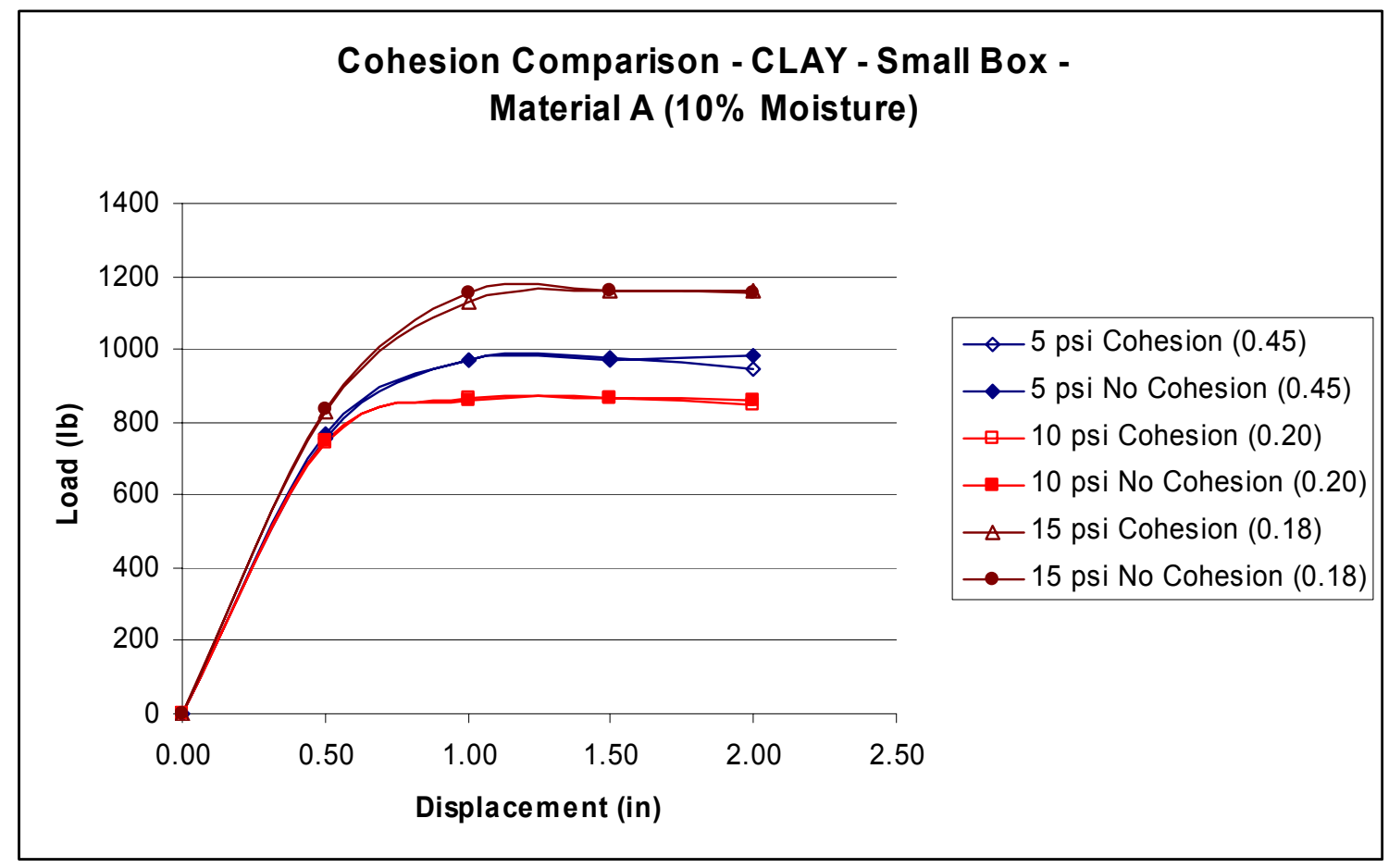

Figure 4.55: Cohesion comparison of clay and material $A$ interaction at $10 \%$ moisture at 5, 10, and 15 psi with their corresponding friction coefficient. 


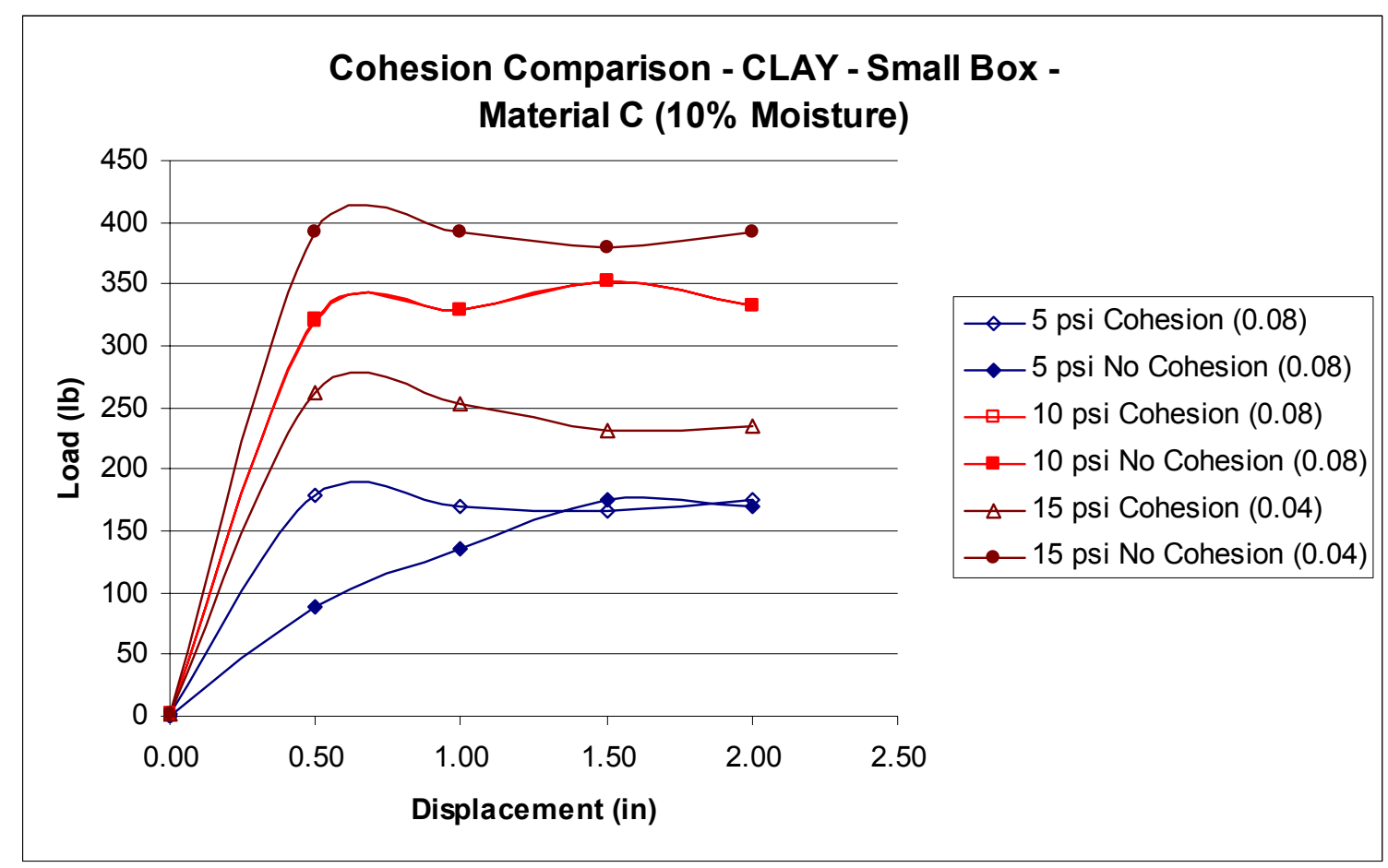

Figure 4.56: Cohesion comparison of clay and material $\mathrm{C}$ interaction at $10 \%$ moisture at 5,10 , and 15 psi with their corresponding friction coefficient.

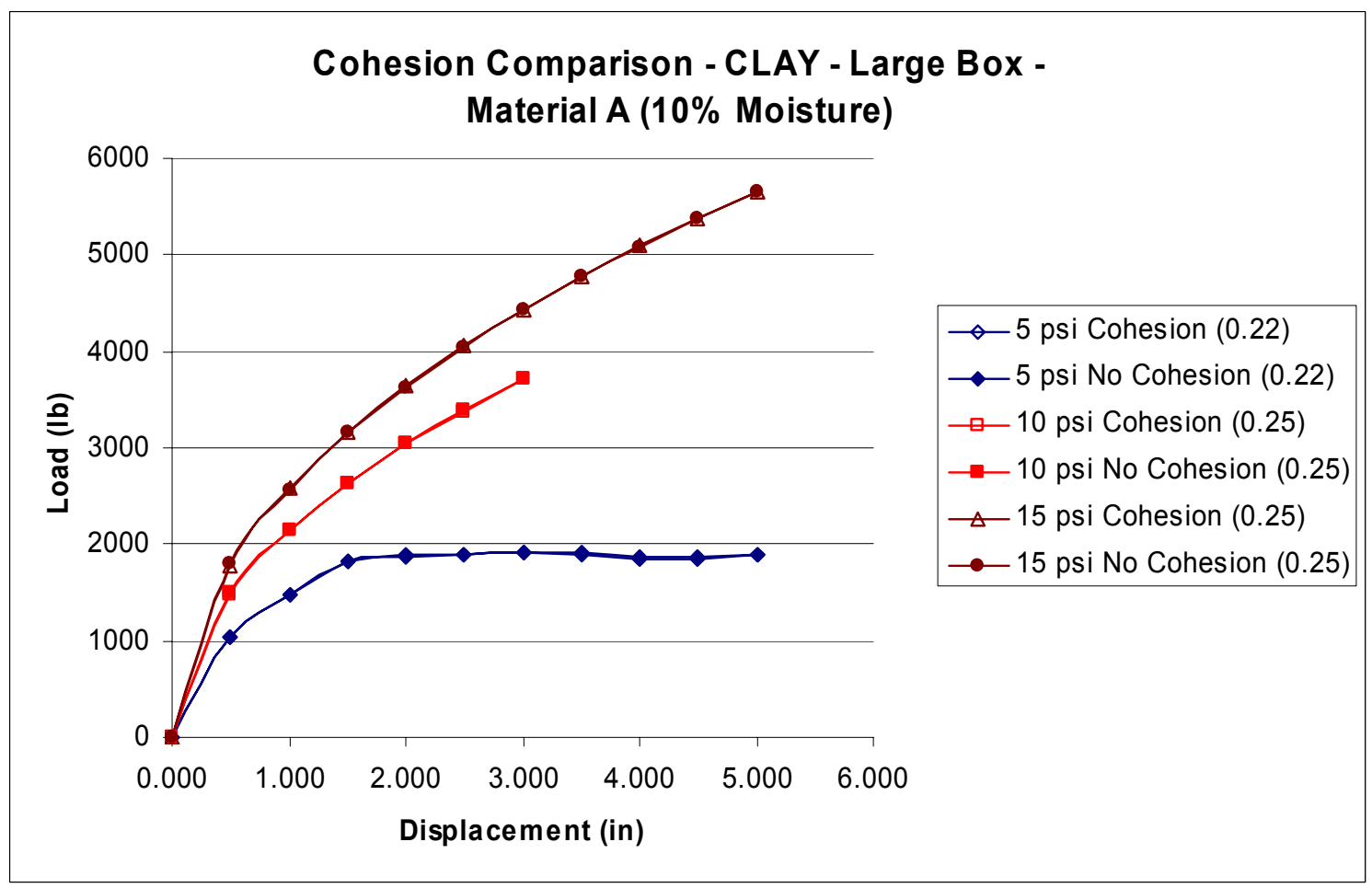

Figure 4.57: Cohesion comparison of clay and material $A$ interaction at $10 \%$ moisture at 5, 10, and 15 psi with their corresponding friction coefficient. 


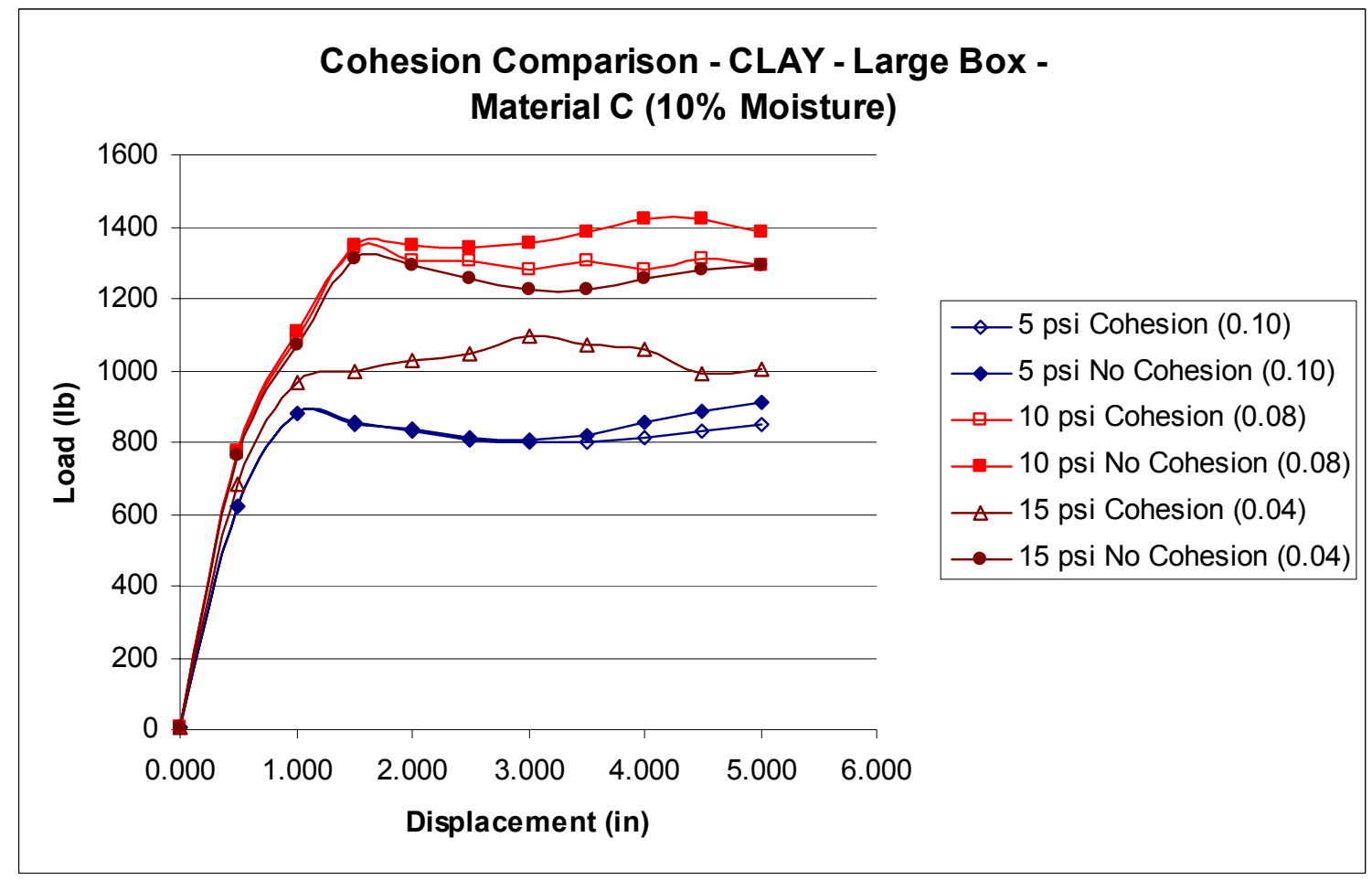

Figure 4.58: Cohesion comparison of clay and material $A$ interaction at $10 \%$ moisture at 5,10 , and 15 psi with their corresponding friction coefficient. 


\section{CHAPTER 5}

\section{SUMMARY AND CONCLUSIONS}

\subsection{Summary}

The objective of this study was to investigate the effect of normal pressure, moisture content and pullout box size on the friction at the interface between the soil and the geosynthetic. Three soil types (sand, silt, and clay) and three geosynthetic types were used in this study. The geosynthetics consisted of two types of geogrids and one geotextile. The tests were performed with two different sized pullout devices; pullout Box A (small) and pullout Box B (large). Normal pressures of 5 psi, 10 psi, and 15 psi and moisture contents of $0 \%, 10 \%$, and $15 \%$ were used in this study. This report includes the results from a computational modeling study. Experimental details can be found elsewhere (Ingram, 2006; Niemiec, 2005).

\subsection{Conclusions}

Finite element models were made with specifications used during previous laboratory experiments (Niemiec, 2005; Ingram, 2006). The friction coefficient was varied in the computational model and the results were compared with that obtained from laboratory experiments. Based on these results, which were presented in previous chapters, the following conclusions can be made.

\subsubsection{Sand - Geosynthetic Interaction}

- Friction coefficient increases as normal pressure increases for geosynthetic materials A and B in both large and small pullout boxes

- Friction coefficient decreases as normal pressure increases for geosynthetic material C 


\subsubsection{Silt - Geosynthetic Interaction}

- Friction coefficient increases as normal pressure increases for geosynthetic materials $\mathrm{A}$ and $\mathrm{B}$ at $0 \%$ and $10 \%$ moisture. However, at $15 \%$ moisture content the friction coefficient decreases as normal pressure increases.

- Friction coefficient decreases as normal pressure increases for material C.

- Friction coefficient seems to decrease as moisture content increases for material A.

- Friction coefficient decreases as moisture content increases from $0 \%$ to $10 \%$ for material B.

- For normal pressures of 5 psi and $10 \mathrm{psi}$, the interface friction coefficient increases as moisture content increases from $10 \%$ to $15 \%$ for geosynthetic materials A and B. However, the results are inconclusive for effect moisture contents on friction coefficient for geosynthetic material C.

- Friction coefficient tends to increase as pullout box size increases for most cases.

\subsubsection{Clay - Geosynthetic Interaction}

- Friction coefficient decreases as normal pressure increases for geosynthetic materials $\mathrm{A}, \mathrm{B}$, and $\mathrm{C}$.

- Results are inconclusive for the effect of moisture content and the box size on friction coefficient at the clay - geosynthetic interface.

\subsection{Recommendations}

- Perform a thorough investigation of the effect of cohesion on the soilgeosynthetic interaction.

- Conduct pullout tests with broader range of soils.

- Perform further investigations on geosynthetic material $\mathrm{C}$ and other geotextiles.

- Sample size seems to have an effect on the results. Larger pullout boxes produce more accurate results due to the fact that larger sample sizes are closer to actual 
results in the field. It is recommended that similar laboratory tests are performed with larger pullout boxes and results be compared with those obtained from field experiments. 


\section{REFERENCES}

ABAQUS version 6.5 (2005) ABAQUS user's manual. Hibbitt, Karlson \& Sorensen, Inc., Pawtucket, RI.

Bathe K. J. (2002) Finite Element Procedures. $5^{\text {th }}$ Edition, Prentice Hall Englewood Cliff, NJ.

Bobet, Anotonio and Lee, Hong-Sung (2005) "Laboratory Evaluation of Pullout Capacity of Reinforced Silty Sands in Drained and Undrained Conditions", Geotechnical Testing Journal, Vol. 8, No. 4

Cook, R. D., Malkus, D. S., Plesha, M. E., and Witt, R. J. (2003) Concepts and applications of finite element analysis. John Wiley and sons, Inc,. Indianapolis, Indiana.

Das, Braja M. (2002) Principles of Geotechnical Engineering. Fifth Edition. Pacific Grove, CA: Brooks/Cole.

Holtz, Robert D. (2001) "Geosynthetics for Soil Reinforcement", $9^{\text {th }}$ Spencer J. Buchanan Lecture, College Station, TX, November 2001

Ingram, Ronald (2006) Geosynthetic-Soil Interface Properties for Cohesionless and Cohesive Media, Masters Thesis, West Virginia University, Morgantown, West Virginia.

Koerner, Robert M., (1990) "Designing with Geosynthetics" $2^{\text {nd }}$ Ed. Prentice Hal, Englewood Cliffs, NJ c1990

Ling, Hoe I. (2003) Civil and Environmental Applications of Geosynthetics.

Lopes, M. L. and Ladeira, M. (1997), “ Role of Specimen Geometry, Soil Height and Sleeve Length on the Pull-Out Behaviour of Geogrids," Geosynthetics International, Vol. 3, No. 6, IFAI, St. Paul, MN, pp 701-719.

Murad, Y. Abu-Farsakh, Khalid Farrag, Izzaldin Almoh'd, Ather Mohuiddin (2004) Evaluation of Interaction between Geosynthetics and Marginal Cohesive Soils from Pullout Tests, Geo Jordan.

Moore, Jack K. et al., (2002, July) "Pullout Resistance of Geogrid Expanded Clay Lighweight Aggregate Material", TRB 2003 Session A2K07 and A2K02 Annual Meeting Recent Developments in Embankment Stabilization 
Niemiec, Jonathan (2005) Laboratory Investigation of Soil-Geosynthetic Interface Properties, Masters Thesis, West Virginia University, Morgantown, West Virginia.

Perkins, S. W., Edens M.Q. (2003) Finite element modeling of a geosynthetic pullout test, Geotechnical and Geological Engineering 21:357-375.

Perkins, S. W. and Cuelho, E. V., (1999) "Soil - Geosynthetic Interface Strength and Stiffness Relationships from Pullout Tests", Geosynthetics International, Vol 6, No. 5, pp. 321-346

Sobhi, S. and Wu, J. T. H. "An Interface Pullout Formula for Extensible Sheet Reinforcement”, Geosynthetics International, Vol. 3, No. 5, pp. 565-582

Sugimoto, M., Alagiyawanna A. M. N. (2003) Pullout Behavior of Geogrid by Test and Numerical Analysis, Journal of Geotechnical and Geoenvironmental Engineering.

Yogarajah, I., Yeo K. C. (1993) Finite Element Modeling of Pull-Out Tests with Load and Strain Measurements, Geotextiles and Geomembranes.

Zornberg, Jorge G., Barry R. Christopher (1999) Geosynthetics, The Handbook of Groundwater Engineering. 